\title{
A new species of Miocene wombat (Marsupialia, Vombatiformes) from Riversleigh, Queensland, Australia, and implications for the evolutionary history of the Vombatidae
}

\author{
Philippa Brewer, Michael Archer, Suzanne Hand, and Gilbert J. Price
}

\begin{abstract}
A new species of wombat, Rhizophascolonus ngangaba sp. nov., is described from Miocene deposits at Riversleigh along with additional specimens of Rhizophascolonus crowcrofti, and some maxillary and mandibular fragments attributable to Rhizophascolonus. A phylogenetic analysis indicates that Rhizophascolonus is the next most plesiomorphic wombat after Nimbavombatus boodjamullensis. Morphological characters common to Nimbavombatus and Rhizophascolonus suggest that adaptations to high rates of tooth wear in wombats had their origin in the late Oligocene, presumably in response to climatic cooling and its effects on the vegetation. A period of climatic amelioration in the early Miocene may have led to diversification of wombats and/or to an expansion of their range into rainforest habitats. Although wombats form a significant component of Australia's open-forest and woodland habitats from the early Pliocene to Holocene, they appear to have been rare in all palaeoenvironments prior to this.
\end{abstract}

Philippa Brewer. Department of Earth Sciences, Natural History Museum, London SW7 5BD, United Kingdom.p.brewer@nhm.ac.uk

Michael Archer. PANGEA Research Centre, School of Biological, Earth \& Environmental Sciences, University of New South Wales, Sydney, 2052, New South Wales, Australia. m.archer@unsw.edu.au Suzanne Hand. PANGEA Research Centre, School of Biological, Earth \& Environmental Sciences, University of New South Wales, Sydney 2052, New South Wales, Australia. s.hand@unsw.edu.au Gilbert J. Price. School of Earth and Environmental Sciences, The University of Queensland, Brisbane, Queensland 4072, Australia. g.price1@uq.edu.au

Key Words: Rhizophascolonus ngangaba; new species; Riversleigh; wombat; phylogeny.

Submission: 12 March 2018 Acceptance: 13 June 2018

http://zoobank.org/AC7667FF-0CDD-4839-8F62-DD7567C86AC4

Brewer, Philippa, Archer, Michael, Hand, Suzanne, and Price, Gilbert J. 2018. A new species of Miocene wombat (Marsupialia, Vombatiformes) from Riversleigh, Queensland, Australia, and implications for the evolutionary history of the Vombatidae.

Palaeontologia Electronica 21.2.27A 1-48. https://doi.org/10.26879/870

palaeo-electronica.org/content/2018/2245-new-rhizophascolonus-species

Copyright: August 2018 Palaeontological Association.

This is an open access article distributed under the terms of Attribution-NonCommercial-ShareAlike 4.0 International (CC BY-NC-SA 4.0 ), which permits users to copy and redistribute the material in any medium or format, provided it is not used for commercial purposes and the original author and source are credited, with indications if any changes are made.

creativecommons.org/licenses/by-nc-sa/4.0/ 


\section{INTRODUCTION}

The evolutionary history of wombats (Vombatidae) is poorly understood. Molecular clock estimates suggest they diverged from phascolarctids (the family that includes their closest living relative, the koala) around $40 \mathrm{Ma}$ (Beck, 2008), but they do not appear in the fossil record until the early Miocene (Brewer et al., 2015). Two monotypic genera of vombatids have been described from early Miocene (Nimbavombatus boodjamullensis; Brewer et al., 2015) and early/middle Miocene (Rhizophascolonus crowcrofti; Stirton et al., 1967; Brewer et al., 2008; Black et al. 2012) deposits, respectively. Following this, we see a single species in the late Miocene (Warendja encorensis; Brewer et al., 2007), and then a radiation of taxa in the Plio-Pleistocene (Murray, 1998). The Riversleigh World Heritage Area (WHA) in northwestern Queensland (Figure 1) is proving central to increasing our knowledge of Miocene wombats, with all pre-Pliocene specimens, except three isolated teeth, having been found there. This paper describes a new species of wombat from Miocene deposits at Riversleigh, additional specimens of $R$. crowcrofti, and some maxillary and mandibular fragments attributable to Rhizophascolonus but not certainly $R$. crowcrofti. The evolutionary implications of these new specimens are discussed.

\section{MATERIALS AND METHODS}

Elements of the upper dentition are identified by upper case letters and the lower dentition by lower case letters, followed by their homologous position in the jaw (e.g., 12 refers to the second upper incisor and dp3 to the lower third deciduous premolar).

Incisor and molar tooth position homology follows Flower (1867). The position of the molar/premolar boundary follows Luckett (1993), with the adult molar dentition consisting of four molars (M14/m1-4) and the final premolar loci represented by $\mathrm{dP} 3 / \mathrm{dp} 3$ and $\mathrm{P} 3 / \mathrm{p} 3$, the only postcanine loci to show replacement in metatherians. In the extant wombats, only a single generation of tooth erupts in the incisor (I1/i1) and final premolar (P3/p3) loci. This appears to be the case for all known wombat taxa with hypselodont teeth (i.e., high-crowned teeth where root formation is suppressed and the teeth continue to grow throughout the life of the individual). It has not yet been conclusively shown whether P3/p3 in hypselodont wombats is a retained deciduous premolar, or whether the deciduous precursor was suppressed or resorbed at an

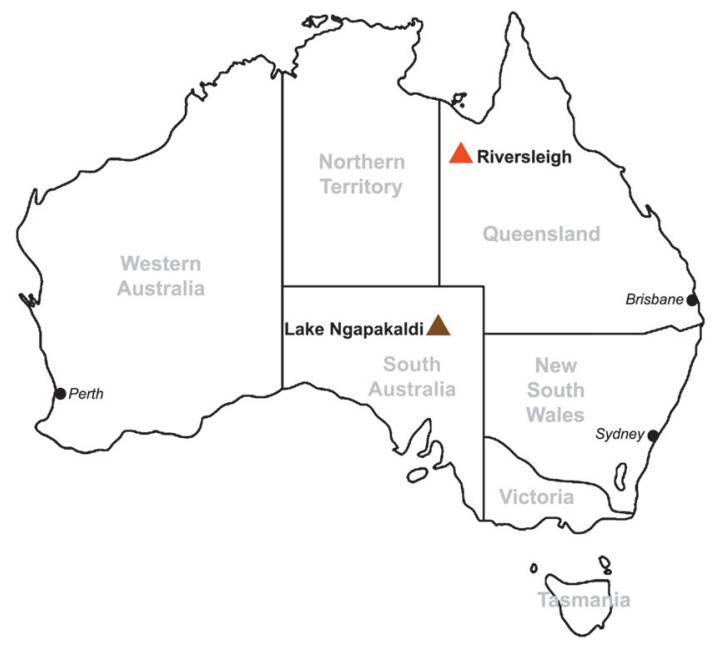

FIGURE 1. Map of Australia showing the localities of all known Oligo-Miocene wombat specimens (indicated by triangles).

early stage during development. This issue is currently being addressed by one of us (PB).

Because DP3/dp3 is on average the first, or one of the first, teeth to erupt and P3/p3 one of the last to erupt in metatherians (Cifelli and Muizon, 1998; Luckett, 1993; Rougier et al., 1998; Van Nievelt and Smith, 2005), the early eruption of a tooth in this position in wombats (Triggs, 2009) could be taken as evidence that it is a retained deciduous premolar. However, accelerated heterochronic development of P3/p3 is known for some marsupials. For example, in Thylacinus, DP3/dp3 is vestigial and $\mathrm{P} 3 / \mathrm{p} 3$ precedes the eruption of $\mathrm{M} 3 /$ m3 (Forasiepi and Sánchez-Villagra, 2014). Overall crown size of newly erupted premolars in extant wombats, particularly Vombatus ursinus, is small relative to the size of the first molar (Appendix 1). This difference in relative size changes in later development as the base of the crowns increase in size due to the hypselodont nature of the teeth. The relatively small premolar crowns in pouch young wombats could be further evidence that they represent retained deciduous premolars. In contrast, the koala (Phascolarctos cinereus), the closest living relative to wombats, has a non-functional $\mathrm{dP} 3 / \mathrm{dp} 3$, which is resorbed by about day 150 postpartum, or occasionally erupts as a reduced calcified spindle (Blanshard, 1990). The timing of the eruption of the permanent premolars in $P$. cinereus matches that of $V$. ursinus (Green and Rainbird, 1987; Blanshard, 1990; Triggs, 2009) and is evidence in favour of the hypothesis that the premolars in $V$. ursinus represent the second generation 
in those loci, rather than the deciduous precursors. Röse (1893) attempted to address the issue for $V$. ursinus, but the results were inconclusive. Lacking definitive evidence, premolar characters are not included in the phylogenetic analysis and detailed comparisons between those described here are not provided.

Systematics of the Plio-Pleistocene vombatids follows Dawson (1981, 1983a, 1983b) and Louys (2015). Higher level systematic nomenclature follows Aplin and Archer (1987).

Tooth crown nomenclature follows KielenJaworowska et al. (2004). Identification of stylar cusps is based on their topological position, rather than assumptions about homology. Stylar cusps are referred to by "St" followed by the letter indicating their position on the stylar shelf (StA is at the anterior of the tooth, StB and StC are anterior and posterior to the paracone, respectively, and StD and StE are anterior and posterior to the metacone, respectively).

A 'dentine tract' (Rensberger, 1975) refers to a gap in the enamel perimeter of the tooth, formed through an occlusal deflection of the base of the crown enamel (decreasing enamel height). An 'enamel tract' is a basal deflection of the base of the crown enamel (increasing enamel height). The term 'constriction' follows Hope and Wilkinson (1982) and refers to a 'pinching-in' of the tooth, usually between the anterior and posterior moieties, although it is used here to refer to any medial inflection of the tooth perimeter. 'Basal' refers to the base of the tooth (away from the occlusal surface) in both hypselodont and non-hypselodont taxa.

Dental measurements were made using electronic digital callipers and are maximum anteroposterior lengths and buccolingual widths. Buccolingual molar widths of hypselodont wombats should be taken with extreme caution due to the curvature of the teeth in the jaw and the difficulty in getting accurate measurements. Many historical specimens (i.e., collected at least 100 years ago) of wombats have the molars glued into the jaw to prevent loss. This means that it is not always possible to measure true width of the crown, but only the occlusal width (which is a function of width, curvature, and wear). A sample of $22 \mathrm{~V}$. ursinus molars, comparing widths measured at the occlusal surface and true width measured at $90^{\circ}$ to tooth height, suggests that occlusal widths are around 1 $\mathrm{mm}$ wider than true width, although this varies with tooth position and from tooth to tooth (Appendix 2). Measurements used here are a mixture of both (i.e., the best available measurement), and specimens where true width was measured are indicated in Appendix 3.

Faunal and chronostratigraphic terminology of the Riversleigh Oligo-Miocene deposits follows Travouillon et al. (2006) and Arena et al. (2016). Faunal and lithostratigraphic terminology of South Australian Oligo-Miocene deposits follows Woodburne et al. (1993). The age of the Kutjamarpu Local Fauna (LF), Wipajiri Formation, is considered to be early to middle Miocene following Archer et al. (1997), Black et al. (2012b, 2013), and Travouillon et al. (2015).

Body mass estimates are based on the third upper and lower molar areas using the regression equations of Myers (2001) for the 'Diprotodontians only' data set. Ontogenetic age is estimated based on Green and Rainbird (1987), Blanshard (1990), Taggart et al. (2007), and Triggs (2009).

\section{Phylogenetic Analysis}

A phylogenetic analysis was performed using three outgroups: one representative of each of the two vombatiform families which are consistently shown to be more plesiomorphic than wombats i.e., Phascolarctidae and Thylacoleonidae (e.g., Black et al., 2012a; Brewer et al., 2015), and a bandicoot, considered plesiomorphic relative to Diprotodontia (e.g., Beck 2008) and with a relatively unspecialised tooth morphology in comparison to notoryctemorphians and dasyuromorphians. Species selected were based on availability of relatively complete specimens and their phylogenetic position within their respective families.

A total of 13 taxa were coded in the analysis, including the outgroups. The data set consisted of dental, cranial and postcranial characters taken from the literature and personal observations. Where characters were taken from the literature, they were re-scored, where possible, for each of the taxa in the analysis in order to verify the results of others and to ensure consistency. Some characters used by other authors in their phylogenetic analyses were excluded from this analysis because they were found to be highly intraspecifically variable (e.g., presence of frontal-squamosal contact: Springer et al., 1997; Wroe et al., 1998; Horovitz and Sánchez-Villagra, 2003; Black et al., 2012a), or they were not parsimony-informative for any of the taxa examined.

A total of 62 characters were used in the analysis of which 18 are of the type ordered (Wagner) and 44 are of the type unordered (Appendix 4). The data matrix (Appendix 5) was analysed using 
Paup 4.0b10 (Swofford, 2002) using PaupUp graphical interface (Calendini and Martin, 2005). The branch and bound search option was utilised. Multistate characters were treated as polymorphisms. All characters were presumed to have equal weight. Accelerated transformation (ACCTRAN) and delayed transformation (DELTRAN) character state optimisation methods were employed. Bootstrap support (50\%) for clades was determined using 10,000 replicates.

\section{Institutional Abbreviations}

AM, Australian Museum, Sydney; AMNH, American Museum of Natural History; MCZ, Museum of Comparative Zoology at Harvard University; NHMUK, Natural History Museum, London; NMV, Museum Victoria, Melbourne; QM, Queensland Museum, Brisbane; RCSOM, Odontological Collection at the Royal College of Surgeons of England, London; SAM, South Australian Museum, Adelaide (palaeontological collection); SAMA, South Australian Museum, Adelaide (zoological collection); UCMP, University of California, Berkeley; UNSW, comparative collection held at the University of New South Wales, Sydney; WAM, Western Australian Museum, Perth.

\section{Abbreviations}

C, upper canine; EDJ, enamel-dentine junction; FZ, Faunal Zone; I, upper incisor; i, lower incisor; IZ; Interval Zone; LF, Local Fauna; M, upper molar; $\mathrm{m}$, lower molar; Ma, million years; $\mathrm{P}$, upper premolar; p, lower premolar; WHA, World Heritage Area.

New fossil material described in this work is deposited in the fossil collection of the Queensland Museum, Brisbane, Australia.

\section{SYSTEMATIC PALAEONTOLOGY}

Order DIPROTODONTIA Owen, 1866

Suborder VOMBATIFORMES Woodburne, 1984

Family VOMBATIDAE Burnett, 1830

Genus RHIZOPHASCOLONUS Stirton, Tedford, and Woodburne, 1967

Type species. Rhizophascolonus crowcrofti Stirton, Tedford and Woodburne, 1967, from the early to middle Miocene Leaf Locality (UCMP Locality V6213), Kutjamarpu LF, Wipajiri Formation, Lake Ngapakaldi, South Australia.

Included species. Rhizophascolonus ngangaba sp. nov.

Emended diagnosis. Differs from other vombatids in the unique combination of the size of the molars (anteroposterior length averaging around $13 \mathrm{~mm}$ ) and rooted molars with large inflections in enamel height and variations in enamel thickness around the perimeter of the teeth. Enamel extends down the lingual surface of the upper molars and buccal surface of the lower molars onto the root surfaces and extends as far as root apices on M2-3/m2-3. In addition, the postprotocrista meets the premetaconulecrista at the lingual constriction to form an almost complete continuous lingual crest.

Differential diagnosis. Differs from all other wombats, except $N$. boodjamullensis, in the presence of tooth roots on the cheek teeth. Differs from $N$. boodjamullensis in the presence of more extensive enamel tracts. Differs from all hypselodont wombats except species of Warendja in the relatively shallow constriction between the moieties on the lingual side of the upper molars and buccal side of the lower molars and in the presence of enamel tracts on the buccal side of the upper molars and lingual side of the upper molars. Differs from species of Warendja in the absence of a dentine tract at the buccal constriction on $\mathrm{m} 1$. Differs from $N$. boodjamullensis, species of Warendja, V. ursinus and Lasiorhinus latifrons in the larger size of its molars. Differs from $N$. boodjamullensis, $V$. ursinus and $L$. latifrons in the presence of a relatively high and complete crest forming the anterior margin of the occlusal surface on $\mathrm{M} 2-4$ and m2-4. Differs from Phascolonus gigas, Warendja wakefieldi and $V$. ursinus in that enamel height on the lingual surface of M1 decreases at the constriction or just posterior to this point. Differs from $V$. ursinus, $L$. latifrons, Sedophascolomys medius, and species of Warendja in the anterior moiety being wider than the posterior moiety on M2. Differs from $V$. ursinus and $L$. latifrons in the lingual cusps being slightly higher than the buccal cusps on the upper molars, and that the preentocristid and postmetacristid do not actually meet except at their base. Differs from $V$. ursinus in the absence of a low crest adjacent to the constriction and buccal to the stylar cusps on the upper molars.

\section{Rhizophascolonus crowcrofti Stirton, Tedford and Woodburne, 1967 \\ Figures 2-6}

Holotype. SAM P13846, a right M4 from the early to middle Miocene Leaf Locality (UCMP Locality V6213), Kutjamarpu LF, Wipajiri Formation, Lake Ngapakaldia, South Australia.

Previously referred material. QM F52745 and QM F52746 (left m2-3s from the type locality; Brewer et al., 2008).

Referred specimens. QM F20838 (right I1) and QM F30790 (right M1) from Dirk's Towers Site; QM F23461 (left M1), QM F20494 (left M, probably 


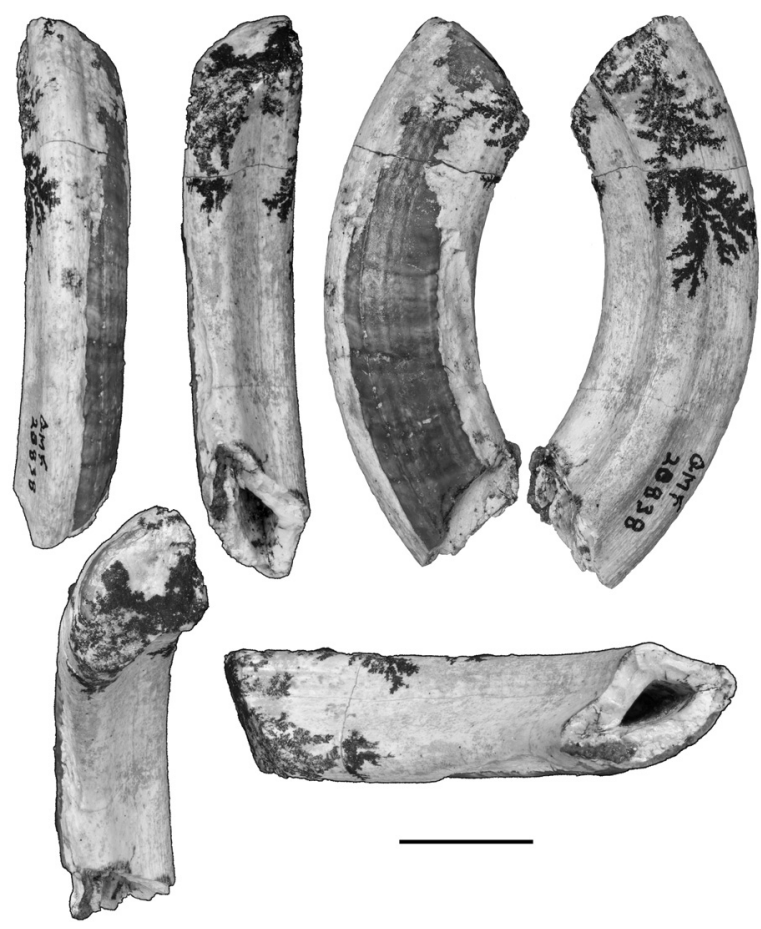

FIGURE 2. QM F20838, right I1 of Rhizophascolonus crowcrofti from Dirk's Towers Site in dorsal, ventral, distal and mesial view (top row), and occlusal and basal view (bottom row). Scale bar represents $10 \mathrm{~mm}$.

M2), QM F57963 (right M, probably M2), QM F57959 (left M, probably M2 or M3), QM F23771 (left M, probably M2 or M3), QM F20708 (right M, probably M2 or M3), QM F29656 (left M, probably M3 or M4), QM F57961 (left m, probably m2 or m3), QM F57962 (right m), QM F12452 (right m) and QM F57960 (right $m$ ) from Cleft of Ages Site; QM F57958 (right M, probably M2 or M3) from Wholly Dooley Site.

Occurrence and stratigraphy. Dirk's Towers Site is located on the north side of the D-Site Plateau and Cleft of Ages Site is on the south side of the Gag Plateau, within the Riversleigh WHA in northwestern Queensland (Creaser, 1997). Wholly Dooley Site is located west of the WHA on Wholly Dooley Hill (Archer et al., 2016). Dirk's Towers Site is interpreted to be a freshwater limestone tufa pool (Creaser, 1997) or a cave deposit (Archer et al., 1997), part of FZ B (Archer et al., 1997; Travouillon et al., 2006, 2011) and IZ B1 by Arena et al. (2016). Based on comparisons between radiometric dates of other FZ B sites (Woodhead et al., 2014) and faunal comparisons (Arena et al., 2016), this site is estimated to be between 20.5 to $23 \mathrm{Ma}$, i.e., early Miocene. Cleft of Ages Site is interpreted to be a fissure fill (Archer et al., 1997; Creaser, 1997) or cave deposit (Arena et al., 2014), part of FZ C (Travouillon et al., 2006, 2011; Arena et al., 2016). It is estimated to be between 16 and $13 \mathrm{Ma}$ based on radiometric dates of other FZ C sites and faunal comparisons (using Woodhead et al., 2014, and Arena et al., 2016), i.e., middle Miocene. Wholly Dooley Site is considered to be late Miocene in age (Archer et al., 2016).

\section{Diagnosis}

Emended diagnosis. Differs from other wombats in the unique combination of the size of its molars (anteroposterior length around $13.5 \mathrm{~mm}$ ), the presence of cheek tooth roots, large inflections in enamel height around perimeter of the teeth (varying between $0 \mathrm{~mm}$ in height to extending almost as far as the root apices) and large variations in enamel thickness on individual molars (varying between 0 and $1.5 \mathrm{~mm}$ ); M4 is similar in size to M2-3.

Differential diagnosis. Differs from $R$. ngangaba in overall size (anteroposterior molar lengths average around $11.5 \mathrm{~mm}$ for $R$. ngangaba and $13.5 \mathrm{~mm}$ for $R$. crowcrofti), width of the posterior moiety on M1 (wider on $R$. ngangaba molars), presence of a cusp posterior to the metaconule on upper molars and absence of a well-developed cusp in the StC position. Differs from N. boodjamullensis in overall size (anteroposterior molar lengths average around $13.5 \mathrm{~mm}$ for $R$. crowcrofti and $7 \mathrm{~mm}$ for $N$. boodjamullensis), in having more extensive enamel tracts on the molars (extending further down crown and root surfaces) and the presence of a relatively high and complete crest forming the anterior margin of the occlusal surface on M2-4.

Differs from hypselodont wombats in the presence of tooth roots. Of the hypselodont wombats, the unworn molar crown morphology is only known for three species: Warendja encorensis (one upper and one partial lower molar), $V$. ursinus, and $L$. latifrons. Molar cusp morphology of $R$. crowcrofti differs from $W$. encorensis in the absence of strongly curved cusps that lean posteriorly, in the presence of a postprotocrista which connects to the premetaconulecrista and in the absence of the anterobuccal and posterobuccal crests associated with the protoloph. Differs from $V$. ursinus and $L$. latifrons in the lingual cusps being higher than the buccal cusps on upper molars and the presence of a relatively high and complete crest forming the anterior margin of the occlusal surface on M2-4/ $\mathrm{m} 2-4$. It further differs from $V$. ursinus in the absence of a low crest adjacent to the constriction and buccal to the stylar cusps on upper molars. 

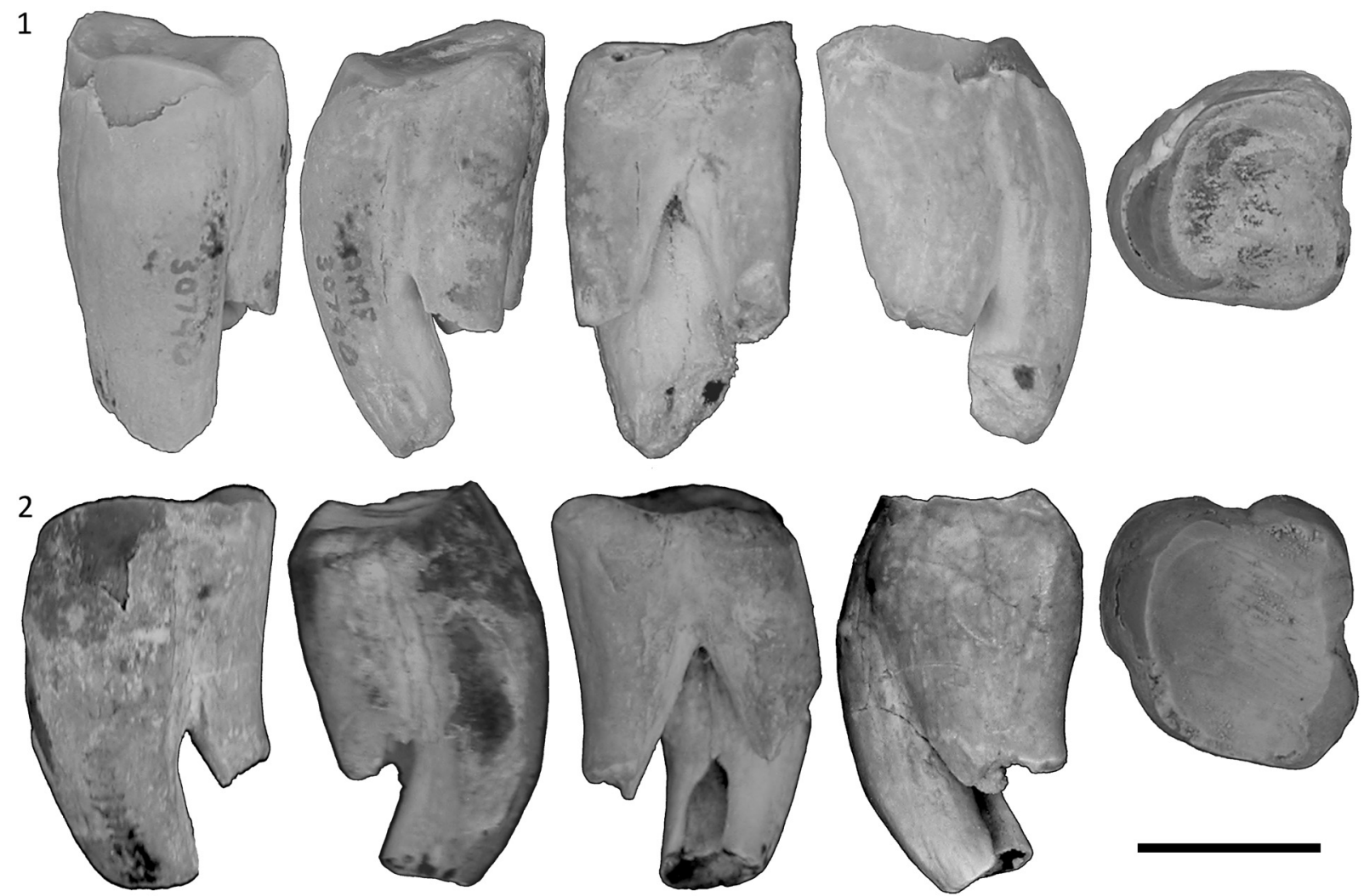

FIGURE 3. M1 of $R$. crowcrowfti in lingual, anterior, buccal, posterior, and occlusal view (left to right). 1. QM F30790, right M1 from Dirk's Towers Site. 2. QM F23461, left M1 from Cleft of Ages Site. Scale bar represents 10 mm.

Molars of $R$. crowcrofti also differ from those of $W$. encorensis, $W$. wakefieldi, $V$. ursinus and $L$. latifrons in being anteroposteriorly longer on average. The molars differ from all hypselodont wombats, except species of Warendja, by being equally constricted on buccal and lingual sides. The molars of $R$. crowcrofti differ from all hypselodont wombats, except $L$. latifrons, in having an $M 1$ with a decrease in the enamel height on the lingual surface at the constriction or just posterior to this point. However, this character is variable and only rarely observed in $L$. latifrons (in the same way that enamel tracts on the leading surfaces of $V$. ursinus molars, in a similar position to those on species of Warendja, are sometimes observed). I1 of $R$. crowcrofti differs from those of all hypselodont wombats (except species of Warendja) in being deeper than wide.

\section{Description}

Upper incisor. QM F20383 (Figure 2) is a right I1, clearly identifiable as vombatid because of its overall shape, enamel cover, and hypselodonty. Its overall size indicates that it can be referred to Rhizophascolonus. Because the only wombat known from Dirk's Towers Site is $R$. crowcrofti, QM F20383 is here tentatively allocated to that taxon.

In cross-section, QM F20383 has three surfaces. The mesial and ventral surfaces lack an enamel cover and are each traversed by a central longitudinal groove extending between the growing end of the tooth and the occlusal facet. The groove on the ventral surface is more pronounced than the one on the mesial surface. The mesial and ventral surfaces form an angle of c. $115^{\circ}$ to one another. The dorsal surface is broadly convex and is covered by enamel except at the dorsomesial and ventrodistal apices of the tooth. A partial cover of thin cementum is evident and may have completely surrounded the specimen. The enamel surface is not smooth and there are thin longitudinal ridges running the length of the tooth. 11 is broader (maximum mesiodistal width is $11.8 \mathrm{~mm}$ ) than tall (maximum dorsoventral height is $9.2 \mathrm{~mm}$ ). However, these measurements are not at $90^{\circ}$ to one another and, like other wombats, the incisor would be posi- 

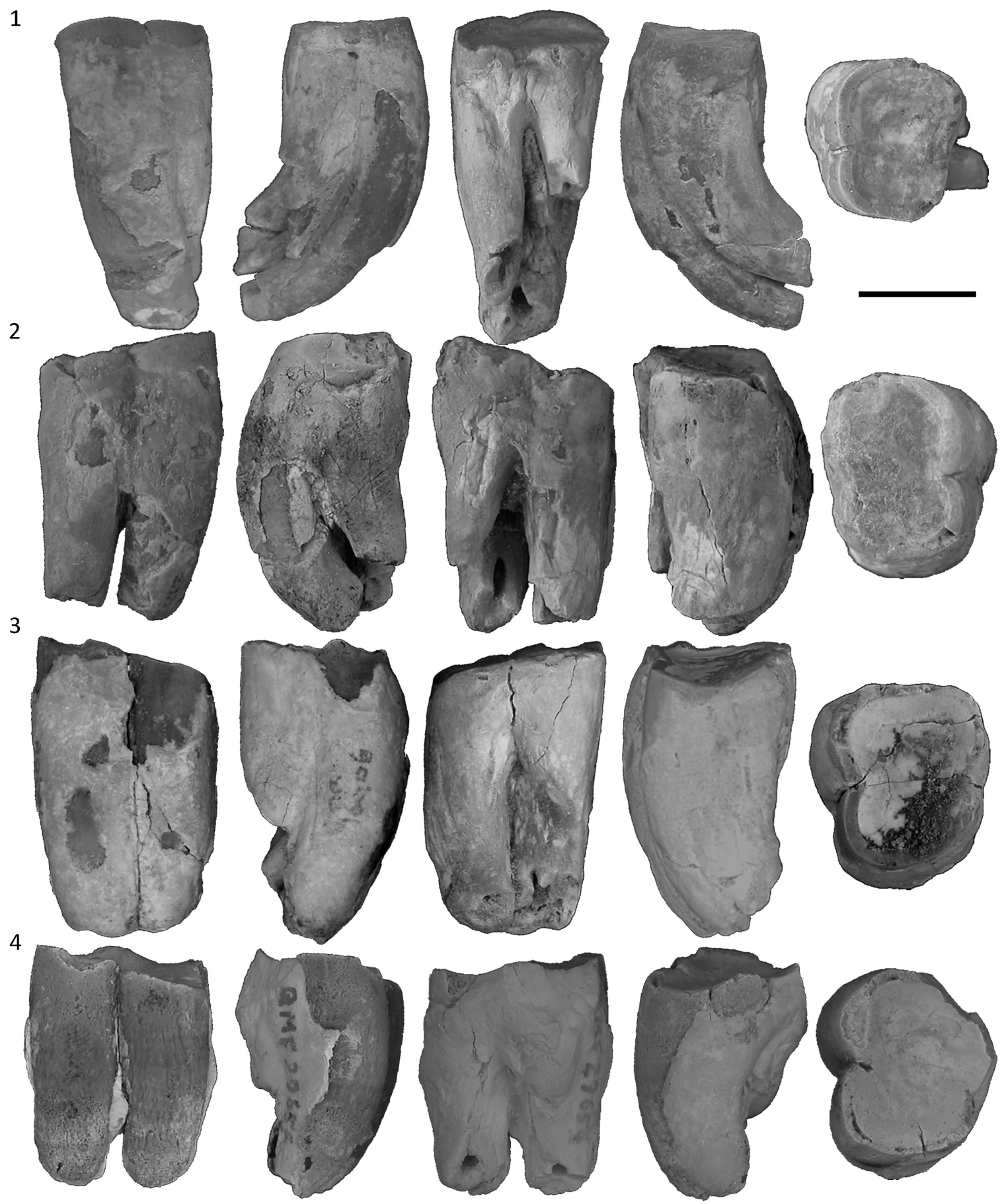

FIGURE 4. Upper molars of $R$. crowcrofti in lingual, anterior, buccal, posterior and occlusal view (left to right) from Cleft of Ages Site. 1. QM F20494, left M (probably M2). 2. QM F20708, right M (probably M2 or M3). 3. QM F23771, left M (probably M2 or M3). 4. QM F29656, left M (probably M3 or M4). Scale bar represents $10 \mathrm{~mm}$.

tioned slightly obliquely in the jaw (so no surface is quite at $90^{\circ}$ to the median plane of the skull).

The growing end of the tooth is broken on this specimen; however, it was probably not much longer than is preserved because the pulp cavity is visible at the base of the tooth. There is no overall change in mesiodistal width or dorsoventral height of the specimen along its length confirming that it was hypselodont and that it belonged to an adult individual. The occlusal surface is slightly convex and it is unlikely that this was the original shape of the facet. 
1

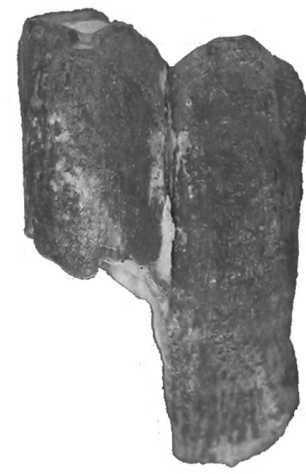

2

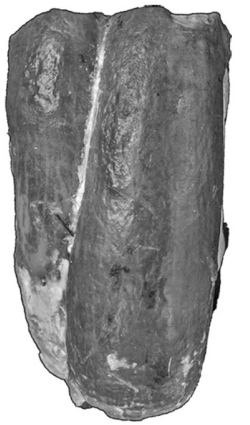

3

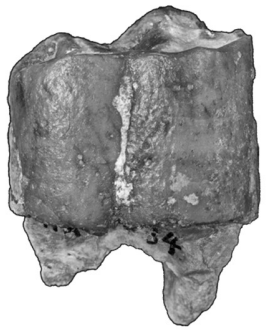

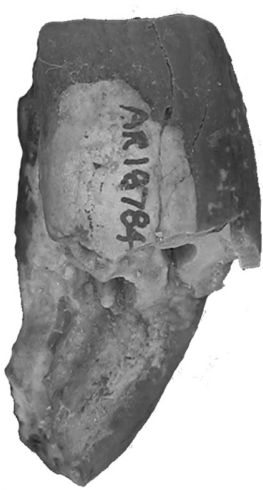
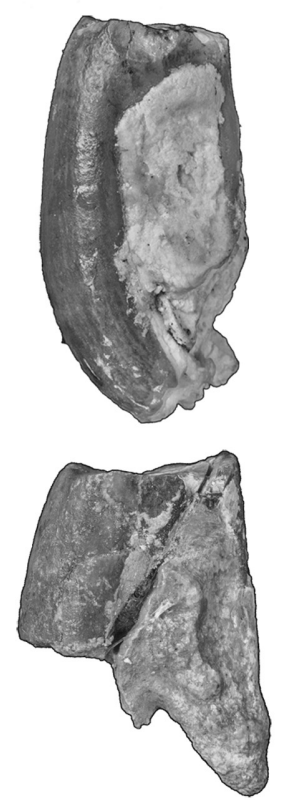
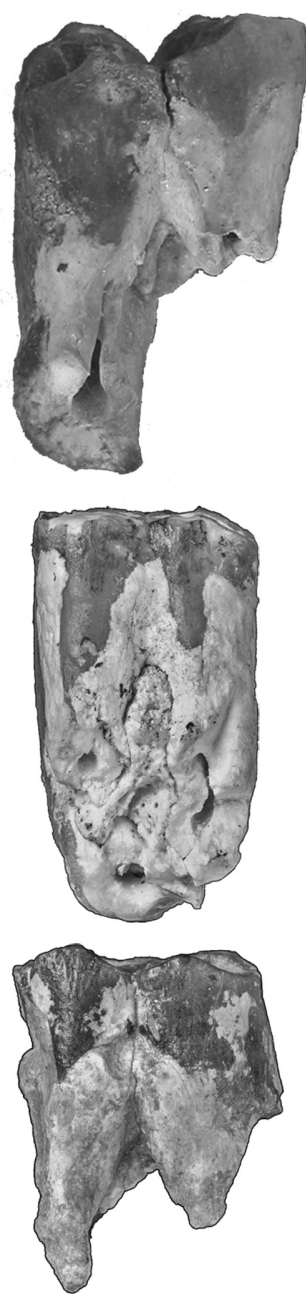
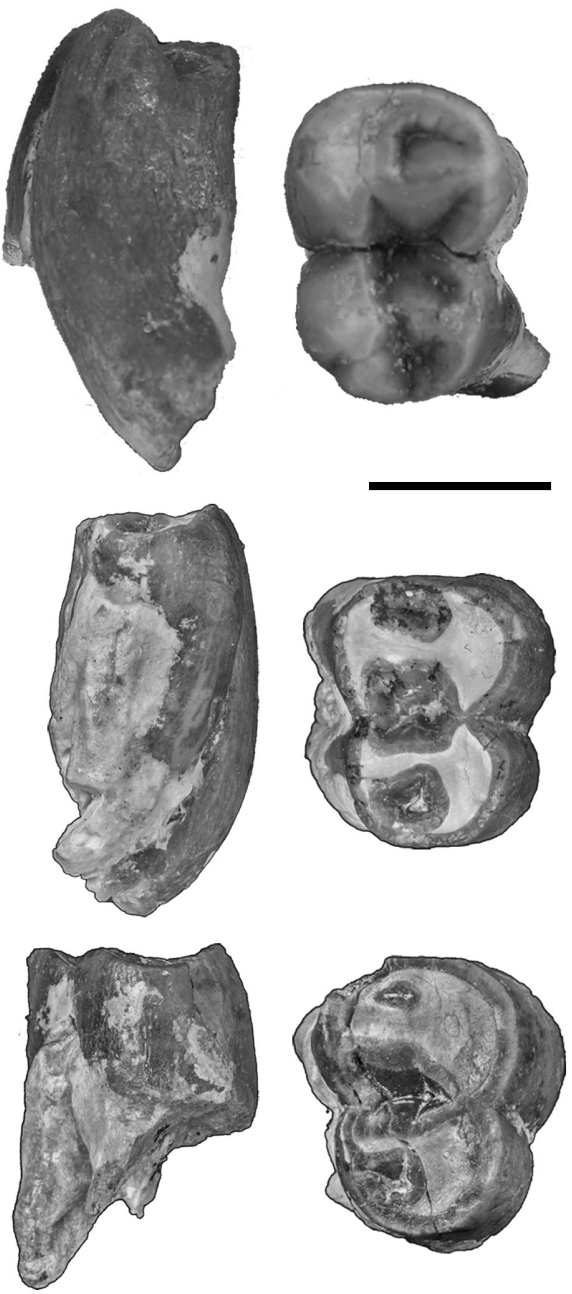

FIGURE 5. Upper molars of $R$. crowcrofti in lingual, anterior, buccal, posterior, and occlusal view (left to right). 1. QM F57959, left M (probably M2 or M3) from Cleft of Ages Site. 2. QM F57963, right M (probably M2) from Cleft of Ages Site. 3. QM F57958, right M (probably M2 or M3) from Wholly Dooley Site. Scale bar represents $10 \mathrm{~mm}$.

Upper molars. Of the nine new upper molar specimens described here, all except one (QM F57959) show heavy occlusal wear. On the most worn specimens (QM F23461, QM F30790, QM F20494, QM F23771. and QM F29656) an enamel perimeter is the only enamel on the occlusal surface, with the remainder of the surface being exposed dentine. On QM F57958, QM F20708, and QM F57963, small enamel remnants remain on the occlusal surface in addition to around the perimeter. Occlusal detail is described for the relevant tooth positions (below).

Anterior and posterior moieties are either subequal in anteroposterior length or the anterior moiety is slightly longer than the posterior (on average for M1-4). The moieties are most equal in antero- posterior length on the buccal side. On the lingual side, the anterior moiety can be up to three times the length of the posterior moiety at the anterior of the molar row (e.g., in later wear stages of M1). The anterior moiety is wider in buccolingual width relative to the posterior moiety. Both moieties are wider than long. Overall tooth width increases slightly below the occlusal surface on unworn molars due to the curving lingual surface (convex lingually).

There are three roots; the anterior root is the smallest in all dimensions and is located below the anterolingual quadrant of the crown. The posterior root is located beneath the posterior moiety of the tooth and extends between buccal and lingual sides where it meets the crown. The anterolingual 
1

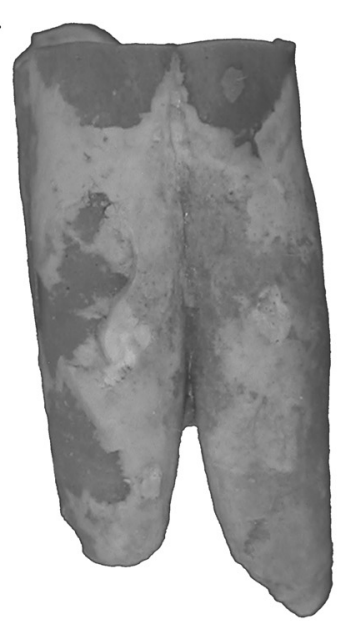

2
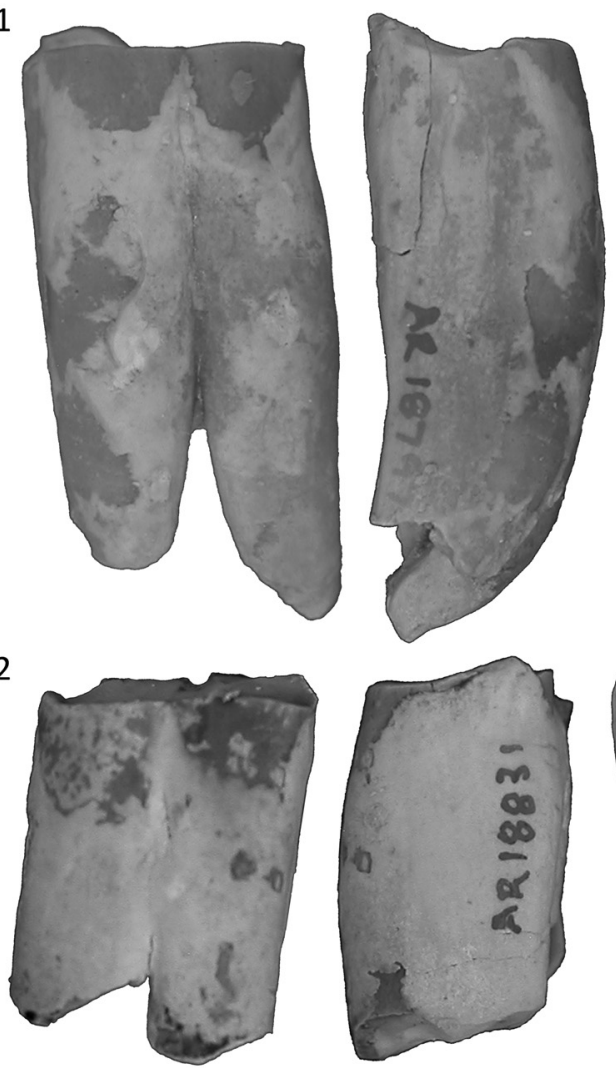

3

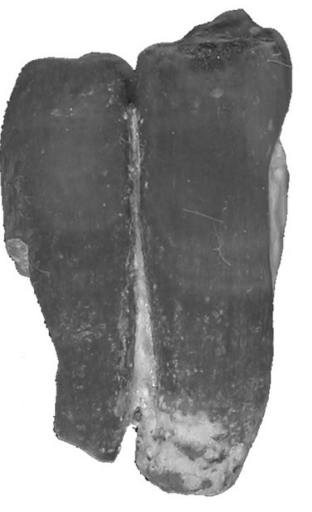

4
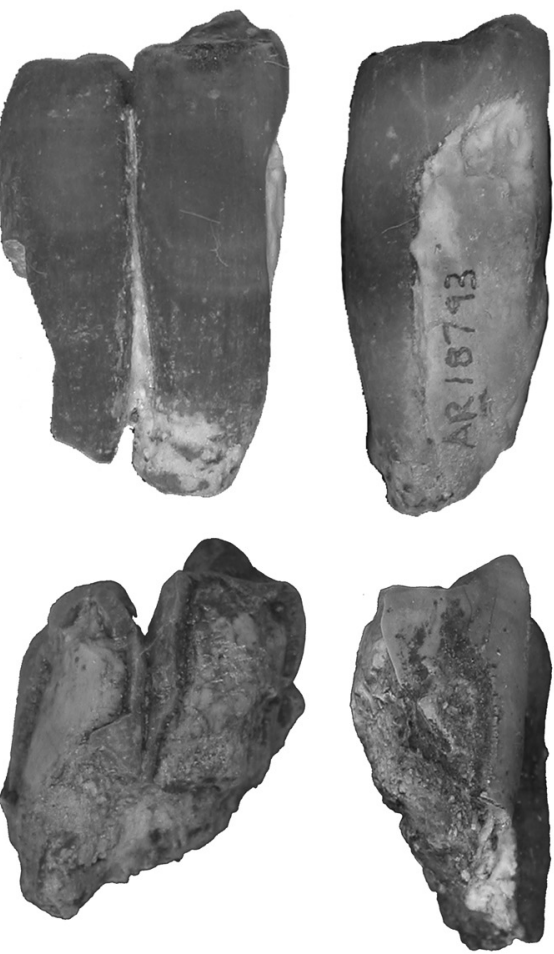
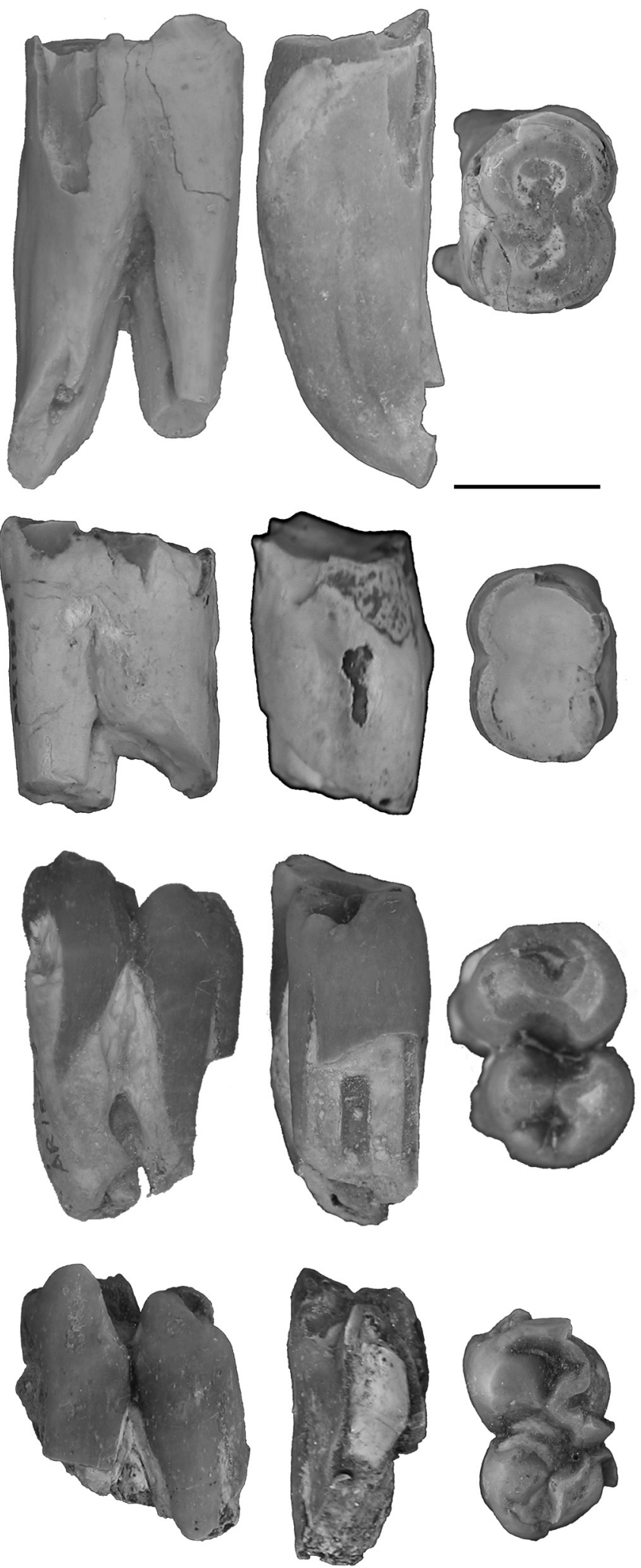

FIGURE 6. Lower molars of $R$. crowcrowfti in buccal, anterior, lingual, posterior, and occlusal view (left to right) from Cleft of Ages Site. 1. QM F57961, left m (probably m2 or m3). 2. QM F57962, right m (probably m2 or m3). 3. QM F57960, right $\mathrm{m}$ (probably m2 or m3). 4. QM F12452, right m (probably m3 or m4). Scale bar represents $10 \mathrm{~mm}$. 
root is located beneath the anterolingual quadrant of the crown and is usually the most prominent root due to its convex lingual surface and long length (occlusobasally), particularly at the anterior of the molar row.

The junction between all three roots is closest to the occlusal surface midway between anterior and posterior surfaces on the buccal side of the tooth, where the hypsodonty index (Janis, 1988) is around 1 (QM F57959). Enamel height is minimal at this point even on unworn specimens $(\leq 3 \mathrm{~mm})$. In contrast, on the lingual side of the tooth, the lingual and posterior roots are physically joined until a significant distance below the occlusal surface (although root canals are separate), with enamel extending across this surface and down the surface of the roots. In effect, the tooth appears hypsodont on this side. The external surface of the anterobuccal and anterolingual roots is also physically connected below the occlusal surface in anterior view.

On the buccal surface, enamel height is minimal except midway across each moiety, directly above the roots, where thin tongues of enamel extend for a short distance down the surface of the tooth onto the top of the roots. This is similar to the lingual surface of the lowers as described by Brewer et al. (2008) for specimens from South Australia. On anterior and posterior surfaces, enamel height is small (except where there is an increase onto the lingual and buccal surfaces) and decreases slightly towards the buccal side. Where enamel height is smallest, the enamel surrounding the perimeter of the tooth at the occlusal surface can be breached with heavy wear (such as on the anterior surface of QM F30790 and QM F23461). Enamel is generally thickest where enamel height is greatest (such as on the lingual surface) and is up to $1.4 \mathrm{~mm}$ thick on QM F23771, although more usually about $1 \mathrm{~mm}$ in thickness on this surface on other specimens. Cementum surrounds the tooth.

The lingual surfaces of the upper molars are convex with the apical (basal) end of the anterolingual and posterior roots following the curvature of that surface. The anterior, posterior, and buccal surfaces are flatter. In addition to the buccally curving lingual crown and root surfaces, the anterolingual root curves posteriorly towards its apex. In early wear stages, the occlusobasal length of the anterolingual and posterior roots decreases from M2 to M4. It is possible that M1 also follows this trend; however, the two M1 specimens are both heavily worn.
M1. M1 is represented by two specimens, QM F23461 and QM F30790 (Figure 3). QM F24904 is an M1 or M2 (Figure 4.1). The anterolingual root is relatively large and centrally located on the lingual surface between anterior and posterior surfaces. The posterior moiety is reduced in anteroposterior length on the lingual side relative to the anterior moiety, but contributes to approximately half the length of the tooth on the buccal side. In occlusal view, the lingual side of the tooth is arcuate between the anterobuccal and posterobuccal 'corners' of the tooth. The arc is asymmetric, with the apex being anterolingual to the midpoint between anterior and posterior surfaces. QM F23461 is more bilobate and less arcuate on the lingual side than QM F30790. The lingual constriction is poorly defined (relative to M2-4) and approximately dorsoventral in orientation in lingual view.

The division between the roots is located close to the occlusal surface (presumably due to advanced wear of the occlusal surface relative to M2-4 specimens). The inside surfaces of the roots on QM F23461 are marked by longitudinal grooves that are continuous with the apical foramina. This is least obvious on QM F30790. The anterolingual root on QM F23461 has a wide apical foramen that has expanded along the medial groove.

Enamel is extensive on the anterior half of the lingual surface, where it extends down the length of the preserved anterolingual root. There is a significant decrease in enamel height between the anterior and posterior moieties on the lingual side (to as little as c. $1 \mathrm{~mm}$ in height on QM F30790). This decrease in enamel height is located slightly anterior to the furcation between the anterolingual and posterior roots on QM F30790. On the buccal side, enamel height has been worn away leaving a dentine tract at the division between the moieties, and the enamel is relatively thin either side of this tract. A wide dentine tract is also present on the anterior surface directly above the furcation between the anterolingual and anterobuccal roots.

Neither M1 specimen preserves the original crown surface detail. The enamel around the perimeter of the tooth is extensively chipped at the occlusal surface, especially on the buccal side and to a lesser extent on the posterior margin. This is particularly obvious on QM F23461 where the top of the enamel forming part of the buccal surface is up to $2.5 \mathrm{~mm}$ below the occlusal surface. The dentine at this position is rounded (despite an adjacent facet in the dentine having a sharp edge), which is consistent with the chipping having occurred premortem. 
The posterobuccal 'corner' and the anterior half of the lingual margin form the highest points on the occlusal surface (with the anterobuccal 'corner' also forming a topographic high on QM F30790). The enamel at and adjacent to these points is flush with the central dentine, and together they form a continuous curved wear facet. The occlusal dentine surface curves between these points with the lowest point being at or just lingual to the median plane of the tooth. This wear facet is continuous with the lingual enamel on QM F23461, but not QM F30790. The lowest point on the occlusal surface is at the anterior dentine tract on the buccal half of the anterior surface. On both molar specimens, this part of the occlusal surface is irregular and slopes away from the occlusal surface towards the roots.

Deeply etched wear striations within the central dentine basin on QM F23461 are oriented anterolingually/posterobuccally. The wear striations form an angle of c. $60^{\circ}$ to the buccal edge of the tooth. They are largely concentrated within a 6 $\mathrm{mm}$ wide band that extends obliquely across the occlusal surface, between the anterolingual and posterobuccal topographic 'highs'. The striations are better defined on the buccal side relative to the lingual side. Anterior to this band, similarly oriented striations are also present on the anterobuccally and basally sloping dentine of the anterobuccal 'corner'. Wear striations are also visible in the enamel on the lingual margin and have a similar anterolingual/posterobuccal orientation.

M2-3. M2-3 (Figures 4-5) are represented by up to seven specimens (although QM F20494 may be an M1, and QM F29656 may be an M4), with three specimens (QM F57958, QM F20708, and QM F57963) preserving some occlusal enamel remnants, and one specimen (QM F57959) being relatively unworn. In contrast to M1, M2-3 are distinctly bilobed in occlusal view. The protocone forms the highest cusp, followed by the metaconule, partly due to the fact that the entire anterior moiety is higher than the posterior moiety. Wear is concentrated on the lingual side. Crests extend lingually from the buccal margin on anterior and posterior moieties, dividing the occlusal surface into three (an anterior basin, a central basin between the moieties, and a posterior basin).

The protocone and metaconule are located on the lingual margin, midway across the anterior and posterior moieties, respectively. Anterior and posterior crests extending from these cusps enclose the lingual side of the crown. The lingual surface is convex away from the occlusal surface and the occlusal surface buccal to the lingual margin is steeply inclined. The occlusal surface is deepest on the lingual side. The buccal surface of the tooth is relatively flat away from the occlusal surface, in contrast to the lingual surface. The anterior margin of the tooth is enclosed by a crest, continuous with the lingual and buccal margins.

The paracone is located lingual to the buccal margin, on a moderately developed protoloph. The paracone is identifiable by a slightly raised area on QM F57958, QM F57959, and QM F57963. The protoloph extends from the buccal margin, to at least the base of the protocone (the lingual side is worn on all specimens). The metacone is also located lingual to the buccal margin, but a clear loph-like structure is not present on the posterior moiety. A short poorly-defined crest connects the metacone to the buccal margin. The metacone appears anteroposteriorly elongated (possibly a poorly defined crest), and a short crest extends anterolingually from the metacone, terminating anterobuccal to the metaconule.

A relatively well-developed posterolingual cusp is present immediately posterior to the metaconule on the lingual surface of QM F57959. Distinct grooves demarcate it from the metaconule on the lingual surface, and to a lesser extent on the medial surface. It is not possible to tell whether a similar cusp is present on other upper molars, as all other specimens show extensive wear at this position. The enamel on the posterior and anterior margins of QM F57959 is wrinkled.

Anterolingual and posterior roots are similar in size in lingual view in contrast to the dominant anterolingual root on M1s. On some specimens (QM F209494 and QM F57963), the anterolingual root is twisted over the posterior root away from the occlusal surface. This is interpreted to be a feature more commonly seen at the anterior of the tooth row (Brewer et al., 2015), due to individual variation or possibly due to impacted growth.

Enamel extends further down the posterior root on the lingual side than is seen on M1 specimens and to a similar extent as the enamel on the anterolingual root. Enamel extends across the lingual surface except where the roots diverge towards the root apices. The anterobuccal and posterior roots are more closely associated in buccal view compared to M1. A dent is present on the lingual surface of the anterolingual root on QM F20494 (a pathology possibly due to illness, injury, or lack of room in the jaw during development). Unlike the M1 specimens, there is a step between the central dentine and the lingual enamel edge. 
M4. M4 has already been described for the type specimen, SAM P13846 (Brewer et al., 2008). QM F29656 (Figure 4.4) is either an M3 or M4.

Lower molars. Two $R$. crowcrofti lower molars from South Australia were described by Brewer et al. (2008; QM F52745-6). Four additional specimens from Riversleigh are recognised here (QM F57960, QM F57961, QM F57962, and QM F12452; Figure 6).

QM F57961 and QM F57962 are interpreted to be $\mathrm{m} 2$ or $\mathrm{m} 3 \mathrm{~s}$ based on the similar size of the moieties (length and width) and the relatively wide dentine tracts on anterior and posterior surfaces (Brewer et al., 2007, 2015). QM F57960 and QM F12452 have a narrow dentine tract on the posterior surface, which may indicate that they are $\mathrm{m} 3$ or m4s. QM F12452 also leans strongly anteriorly, with a marked difference in height between anterior and posterior moieties. This may indicate that it is either an $\mathrm{m} 3$ or $\mathrm{m} 4$ (probably the latter). There is no inter-tooth facet on the posterior surface of QM F57960; however, this could be due to the fact that the posterior tooth (if there was one) had not come into functional occlusion at the time of death. The roots on QM F57960 are quite long and straight, which argue against it being on $\mathrm{m} 4$. It is most likely an $\mathrm{m} 3$.

The average tooth length of all six lower molars (including the specimens from South Australia) is $14 \mathrm{~mm}$ (ranging between 13.4 and 15.5 $\mathrm{mm}$ ). Tooth width is $60-80 \%$ that of the length (but based mostly on worn specimens). Anterior and posterior moieties are subequal in length and width, except QM F57960, where the anterior moiety is slightly wider than the posterior moiety (possibly due to the fact that we can measure this at the unworn occlusal surface). Width at the constriction between the moieties is $50-75 \%$ that of length (mostly based on worn specimens). The constriction is equally as deep on buccal and lingual sides.

Occlusal detail is visible on QM F57960 and QM F12452. QM F57960 shows some wear of the occlusal surface (concentrated on the buccal cusps, but also on the metaconid). QM F12452 shows little wear; however, the buccal side of the tooth is damaged. The occlusal description is based on QM F57960, unless otherwise stated. There are four main cusps; the protoconid, metaconid, entoconid, and hypoconid, occupying the four main quadrants of the tooth.

The lingual cusps are located slightly closer to the anterior surface of the tooth relative to the buccal cusps. The anterior and posterior lophids, connecting protoconid to metaconid and hypoconid to entoconid, respectively, are consequently anterolingual/posterobuccal in orientation. Both lophids are lowest midway across the occlusal surface, as an anteroposterior groove/valley extends from the anterior tooth margin across the anterior and posterior lophids to the posterior margin of the tooth.

The anterior moiety is higher than the posterior moiety. The posterior surface of the protolophid is almost vertical. In contrast, the anterior surface of the posterior lophid (hypolophid) is shallower in inclination. The deepest part of the occlusal surface is in the transverse valley between the moieties. This valley is s-shaped along an overall anterolingual/posterobuccal trend. This is due to the anterolingual/posterobuccal orientation of the occlusal features, but also a slight lingual shift of the anterior moiety relative to the posterior moiety. This has resulted in the pre-entocristid and the postprotocristid blocking off the valley on the lingual and buccal sides, respectively, so that the valley snakes around them. Neither the postprotocristid and prehypocristid nor the postmetacristid and pre-entocristid meet at the constriction between the moieties. These crests all curve medially before terminating at the constriction, so that the central transverse valley is open at both sides (albeit through a very narrow gap).

The paracristid curves anteriorly and lingually to form the anterior margin of the occlusal surface. A small anterolingual swelling, just anterior to the metaconid may represent a poorly developed paraconid. The anterior margin encloses a small, but deep, anterior basin immediately anterior to the protolophid. The posterior margin is not as high as the anterior one and curves basally away from the tip of the hypoconid to a low at its midpoint (marked by a couple of grooves in the margin). Consequently, the small posterior basin just anterior to it is shallow. There is a small swelling on the posterolingual margin, probably representing the hypoconulid.

Tooth length is slightly greater at the occlusal surface than at the furcation between the roots. The anterior surface is relatively flat and wide (partly due to presence of the anterior dentine tract); the posterior surface is more rounded.

\section{Remarks}

The upper incisor of $R$. crowcrofti is very similar to that of $W$. encorensis (especially QM F51408), differing in overall size, greater overall mesiodistal width, and the absence of enamel on the dorsal apex and dorsal part of the mesial surface. 
The relative widths of the moieties for each of the upper molar tooth positions (Figure 7) follows a similar pattern to other wombat taxa and $P$. cinereus, with M1 having a wider posterior moiety/ smaller anterior moiety than M2-3, and M4 being absolutely smaller than M2-3 and having a narrower posterior moiety. However, the absolute and relative dimensions of the moieties can discriminate between taxa. For $P$. cinereus, $N$. boodjamullensis, and $R$. crowcrofti, the relative widths of the moieties on M1 are more similar to M2-3 than for $V$. ursinus, L. latifrons, and $W$. wakefieldi (presumably the condition of the latter taxa is derived). In addition, the posterior moiety is always smaller than the anterior moiety for $P$. cinereus, $N$. boodjamullensis, and $R$. crowcrofti; presumably a primitive characteristic. Another exception is the M4 of $R$. crowcrofti, which occupies the same morphospace as M1-3 of this taxon (Figure 7). This could indicate that the tooth positions have been misidentified here (considered unlikely) or that there is more than one species represented. The latter is certainly a possibility, particularly due to the time range represented (possibly as great as late Oligocene to late Miocene); however, if we exclude all specimens except the ones from Cleft of Ages Site, the expected pattern (with M4 being smaller overall relative to M2-3 and with a reduced posterior width) still does not result. We have therefore interpreted this as a derived morphology for $R$. crowcrofti. Nonetheless it is possible that this does represent a mixed sample, or that $R$. crowcrofti shows large size variation (e.g., sexual dimorphism) that masks any underlying pattern. More complete specimens are needed for testing. The Coefficient of Variation (CV) of all R. crowcrofti specimens (for anteroposterior length of molars) is 7.4 (Table 1). It is 6.4 if restricted to just specimens from Cleft of Age Site. $\mathrm{CVs}$ for other wombat taxa and $P$. cinereus for this measurement range from 6.2 to 12.7 (the latter is for $W$. encorensis). Based on this information, it is not unreasonable to assume that all specimens identified here as $R$. crowcrofti belong to a single species (see also Figure 8).

The two South Australian lower molars (QM F52745-6) and QM F57961 and QM F57962 described here, cluster closely together on Figure 7 (see Appendix 3 for measurements). In contrast, QM F57960 is narrower buccolingually and has a slightly smaller posterior moiety relative to the other m2-3 specimens. This may be because it is relatively unworn, with no differential wear on one side of the tooth (which can affect width and length measurements) and no cementum. Other possibili- ties are that we have only captured a very small range of possible variation, that it is an $\mathrm{m} 4$ or that it has wrongly been identified as $R$. crowcrofti. We consider the latter possibility to be the least likely.

\section{Rhizophascolonus ngangaba sp. nov.}

Figures 9-12

zoobank.org/12395C10-57DB-4FE0-9D15-AC3498FF96F8

Holotype. QM F23772 (left M1) from Camel Sputum Site.

Paratypes. QM F23903 (left P3), QM F20706 (left M), QM F57967 (right m1), and QM F23769 (anterior half of right $\mathrm{m} 2-3$ ) from Camel Sputum Site; QM F23765 (left M1), QM F23764 (right m1), and QM F23768 (left m2 or m3) from Upper Site; QM F57968, left m2 from Gen's Grand Slam Site.

Occurrence and stratigraphy. Camel Sputum Site and Upper Site are located on Godthelp's Hill on the central part of D-Site Plateau, within the Riversleigh WHA in northwestern Queensland (Creaser, 1997). Both sites were interpreted to represent lacustrine carbonates by Archer et al. (1989), lacustrine/tufa/cave deposits (Archer et al., 1997) and cave deposits by Arena (2004), part of FZ B (Archer et al., 1989; Black, 1997; Creaser, 1997; Travouillon et al., 2006, 2011) and IZ B3 by Arena et al. (2016). A single radiometric date of $17.75+/-0.78 \mathrm{Ma}$ has been obtained for Camel Sputum site by Woodhead et al. (2014). Upper Site and Camel Sputum Site have been allocated to the same palaeocommunity by Myers et al. (2017) and are assumed to be similar in age (c. $18 \mathrm{Ma}$ ).

Etymology. Ngangaba is a Waanyi (the local Aboriginal language of Riversleigh) word meaning 'light' (in weight), referring to the delicate build of the occlusal surface relative to the other species of Rhizophascolonus.

\section{Diagnosis}

Presence of a bulbous posterior moiety on $\mathrm{M} 1$, which is equal to or greater in width than the anterior moiety until just below the division between anterior and posterior roots on the buccal side; unique combination of size of the molars (with M2-3/m2-3 averaging between 10.5 and $12.5 \mathrm{~mm}$ in maximum anteroposterior length) and rooted molars with large inflections in enamel height and variations in enamel thickness around the perimeter of the teeth.

Differential diagnosis. Differs from $R$. crowcrofti in overall size (anteroposterior molar lengths average around $11.5 \mathrm{~mm}$ for $R$. ngangaba and $13.5 \mathrm{~mm}$ for $R$. crowcrofti), width of the posterior moiety on M1 (wider on $R$. ngangaba molars) and absence of a cusp posterior to the metaconule on the upper 

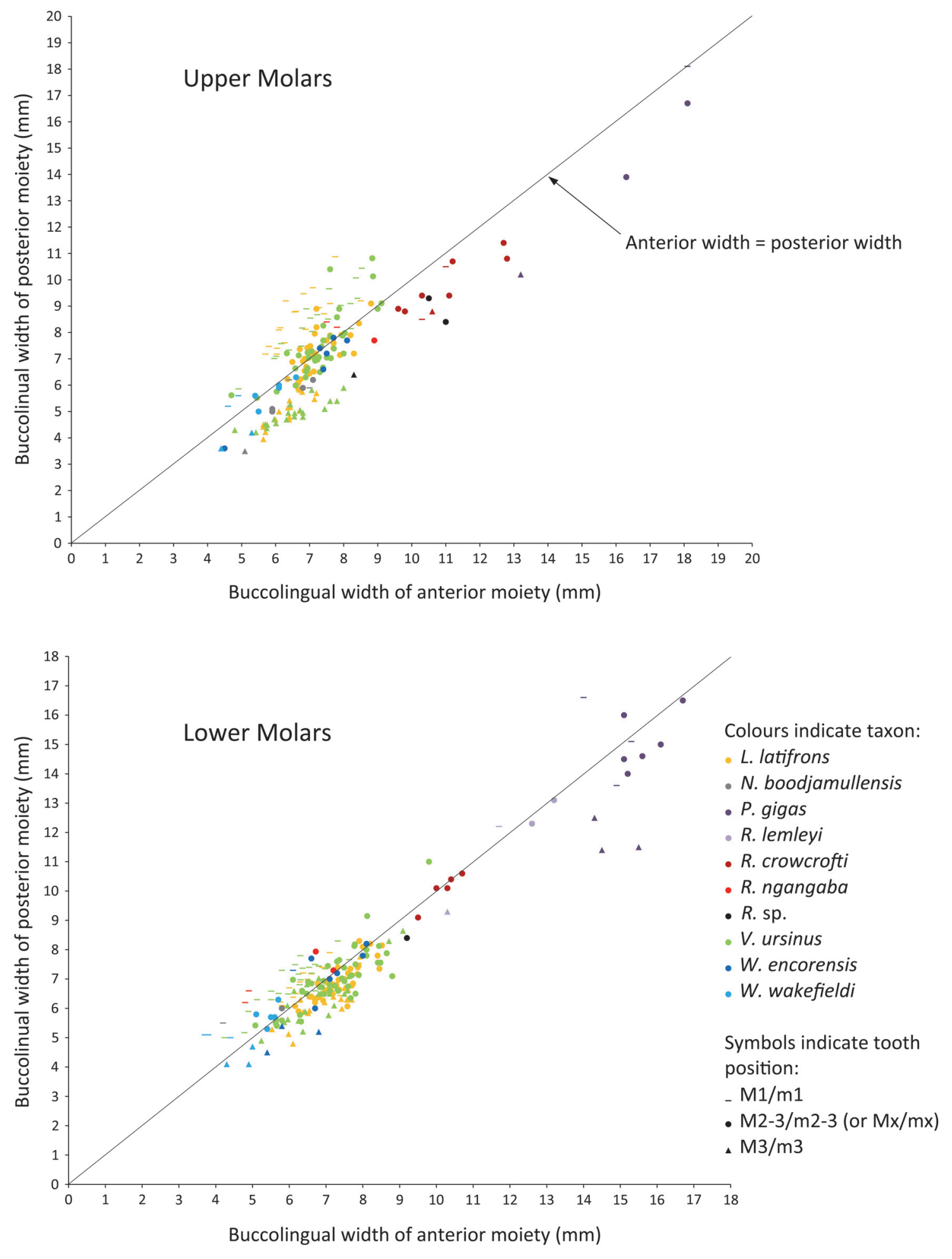

FIGURE 7. Bivariate plots showing relative width of anterior and posterior moieties of molars. The upper molars of Rhizophascolonus sp. are represented by QM F57964-5 and the lower molars by QM F20613. 
TABLE 1. Univariate statistics for anteroposterior tooth length $(\mathrm{mm})$ of specimens listed in Appendix $3 . \mathrm{n}=\mathrm{number}$ of specimens, Mean = arithmetic mean, StDev = standard deviation, CV = coefficient of variation expressed as a percentage.

\begin{tabular}{lcccc}
\hline \multicolumn{1}{c}{ Taxon } & $\mathbf{n}$ & Mean & StdDev & CV (\%) \\
\hline L. latifrons & 177 & 9.4 & 1.0 & 10.4 \\
N. boodjamullensis & 10 & 7.1 & 0.6 & 8.7 \\
P. cinereus & 621 & 7.5 & 0.5 & 6.3 \\
P. gigas & 45 & 22.6 & 2.6 & 11.5 \\
R. magna & 16 & 19.6 & 2.0 & 10.1 \\
S. medius & 25 & 13.7 & 0.9 & 6.8 \\
V. ursinus & 236 & 10.4 & 1.1 & 10.3 \\
W. encorensis & 18 & 9.3 & 1.2 & 12.7 \\
W. wakefieldi & 21 & 7.2 & 0.9 & 12.4 \\
R. crowcrofti & 15 & 13.7 & 1.0 & 7.4 \\
R. ngangaba & 7 & 11.6 & 0.7 & 6.2 \\
Specimens from BaD & 4 & 11.5 & 1.0 & 8.9 \\
Specimens from BR & 2 & 12.6 & 0.3 & 2.2 \\
R. crowcrofti and R. ngangaba combined & 22 & 13.0 & 1.4 & 10.6 \\
R. crowcrofti from COA only & 11 & 13.7 & 0.9 & 6.4 \\
R. crowcrofti and specimens from BR combined & 17 & 13.6 & 1.0 & 7.6 \\
R. crowcrofti and specimens from BaD combined & 19 & 13.3 & 1.4 & 10.2 \\
R. crowcrofti and QM F23763 combined & 16 & 13.7 & 1.0 & 7.4 \\
R. ngangaba and specimens from BR combined & 9 & 11.8 & 0.8 & 6.6 \\
R. ngangaba and specimens from BaD combined & 11 & 11.6 & 0.8 & 6.8 \\
R. ngangaba and QM F23763 combined & 8 & 11.7 & 0.8 & 7.0 \\
\hline & & & & \\
\hline
\end{tabular}

molars. Differs from $N$. boodjamullensis in overall size (anteroposterior molar lengths average around $11.5 \mathrm{~mm}$ for $R$. ngangaba and $7 \mathrm{~mm}$ for $N$. boodjamullensis), in having more extensive enamel tracts on the molars (extending further down crown and root surfaces), presence of a relatively high and complete crest forming the anterior margin of the occlusal surface on M2-4 and the posterior moiety of $\mathrm{M} 1$ being wider than anterior moiety. P3 of $R$. ngangaba differs from that of $N$. boodjamullensis in the presence of well-defined anterior cusps (anterior to the paracone), a better developed posterolingual crest and lingual cusp and in the more extensive enamel cover, particularly on the posterior half of the buccal surface.

The cheek teeth of $R$. ngangaba differ from those of all hypselodont wombats in the presence of tooth roots. Of the hypselodont wombats, the unworn molar crown morphology is only known from three species: $W$. encorensis (one upper and one partial lower molar), $V$. ursinus and $L$. latifrons. Cusp morphology of $R$. ngangaba molars differs from $W$. encorensis in the absence of strongly curved cusps which lean posteriorly, in the pres- ence of a postprotocrista which connects to the premetaconulecrista and in the absence of the anterobuccal and posterobuccal crests associated with the protoloph (with the exception of a single crest seen on QM F20706). They differ from $V$. ursinus and $L$. latifrons molars in the lingual cusps being higher than the buccal cusps on upper molars, presence of a stylar cusp posterobuccal to the paracone (in the position of StC), which is large and well-developed, in that the postprotocrista meets the premetaconulecrista, presence of a relatively high and complete crest forming the anterior margin of the occlusal surface on M2-4/m2-4 and poor development/absence of a cusp on the posterobuccal side of M1 (and occasionally M2) in the position of StE. They further differ from $V$. ursinus in the absence of a low crest adjacent to the constriction and buccal to the stylar cusps on the upper molars and in the paracone being located on the buccal margin of M1 (as opposed to lingual to this on $V$. ursinus molars).

Molars of $R$. ngangaba differ from $W$. encorensis, $W$. wakefieldi, $V$. ursinus, and $L$. latifrons in being anteroposteriorly longer on average than the 


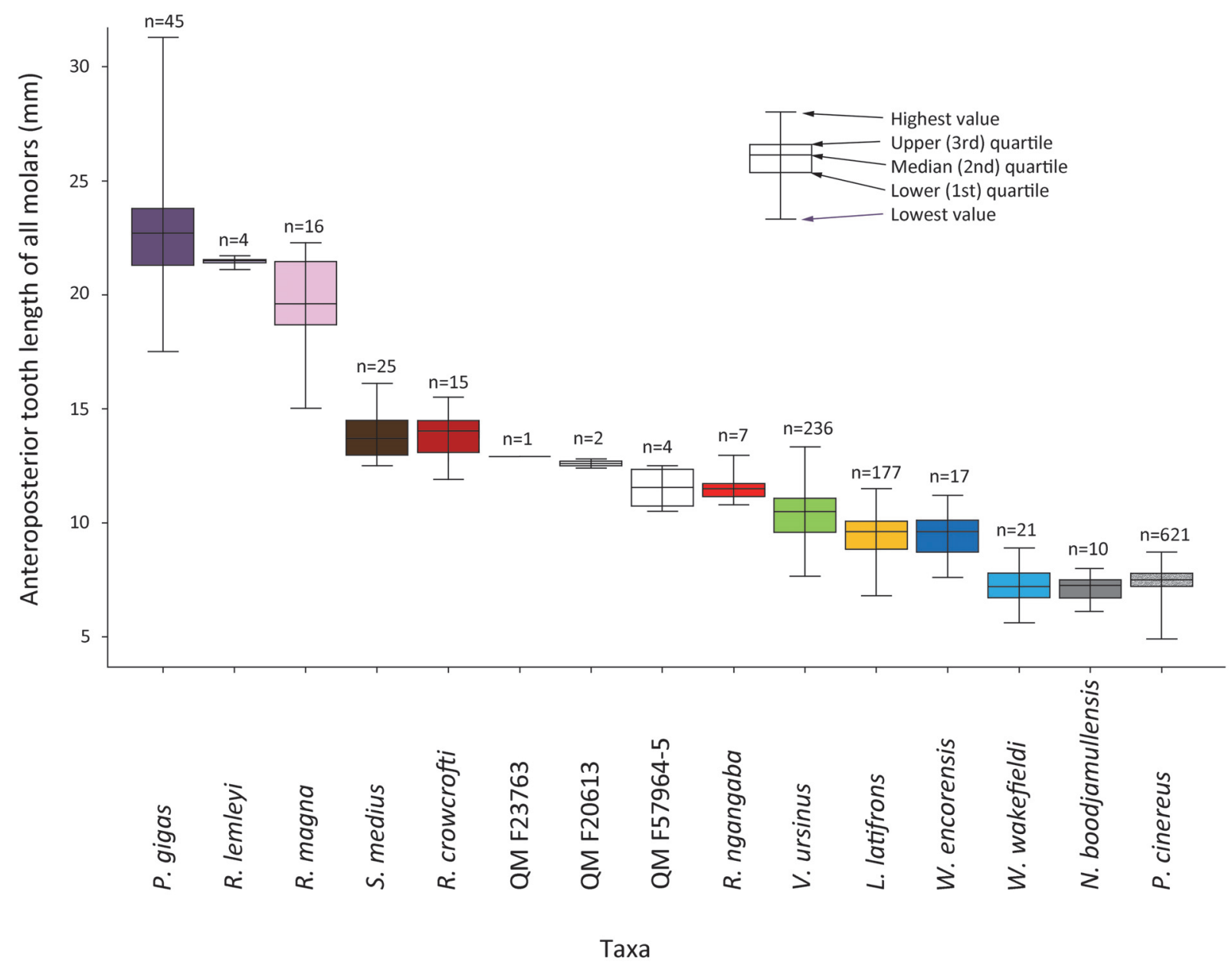

FIGURE 8. Box and whisker plot of anteroposterior length of molars of a range of wombat taxa and Phascolarctos cinereus. Number of specimens measured for each taxon is indicated above highest value for each taxon.

latter taxa. They differ from those of $S$. medius, Ramsayia magna, and $P$. gigas in being smaller in anteroposterior length. M2 of $R$. ngangaba differs from $W$. encorensis, $W$. wakefieldi, $V$. ursinus, $L$. latifrons, and $S$. medius in the anterior moiety being wider than the posterior moiety. The molars differ from all hypselodont wombats, except species of Warendja, by being equally constricted on buccal and lingual sides. They differ from species of Warendja in the absence of a dentine tract at the buccal constriction on $\mathrm{m} 1$. The molars of $R$. ngangaba differ from those of all hypselodont wombats, except $L$. latifrons, in having an M1 with a decrease in the enamel height on the lingual surface at the constriction or just posterior to it. However, this character is variable and only rarely observed in $L$. latifrons (in the same way that enamel tracts on the leading surfaces of $V$. ursinus molars, in a similar position to those on species of Warendja, are sometimes observed).

\section{Description}

P3. P3 is represented by a relatively complete specimen with little wear (QM F23903; Figure 9). P3 is ovate in occlusal view and longer than wide ( $8.2 \mathrm{~mm}$ and $6.2 \mathrm{~mm}$, respectively). The occlusal surface is dominated by a central cusp (referred to here as the paracone, although its homology with the paracone of other Vombatiformes is uncertain), which is centrally located between anterior and posterior edges of the tooth. The apex of the paracone forms the highest point on the occlusal surface. The paracone is kite-shaped or teardropshaped in occlusal view in that its buccolingual width tapers more abruptly anterior to the apex than posterior to it. Posterior to the paracone is a smaller cusp (referred to here as the metacone 


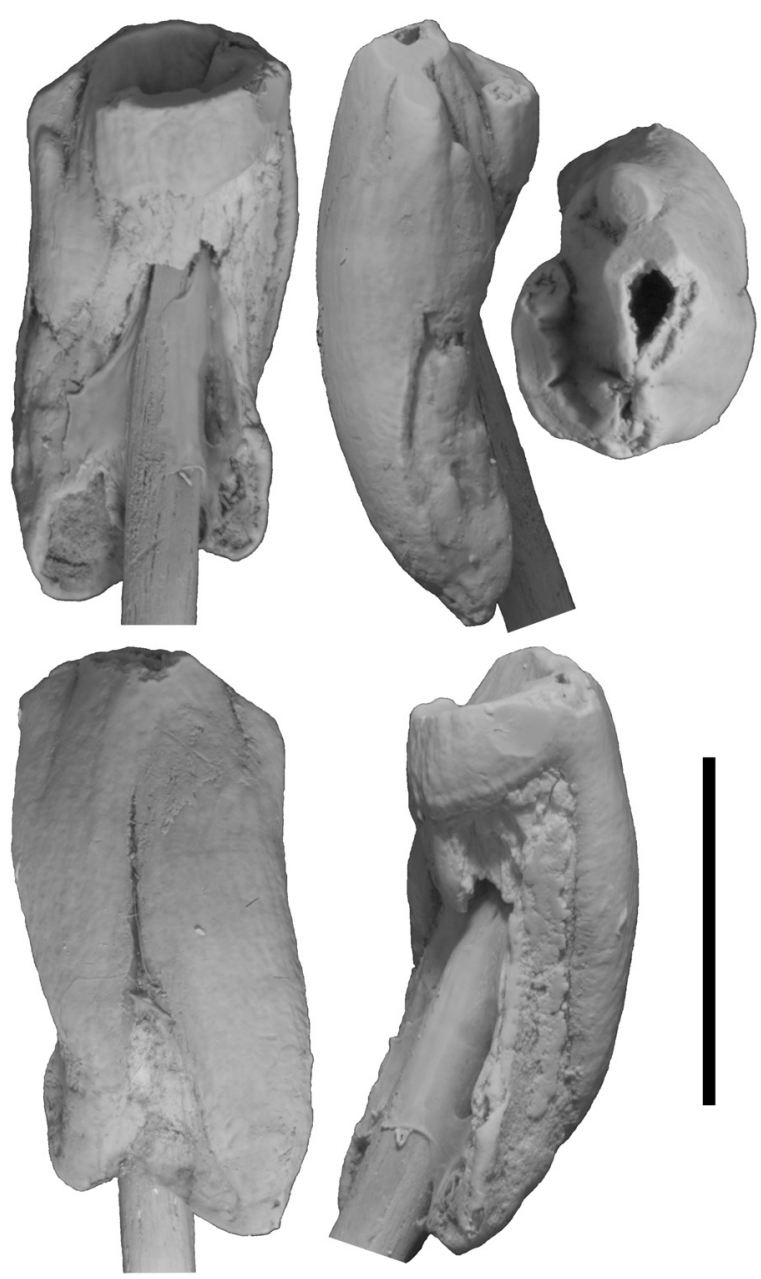

FIGURE 9. QM F23903, left P3 from Camel Sputum Site in lingual, anterior, and occlusal view (top row) and buccal and posterior view (bottom row). Scale bar represents $10 \mathrm{~mm}$.

based on its topographical position) and lingual to the paracone is another cusp, similar in size to the metacone. Anterior and slightly lingual to the paracone is an anterior cusp (similar in size or slightly larger than the metacone and lingual cusp) and lingual to the anterior edge of this is a small parastyle.

The paracone, metacone, and anterior cusp form a slightly curved (concave lingually) anteroposterior crest. The metacone and anterior cusp are separated from the paracone by grooves in this longitudinal crest. The grooves extend a short distance down the occlusal surface either side of the crest. The metacone is located on, or close to, the posterior edge of the occlusal surface. A low crest curves anterolingually from the metacone and forms the lingual edge of the occlusal surface as far as its anterior termination (the lingual cusp).
This posterolingual crest is grooved along its buccal surface. The posterolingual crest and the paracone-metacone crest bound an anteroposteriorly elongate deep and narrow basin. The groove/ notch in the central crest between the paracone and metacone extends lingually into this basin. A groove extends anterolingually from the anterolingual face of the paracone towards the parastyle. Wear has been concentrated across the central crest (particularly at the paracone) and on the posterolingual crest. An inter-tooth facet (for M1) is located at the posterior end of the posterolingual crest, near the posterolingual 'corner' of the tooth.

There are two roots (anterior and posterior). The external surfaces of the roots are continuous with the crown and have a similar curvature. The roots are poorly separated externally, particularly on the buccal side where they appear fused in buccal view. The division between the roots is represented by a groove on the buccal surface. This groove is immediately buccal to the paracone, but does not extend as far occlusally as the apex of this cusp. Enamel height is greatest on the buccal side and extends a significant distance below the occlusal surface onto root surfaces as enamel tracts. Enamel height decreases at the groove between the roots on the buccal surface and the enamel tracts taper in width towards the root apices. Enamel height decreases markedly from the buccal surface on to the anterior and posterior surfaces of the tooth (particularly on the posterior surface) with an approximately vertical EDJ. On the anterior surface, enamel decreases in height below the anterior crest of the paracone, and then decreases again posterior to the parastyle on the lingual surface. On the lingual surface, enamel height remains small (and slightly decreases in height) between the parastyle and the posterior edge of the tooth.

Upper molars. There are three juvenile upper molars attributable to $R$. ngangaba; two M1s (Figure 10.1-2) and one M2/M3 (Figure 10.3). The latter is an enamel cap only. Most of the features are shared with $R$. crowcrofti so only features which either differ from or are not preserved on any $R$. crowcrofti specimen will be described below.

M1. M1 is represented by two specimens, QM F23772 and QM F23765 (Figure 10.1-2). Both specimens are from immature individuals as demonstrated by the incomplete roots and partially mineralised enamel around the base of the crown and roots. In addition, both specimens show little to no wear of the occlusal surface. QM F23765 is the more immature of the two specimens, with no visi- 
1

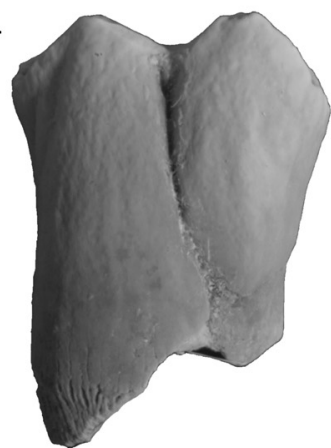

2

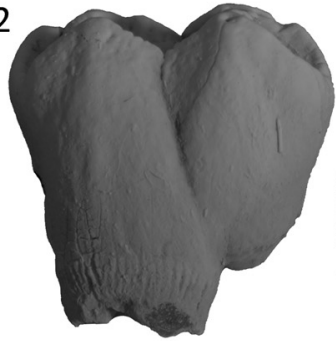

3

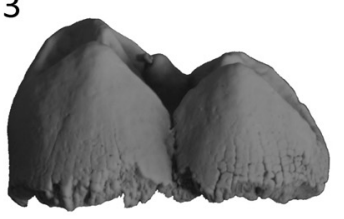

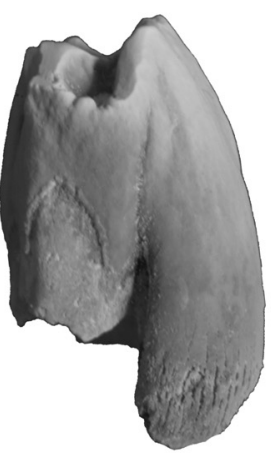
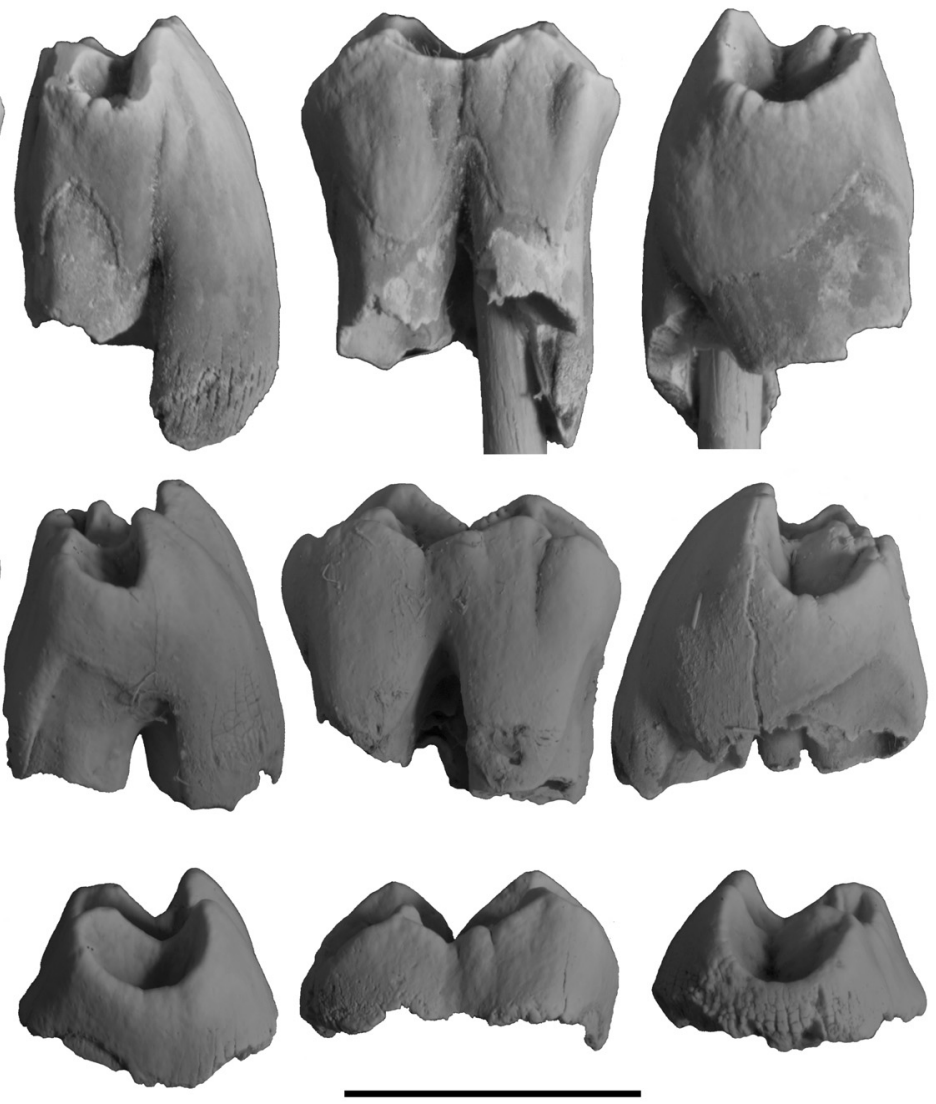
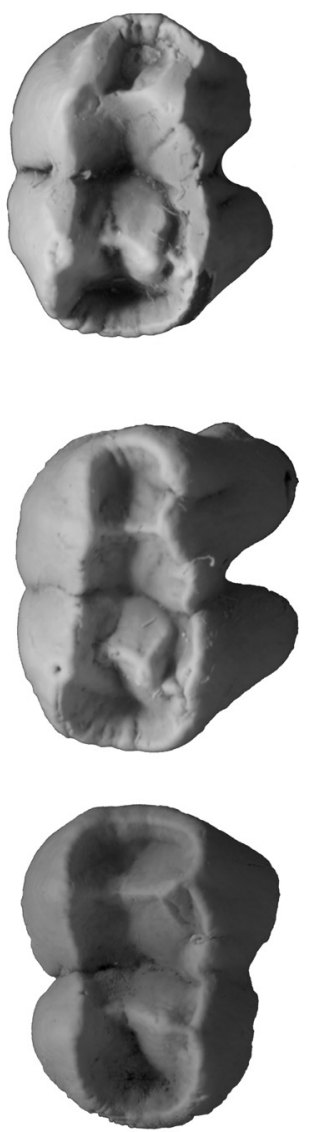

FIGURE 10. Upper molars of Rhizophascolonus ngangaba in lingual, anterior, buccal, posterior and occlusal view (left to right). 1. QM F23772, left M1 from Camel Sputum Site. 2. QM F23765, left M1 from Upper Site. QM F20706, left M (probably M2 or M3) from Camel Sputum Site. Scale bar represents $10 \mathrm{~mm}$.

ble wear of the occlusal surface. The occlusal surface of QM F23772 shows evidence of tooth wear on the buccal and lingual margins. Wear is particularly concentrated between the metaconule and protocone on the lingual margin, and between the metacone and paracone on the buccal margin. Anterior to this, wear is present on the anterolingual 'corner' and around the position of the paracone on the buccal margin.

The occlusal surface is enclosed by a marginal crest. It is narrowest across the protoloph and at the anterior edge of the tooth, and widest at the posterior edge of the tooth. Crown width increases below the occlusal surface to a point just below where the anterobuccal and posterior roots divide. Below this, anterior tooth width continues to increase due to the convex and lingually protruding anterolingual root; however, tooth width decreases below the posterior moiety.

Maximum anteroposterior length is greatest at the level of the marginal crest at the occlusal surface, or immediately below it. Tooth length then decreases below the occlusal surface to a point just below the division between the anterobuccal and posterior roots. Below this, tooth length increases again slightly on the anterior side. Anterobuccal and posterior roots, and anterobuccal and anterolingual roots, are clearly separated below the level of the division between the roots. In contrast, the root canals of the anterolingual and posterior roots are not physically separated on either specimen by the presence of dentine walls. Both specimens are unilaterally hypsodont, being hypsodont on the lingual side, and brachydont on the buccal side.

Anterior and posterior moieties are similar in anteroposterior length at the occlusal surface. The central transverse valley separating anterior and posterior moieties on the occlusal surface, continues on buccal and lingual surfaces as a groove extending below the occlusal surface. This groove also marks the division between anterobuccal and posterior roots on the buccal surface, and between anterolingual and posterior roots on the lingual sur- 
face. It is approximately vertical away from the occlusal surface on the buccal side of the tooth; however, it slopes posteriorly away from the occlusal surface on the lingual side of the tooth, due to increasing length (and width) of the anterolingual root below the occlusal surface. With increasing wear, this would mean that the anteroposterior length of the anterior moiety would increase on this side relative to the posterior moiety and the tooth would look increasingly asymmetric.

Enamel height varies markedly around the tooth in a similar pattern to that seen on $R$. crowcrofti molars. The lack of cementum on these two M1 specimens means that the enamel pattern around the tooth surfaces is easier to trace than on $R$. crowcrofti. In particular, the decrease in enamel height across the lingual surface from the anterolingual root/anterior moiety onto the posterior root/ posterior moiety is notable. The enamel on the crests that form the margins of the occlusal surface is wrinkled. These crenulations occasionally resemble poorly developed, minor cuspules.

The anterior and posterior moieties are subequal in height. The occlusal height of the posterior margin is slightly lower than the anterior margin. The lingual cusps are slightly higher than the buccal cusps, and the paracone and metacone are slightly higher than the buccal margin. The paracone is located on the buccal margin, which is lingually inflected at this point (with occlusal width being particularly narrow across the protoloph). Slight bumps on the buccal margin either side of the paracone may represent StB and StC. Grooves on the buccal and occlusal surfaces appear to demarcate these potential cusps from the paracone. The groove on the buccal surface between the paracone and StB is particularly welldefined on both specimens. On QM F23765, the central transverse valley between the moieties and the groove on the buccal surface between the moieties (marking the division between anterobuccal and posterior roots) is deflected posteriorly slightly, presumably due to the presence of StC.

In contrast to the paracone, the metacone is not located on the buccal margin, but is lingual to it and separated from it by a deep anteroposterior groove. Buccal to the metacone, the buccal margin is broadly convex in buccal profile on QM F23765, with a peak in the buccal profile slightly posterior to the position of the metacone. On QM F23772, the peak is more accentuated, probably a result of wear. This peak is referred to here as 'StD', the uncertainty being due to the fact that it is located quite posteriorly on the buccal margin. On QM
F23772, there appears to be a poorly defined 'cusp' immediately posterior to the buccal constriction. Posterior to 'StD', on the posterobuccal corner of QM F23765, is a well-developed cusp in the StE position. StE forms a peak on the buccal margin in profile and is separated from the buccal margin anterior to it by a groove in the margin and on the buccal surface. StE is not present on QM F23772. There are poorly defined anterior and posterior crests either side of the metacone.

On QM F23772, a short irregular crest extends anterolingually from a point on the buccal margin (or slightly lingual to it) posterior to 'StD', to a point immediately anterobuccal to the metacone. On QM F23765, the crest is more of a bump in the enamel which does not extend as far as the metacone. On both specimens, the area around the 'metaloph' is irregular with a number of small crests and bumps.

The protoloph and 'metaloph' are concave in anterior/posterior profile view, with the low point on these lophs continuous with a groove connecting anterior and posterior occlusal basins. This longitudinal groove is deflected around the 'metaloph' which is irregular and doesn't fully connect lingual and buccal sides of the occlusal surface. The lingual part of the 'metaloph' consists of a short, steep crest, which descends from the metaconule apex posteriorly, terminating in the posterior basin. It does not meet the crest extending anterolingually from the metacone.

The lingual cusps are centrally located (anteroposteriorly) on the lingual margin on each moiety. They form the highest points on the lingual margin, which slopes away from the cusp tips anterior and posterior to both cusps. The lingual surface below the protocone and metaconule is slightly convex, with faint grooves variably developed either side of these cusps extending down the lingual surface and away from the cusp tips. A shallow pocket at the constriction between the moieties on the lingual surface is slightly developed on both specimens (particularly immediately posterior to the constriction on QM F23765). The anterior basin on QM F23772 is located slightly buccally relative to QM F23765.

M2-3. There is a single specimen of a posterior molar (Figure 10.3). QM F20706 is an enamel cap of what was probably an M2 or M3. The anterior moiety is slightly higher than the posterior moiety. In contrast to M1, buccolingual width of the occlusal surface is similar between the anterior and posterior margins of the tooth; however, tooth width does taper slightly posteriorly. The occlusal surface 
appears slightly shallower than that of M1. The anterior basin is wider (buccolingually), and the anterior margin is wider and flatter than M1.

The paracone is located lingual to the buccal margin, forming part of the protoloph. The protoloph is buccolingual in orientation between the paracone and protocone. An anterobuccal crest connects the paracone with the buccal margin, so that the protoloph is deflected at this point. The deflected protoloph meets the buccal margin at a slight peak at the position of StB, although the margin is not cuspate at this point. The peak at StB is slightly lower in height than the paracone. A second crest extends posterobuccally from the paracone but does not meet the buccal margin. A groove separates the termination of this posterobuccal crest and a low cusp located in the StC position on the buccal margin. The central transverse valley between the moieties and the groove demarcating the moieties on the buccal surface are both deflected posteriorly around StC.

The posterior loph is better developed than on M1. The metacone is linked to 'StD' on the buccal margin by a short buccolingual crest. The metacone is slightly higher than 'StD'. There is no obvious StE. There is a slight irregularity immediately anterior to the apex of the metacone and apart from this there are no anterior or posterior crests associated with the metacone. The deep cleft between the metacone and the buccal margin on M1 is much shallower on QM F20706. The lingual crest of the metacone is oriented slightly anteriorly in a similar manner to M1. At the lingual-most extent of this crest is a similar low crest, which connects it to the anterobuccal base of the metaconule. There is only a slight convexity (rather than a steep crest) on the buccal surface of the metaconule, and it is posterobuccal to the posterior loph.

Lower molars. The lower molars are bilobed. The constriction between anterior and posterior moieties forms a deep groove on buccal and lingual surfaces and is connected by a buccolingual transverse valley on the occlusal surface. The occlusal surface is deepest approximately midway across the transverse valley. The occlusal surface is higher at the buccal constriction than at the lingual constriction. There are two roots. The anterior root is located beneath the anterior moiety and the posterior root is located beneath the posterior moiety. The external furcation between the roots is slightly lower (i.e., further away from the occlusal surface) on the buccal side relative to the lingual side. At the furcation, the roots are wider (anteroposteriorly) on the buccal side relative to the lingual side. The root apices are not preserved on any specimen. Enamel is thickest and most extensive on the buccal surface. Enamel extends across the buccal surface and onto the roots. There are four major cusps; the protoconid, metaconid, hypoconid, and entoconid.

$\mathrm{m} 1$. The $\mathrm{m} 1$ is represented by two specimens (QM F57967 and QM F23764; Figure 11). QM F57967 is more complete than QM F23764, but does show some light wear of the occlusal surface, concentrated at the tips of the buccal cusps. QM F23764 appears unworn. Both specimens are from immature specimens, and roots are not complete apically.

The $\mathrm{m} 1$ is long and narrow; nearly twice as long as its maximum width. Anteroposterior length is greatest at the occlusal surface. The anterior moiety is longer (anteroposteriorly) than wide (buccolingually), whereas the posterior moiety is wider than long. The anterior moiety is around $75 \%$ the width of the posterior moiety. There is very little constriction between the moieties. The buccal surface is only mildly convex (particularly on the anterior moiety). The anterior moiety tapers anteriorly.

The protoconid and hypoconid both form part of the buccal margin. In buccal view, the postprotocristid appears longer than the preprotocristid. On the posterior moiety, the prehypocristid is longer than the posthypocristid in buccal view, as the latter curves round the posterior edge of the tooth. Consequently, both the protoconid and hypoconid appear asymmetric in buccal view. The postprotocristid and the prehypocristid meet at the lowest point on the buccal margin sealing off the talonid basin on the buccal side.

The protoconid is located midway between the anterior edge of $\mathrm{m} 1$ and the constriction between the moieties (QM F23764), or just anterior to this point (QM F57967). The short anteroposteriorly-orientated paracristid descends basally away from the protoconid tip as far as a groove in the buccal margin. Anterior to this, a crest curves anterolingually before terminating around the midpoint of the tooth. This anterior crest is comprised of one or two slight swellings, demarcated by grooves; presumably at least one of these represents the paraconid. Lingual to this anterior crest, the occlusal surface drops steeply basally and is unenclosed by a crest on the lingual side.

A short medial crest extends from the protoconid to meet the metaconid which is located immediately posterolingual to the protoconid. The metaconid is located closer to the medial axis of 

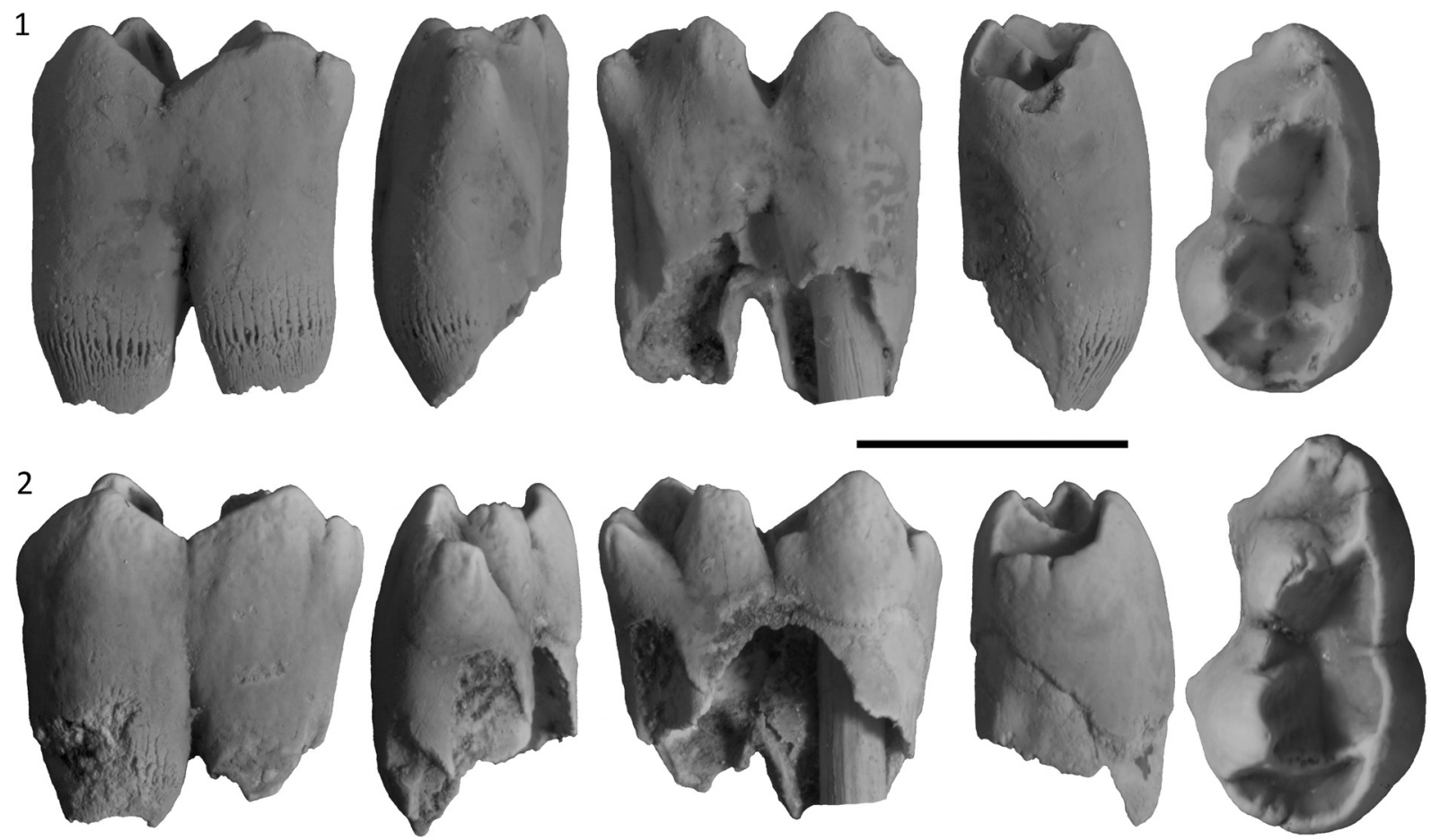

FIGURE 11. $\mathrm{m} 1$ of $R$. ngangaba in buccal, anterior, lingual, posterior and occlusal view (left to right). 1. QM F57967, right $\mathrm{m} 1$ from Camel Sputum Site. 2. QM F23764, right m1 from Upper Site. Scale bar represents $10 \mathrm{~mm}$.

the tooth than the entoconid. This combined with the unenclosed anterolingual margin, means that the tooth appears triangular in shape and tapers towards the anterior apex/anterobuccal corner. The premetacristid is short or absent, and the anterior surface of the metaconid drops steeply basally away from the cusp tip. The postmetacristid extends posterolingually from the metaconid for a short distance before curving buccally. The posterior end of the crest drops steeply basally at the constriction between the moieties and does not meet the pre-entocristid, which likewise curves buccally at the constriction. A cusp is present at the base of the pre-entocristid within the lingual constriction on QM F23764, but not QM F57967.

The entoconid is approximately level (anteroposteriorly) with the hypoconid and is similar to it in height. It forms a relatively tall blunt cusp in lingual view. The postentocristid drops steeply basally and posterolingually to meet the low crest forming the posterior margin of the tooth. A medial crest extends posterobuccally from the entoconid tip (QM F57967) or just posterior to it (QM F23764). This medial crest curves anterobuccally to meet the medial crest from the hypoconid to form a posteriorly convex posterior lophid. A short anteroposterior crest extends from the medial entoconid crest midway along its length on QM F57967. A second, fainter, medial crest extends anterobuccally from the tip of the entoconid for a short distance. The pre-entocristid curves initially lingually and then buccally away from the entoconid cusp tip and terminates posterior and buccal to the posterior end of the postmetacristid.

The medial crest of the hypoconid extends lingually (QM F57967) or posterolingually (QM F23764) away from the tip of the hypoconid on the buccal margin to meet the medial crest of the entoconid. A second short and faint crest extends anterolingually from the cusp tip. The posthypocristid curves posteriorly and lingually to form the posterior margin of the tooth and encloses a posterior basin. The basin is enclosed anteriorly by the posterior lophid. Grooving of the posterior margin of $\mathrm{m} 1$ at its midpoint and lingual to this, in combination with a slight swelling of the margin, may indicate a poorly developed hypoconulid. A groove in the posterior margin demarcates the boundary between the posterior margin/hypoconulid and the postentocristid at the posterolingual 'corner' of the tooth.

The centre of the occlusal surface is formed by a large central basin, which is open through a narrow gap at the lingual constriction. The basin is 

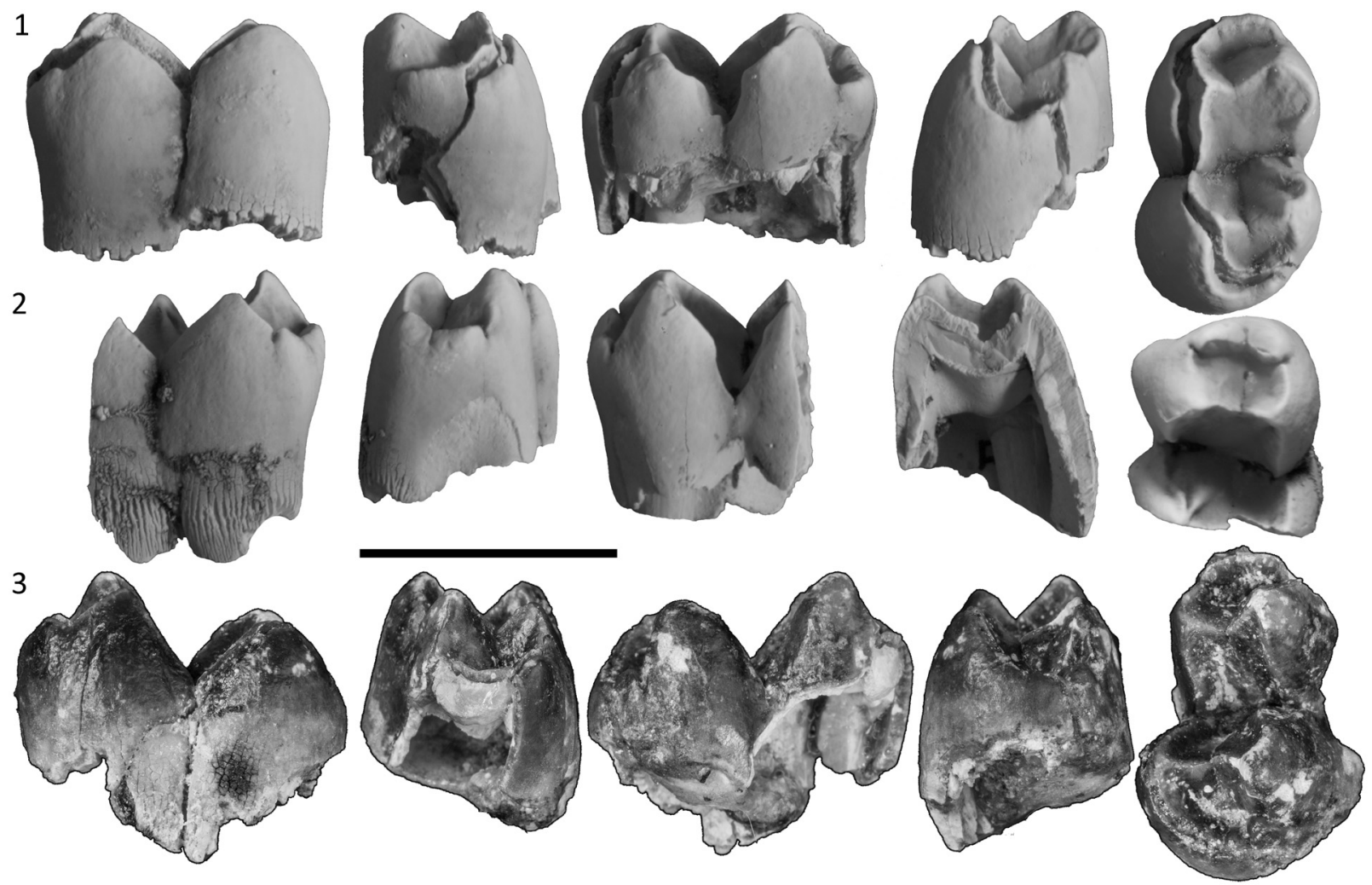

FIGURE 12. Lower molars of R. ngangaba in buccal, anterior, lingual, posterior, and occlusal view (left to right). 1. QM F23768, left $\mathrm{m}$ (probably $\mathrm{m} 2$ or $\mathrm{m} 3$ ) from Upper Site. 2. QM F23769, anterior fragment of right $\mathrm{m}$ (probably $\mathrm{m} 2$ or $\mathrm{m} 3$ ) from Camel Sputum Site. 3. QM F57968, left m2 from Gen's Grand Slam Site. Scale bar represents $10 \mathrm{~mm}$.

interrupted slightly by the pre-entocristid extending for a short distance into the basin. A groove extends from the centre of the basin to just below the tip of the protoconid.

Enamel completely covers the buccal surface of the crown, extending below the division between the roots. The buccal enamel also extends a short distance onto anterior and posterior tooth surfaces before decreasing in height (the EDJ is almost vertical at these points). As a consequence, steep sided dentine tracts are present immediately lingual to the enamel cover on both surfaces. On the lingual surface, enamel height is smallest at the constriction between the moieties and greatest at the anterolingual edge of the tooth, where it forms a sharp enamel spike extending a short distance onto the anterior root. Posterior to this, there is only a small increase in enamel height midway across the posterior moiety. Enamel is thickest on the buccal surface; however, there is not a good crosssection available to measure enamel thickness. Crown height appears greater on the buccal surface of the tooth due to the extensive enamel cover, which extends onto the roots on this surface and the close association of the roots immediately below the point where they divide.

$\mathbf{m} 2-3$. Three specimens are interpreted here to be m2-3s (Figure 12) due to the similarity in width between anterior and posterior moieties (QM F23768), or with the anterior moiety being slightly narrower than the posterior moiety (QM F23769 and QM F57968). All three specimens are from juveniles, and the occlusal surfaces are unworn. Roots are incomplete on all specimens. QM F23769 is missing most of its posterior moiety and QM F57968 is broken along its anterior margin. Features which differ from $\mathrm{m} 1$ are described below.

The m2-3 is slightly longer than $\mathrm{m} 1$, with a wider anterior moiety and a slightly wider posterior moiety. However, this is based on only a handful of incomplete specimens. The anterior lophid (protolophid) is better developed than on $\mathrm{m} 1$. Medial crests extending from lingual cusps (metaconid and entoconid) are slightly longer than those extending from the buccal cusps (protoconid and entoconid). The lingual cusps are also slightly higher than the buccal cusps. The net result is that 
the protolophid and posterior lophid are slightly asymmetric in anterior or posterior view.

The anterior edge of m2-3 is formed by a complete, and relatively high, anterior margin, which encloses an anterior basin. Grooves at the anterobuccal and anterolingual corners of the tooth separate the anterior margin from the preprotocristid and premetacristid, respectively. One or more swellings on the anterior margin (particularly towards the anterolingual corner) may represent a poorly developed cusp(s). One or more grooves also mark this anterior margin so that the enamel looks slightly wrinkled (e.g., QM F23768). A groove in the anterior basin extends to the low point on the protolophid.

The posterior lophid is not convex posteriorly as seen in QM F23764, but varies (e.g., it is anteriorly convex on QM F57968). The posterior lophid is located more centrally between the transverse valley between the moieties and the posterior margin of the tooth on $\mathrm{m} 2-3$, relative to $\mathrm{m} 1$. The central area of the occlusal surface also forms more of a steep-sided transverse valley on $\mathrm{m} 2-3$ as opposed to the wide, shallow basin seen on $\mathrm{m} 1$ specimens. This is partly due to the high, steep-sided anterior and posterior lophids, but also due to the fact that the anterior moiety is higher than the posterior moiety on QM F23769 and QM F57968. It is not clear whether this is the case on QM F23768 due to a break on this specimen.

The anterior moiety is more lingually located relative to the posterior moiety on QM F23769. This may also be the case on QM F23768 and QM F57968, although it is not clear. In addition, the apex of the metaconid is located slightly anterior to the apex of the protoconid. These have resulted in the anterior lophid and the central transverse valley being orientated anterolingual/posterobuccal. The postprotocristid is slightly medial (lingual) to the prehypocristid, which it does not meet.

There is a slight swelling in the talonid notch, immediately anterior to the base of the pre-entocristid on QM F23768, similar to that seen on QM F23764. This is not seen on QM F23769 or QM F57968. QM F23768 and QM F57968 have a poorly developed hypoconulid on the posterior tooth margin, immediately posterior to the entoconid.

The overall tooth shape is slightly more constricted between the moieties, and the buccal surface is slightly more curved relative to $\mathrm{m} 1$. Enamel height and relative thickness appear similar to $\mathrm{m} 1$. The EDJ on anterior and posterior surfaces is slightly inclined, compared to the almost vertical edge on $\mathrm{m} 1$. In addition, there is no sharp enamel spike on the anterolingual corner of the tooth. Instead, there is a slight increase in enamel height midway across the anterior moiety on the buccal surface, in a similar manner to the posterior moiety. Enamel is thickest on the buccal side (up to 1.2 mm on QM F23768).

\section{Remarks}

As discussed in the materials and methods section, it is perhaps unwise to compare the premolar of $R$. ngangaba with that of hypselodont wombats due to the issue of whether P3 in these latter taxa are retained deciduous teeth or not. Regardless, the P3 cusp morphology for $R$. ngang$a b a$ and $V$. ursinus and $L$. latifrons show many differences (Figure 13), and identifying homologous cusps between these taxa and other Vombatiformes is challenging. P3 of $R$. ngangaba is most similar to that of $N$. boodjamullensis (Brewer et al., 2015). Interestingly, the pattern of enamel around the perimeter of the adult teeth of $R$. ngangaba, $N$. boodjamullensis, and species of Warendja is similar and contrasts to that of $V$. ursinus, $L$. latifrons, $P$. gigas, $S$. medius, and $R$. magna, where it is most extensive on the lingual surface, not the buccal. The relative length of QM F23903 compared to the two M1s of $R$. ngangaba is around $70 \%$. This is similar to N. boodjamullensis.

All three molar specimens described here are slightly smaller than $R$. crowcrofti specimens for similar tooth positions; however, most specimens of $R$. crowcrofti are worn. As molars of $R$. crowcrofti wear, length and width can increase (because width increases below the occlusal surface due to the curved lingual surface, and because wear is slightly oblique). This means that the measurements may not be directly comparable. In addition, most $R$. crowcrofti specimens show varying thicknesses of cementum surrounding the teeth, which are absent in these juvenile specimens. However, in imagining slightly oblique wear of the M1s of $R$. ngangaba, it is hard to see how it would be possible to completely wear away the enamel at the lowest points on the occlusal surface while maintaining a pattern of enamel height around the surface of the tooth similar to that seen in $R$. crowcrofti M1s, and not reach the base of the crown where the roots centrally divide (the interradicular furcation). This suggests that overall crown height is greater in $R$. crowcrofti M1s.

Rhizophascolonus sp. indet.

Figure 14 

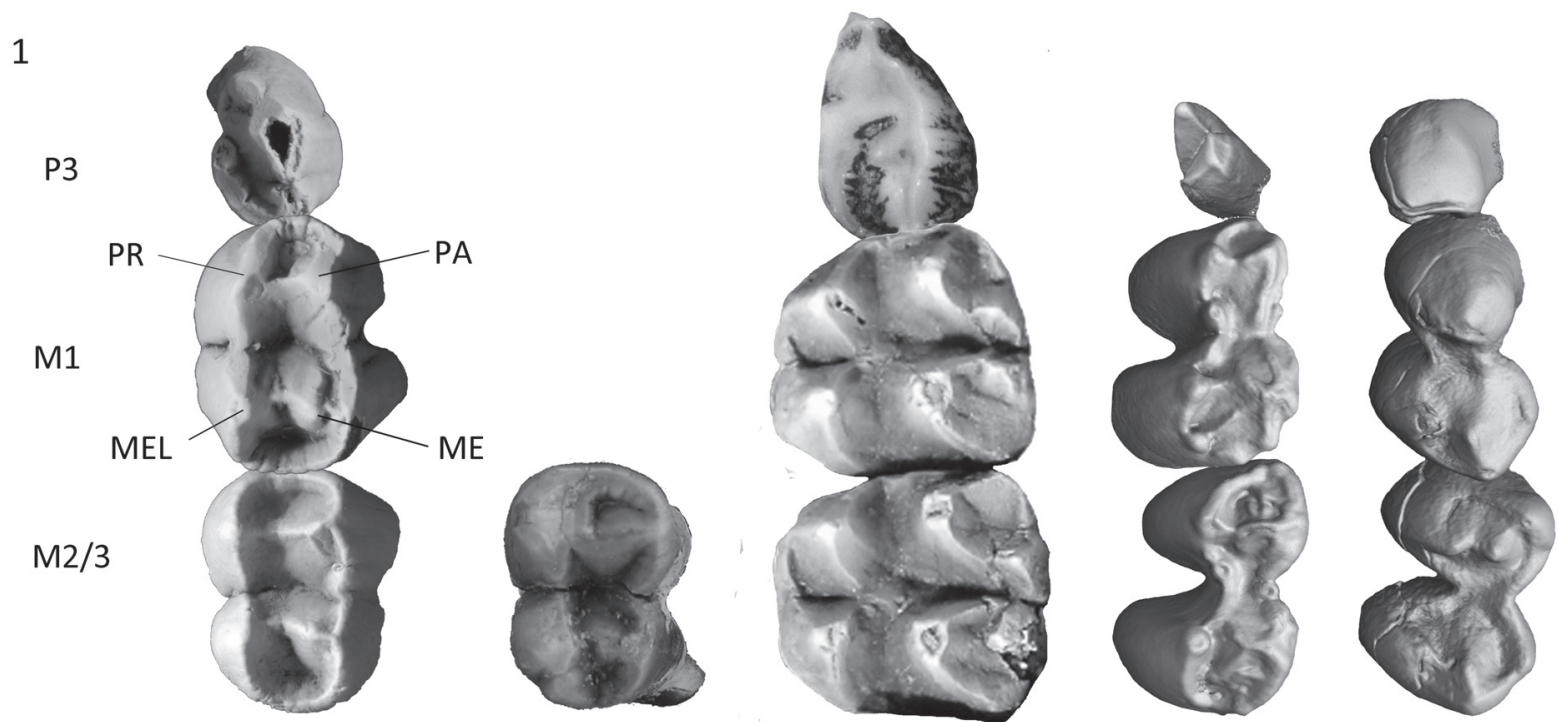

2

Anterior
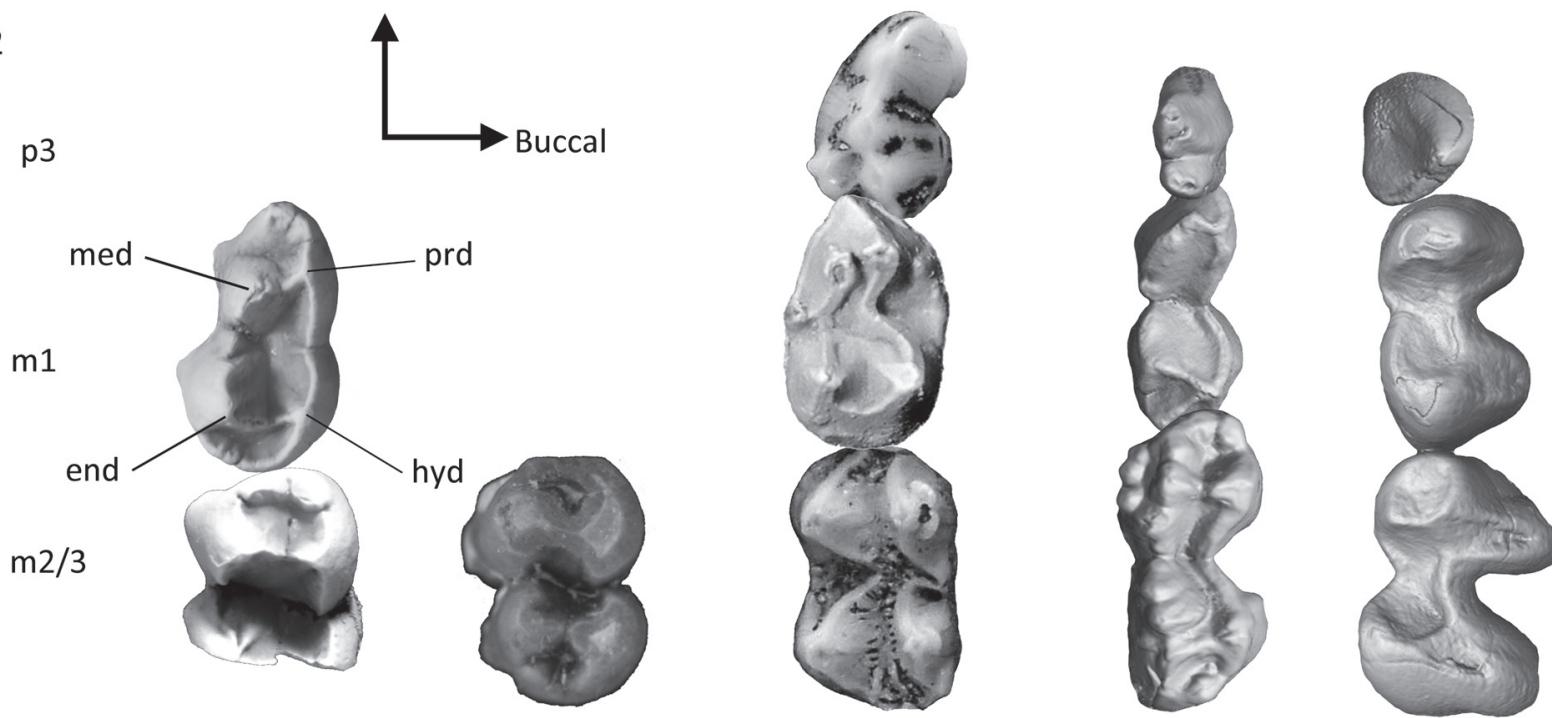

FIGURE 13. Comparison of cusp morphology of teeth of (left to right) $R$. ngangaba, $R$. crowcrofti, Phascolarctidae, Vombatus ursinus and Lasiorhinus latifrons. 1. Left P3 and M1-2. 2. Right $\mathrm{p} 3$ and $\mathrm{m} 1-2$. Phascolarctidae is represented by Priscakoala lucyturnbullae (images from Black et al., 2012) for M1-2 and m1, other tooth positions represented by $P$. cinereus. PR, protocone; PA, paracone; ME, metacone; MEL, metaconule; prd, protoconid; med, metaconid; hyd, hypoconid; end, entoconid. Images are not to scale and are comprised of multiple individuals in order to show the unworn dentition.

Referred specimen. QM F57966, a left ?dp3 or p3 from Cleft of Ages Site.

Occurrence and stratigraphy. Cleft of Ages Site is interpreted to be a fissure fill (Archer et al., 1997; Creaser 1997) or cave deposit (Arena et al., 2014), part of FZ C (Travouillon et al., 2006, 2011; Arena et al., 2016). It is estimated to be between 16 and $13 \mathrm{Ma}$ based on radiometric dates of other FZ C sites and faunal comparisons (using Woodhead et al., 2014 and Arena et al., 2016), i.e., middle Miocene.

\section{Description}

QM F57966 is longer than wide $(5.8 \mathrm{~mm}$ and $4.2 \mathrm{~mm}$, respectively). It has two moieties demarcated by a groove in the enamel and dentine on buccal and lingual surfaces. The anterior moiety is longer than the posterior one, and the posterior moiety is wider than the anterior one. The anterior 


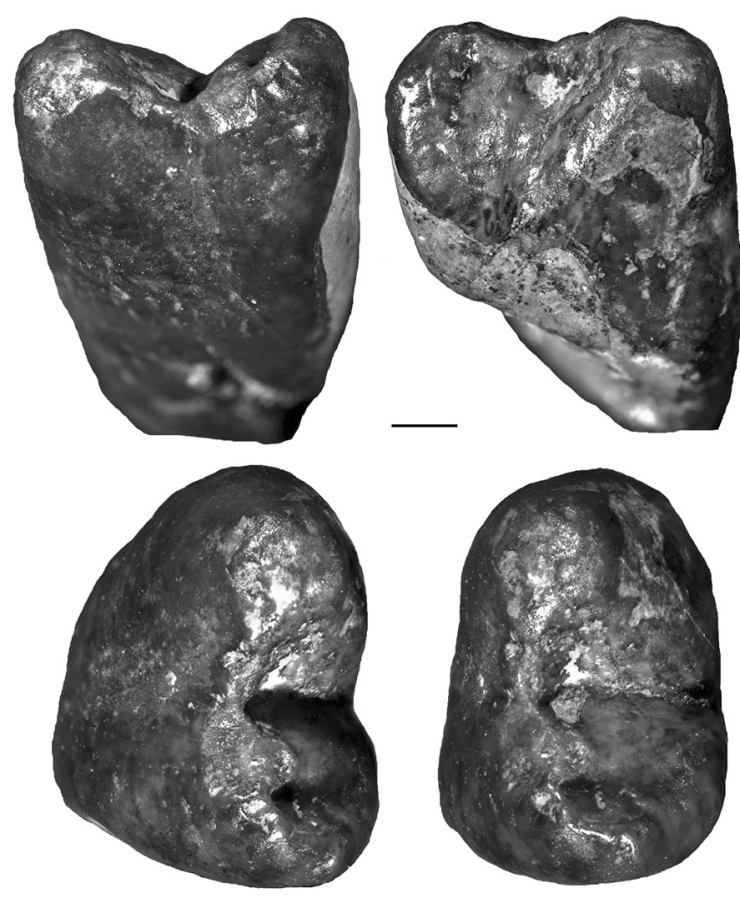

FIGURE 14. QM F57966, left p3 or dp3 from Cleft of Ages Site in occlusal view from buccal (left side, upper and lower rows) and lingual aspects (right side, upper and lower rows). Scale bar represents $1 \mathrm{~mm}$.

moiety is dominated by a central cusp whose tip is worn. Posterior to this anterior cusp, a crest extends posteriorly to the posterior edge of the tooth, before curving lingually and descending away from the occlusal surface as far as the EDJ at the division between the moieties. Halfway between the division between the moieties and the posterior surface, a lingual crest descends from the central anteroposterior crest, meeting the curved posterolingual crest just anterior to its termination. There is a deep valley between this crest and the posterior crest. The central cusp on the anterior moiety has a slight protuberance, possibly a poorly defined crest, which descends posterolingually as far as the lingual constriction between the moieties, terminating just anterior to the posterolingual crest.

Enamel is extensive on the anterior and buccal surfaces of the tooth extending a significant distance down these surfaces. A vertical EDJ is present halfway across the posterior moiety on the lingual surface and at the posterobuccal 'corner' of the tooth. In between these two points, enamel height is small across the lingual surface.

\section{Remarks}

QM F57966 is around $50 \%$ of the length of $\mathrm{m} 1$ of $R$. ngangaba (there is no known $\mathrm{m} 1$ of $R$. crowcrofti). In adult specimens of $V$. ursinus and $L$. latifrons p3 is similar to or slightly smaller than $\mathrm{m} 1$ in anteroposterior length. This could indicate that QM F57966 is a dp3. However, in early ontogeny, the cap size of $p 3$ in $V$. ursinus is very small relative to that of $\mathrm{m} 1$ (Appendix 1; Figure 13; Triggs, 2009), but the relative size of these teeth changes in later development due to the continued presence of an active stem cell niche at the base of the tooth. In addition, the anteroposterior length of $\mathrm{p} 3$ in species of Warendja is about $60-75 \%$ that of $\mathrm{m} 1$, suggesting that there has been an overall increase in relative size of p3 through time. If QM F57966 is a p3 rather than a dp3, this indicates that the width of the lower cheek teeth reduces markedly towards the anterior end of this tooth row in species of Rhizophascolonus.

\section{Rhizophascolonus sp. indet.} Figure 15

Referred specimen. QM F23763 (left juvenile mandibular fragment) from Upper Site.

Occurrence and stratigraphy. Upper Site is located on Godthelp's Hill on the central part of DSite Plateau, within the Riversleigh WHA in northwestern Queensland (Creaser, 1997). It was interpreted to represent a lacustrine carbonate deposit by Archer et al. (1989) and a cave deposit by Arena (2004), part of FZ B (Archer et al., 1989; Black, 1997; Creaser, 1997; Travouillon et al., 2006, 2011) and IZ B3 by Arena et al. (2016). It is estimated to be middle Miocene (c. $18 \mathrm{Ma}$ ) based on faunal correlations with radiometrically dated sites (Myers et al., 2017).

\section{Description}

A partial lower jaw of a juvenile is preserved from a point just anterior to $\mathrm{m} 2$ or $\mathrm{m} 3$ to $1.2 \mathrm{~mm}$ posterior to the masseteric foramen (Figure 15). Anteroposterior length of the fragment is $51.5 \mathrm{~mm}$. Two partial teeth are preserved within their alveoli, and probably represent either $\mathrm{m} 2$ and $\mathrm{m} 3$, or $\mathrm{m} 3$ and $\mathrm{m} 4$. There is a break just below the occlusal surface on the posterior molar that has been repaired and it is likely that the relative position of the two molars has changed slightly. The molar roots on both teeth are incomplete. Both roots narrow towards the lingual side. The occlusal surface of the anterior tooth is not preserved. Enamel thickness is $0.8 \mathrm{~mm}$ on the buccal side of the anterior 


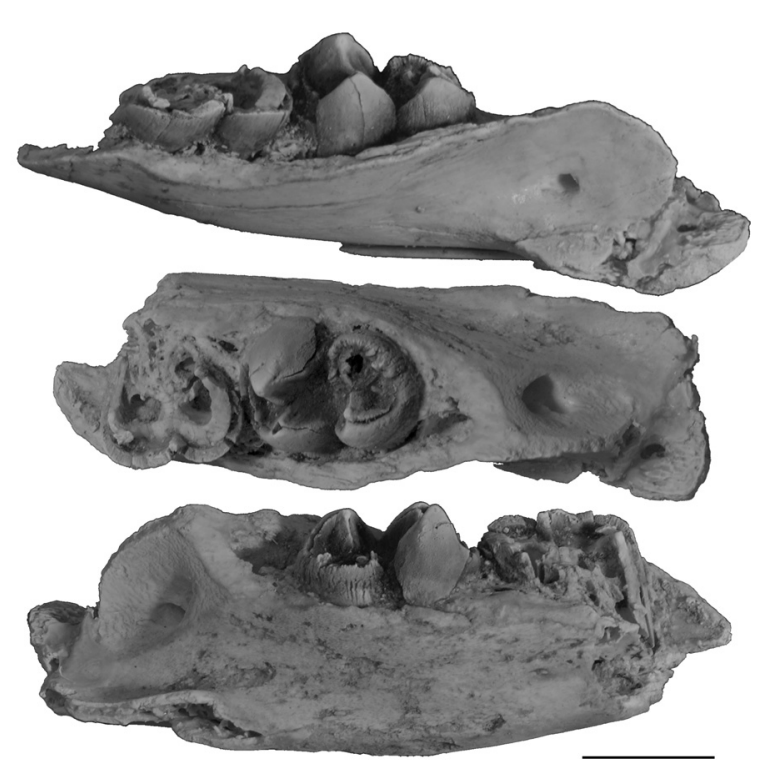

FIGURE 15. QM F23763, fragment of juvenile left mandible with ?m3-m4 in buccal, occlusal and lingual view (top to bottom). Scale bar represents $10 \mathrm{~mm}$.

molar. The occlusal surface of the posterior tooth is largely intact.

\section{Remarks}

Other than QM F23763, all other vombatid specimens identified from Upper Site have been included in $R$. ngangaba. However, molar widths and lengths for the posterior molar of QM F23763 (m3 or $\mathrm{m} 4$ ) fall in between those of $R$. ngangaba and $R$. crowcrofti. If QM F23763 is included in $R$. ngangaba, the CV (calculated for anteroposterior lengths of all molars; Table 1) increases from 6.2 to 7. This number is still reasonable to consider this specimen part of this taxon. However, including QM F23763 with $R$. crowcrofti does not inflate the $C V$ of the latter taxon at all. In addition, the position of QM F23763 on Figure 7 is where the $\mathrm{m} 4$ of $R$. crowcrofti would be expected to fall based on comparisons with other taxa. This raises the possibility that we have two species of Rhizophascolonus present at Upper Site ( $R$. ngangaba and $R$. crowcrofti), and possibly at other sites as well.

\section{Rhizophascolonus sp. indet.} Figure 16

Referred specimens. QM F57964 (right maxillary fragment with M2-3 and a possible associated M1 fragment) and QM F57965 (left maxillary fragment with M2-4) from Baker's Delight Site.

Occurrence and stratigraphy. Baker's Delight Site is an isolated site on the Gag Plateau. The only identifiable specimens recovered from this site are those described here. The sediments visually resemble those of other fissure fills or cave deposits at Riversleigh such as Cleft of Ages Site (pers. obs.). Age is unknown, but probably FZ C based on the age of other mammal-rich deposits on the Gag Plateau (Archer et al., 1989, 1997).

\section{Description}

Maxilla. Represented by two fragments, QM F57964 and QM F57965 (Figure 16). These fragments were closely associated in situ and are of similar size. Both specimens are fragmentary and badly degraded. QM F57964 is the better preserved with a largely complete M2, a partial M3, and the posterobuccal edge of the M1 alveolus. A molar fragment may be part of the lingual enamel of M1. QM F57965 preserves fragments (mainly the lingual enamel) of M2-4. The anterior origin of the zygomatic arch (masseteric process) is located dorsal to M2 and the anterior moiety of M3. The ventral extent of the masseteric process is c. 3.5 $\mathrm{mm}$ dorsal to the alveolar process on QM F57964.

\section{Remarks}

Anteroposterior lengths of M2-3 on QM F57964 and QM F57965 are within the size range of $R$. ngangaba (within 1 standard deviation) and adding them in does not greatly affect $C V$ values of $R$. ngangaba (from 6.2 to 6.8 for all tooth positions; Table 1). In contrast, identifying the Baker's Delight Site specimens as $R$. crowcrofti does inflate the $\mathrm{CVs}$ for anteroposterior length of all tooth positions for this latter taxon (from 7.4 to 10.2; Table 1). However, the Baker's Delight Site specimens are wider than the single upper M2-3 of $R$. ngangaba (Appendix 3). This may be related to wear, and the curved lingual surface of the upper molars; however, with so few specimens available we choose to be cautious here. If QM F57964-5 are referable to $R$. ngangaba, it means that the latter taxon has a much smaller M4, with a small posterior width, relative to M2-3. This would clearly distinguish this taxon from $R$. crowcrofti.

\section{Rhizophascolonus sp. indet. Figure 17}

Referred specimen. QM F20613 (fragment of left mandible with m2-4 fragments) from Bone Reef Site.

Occurrence and stratigraphy. Bone Reef site is located on the south side of D-Site Plateau within the Riversleigh WHA (Creaser, 1997). It was interpreted to be formed by tufagenic processes in a large lake (Archer et al., 1989) or fluvial barrage 


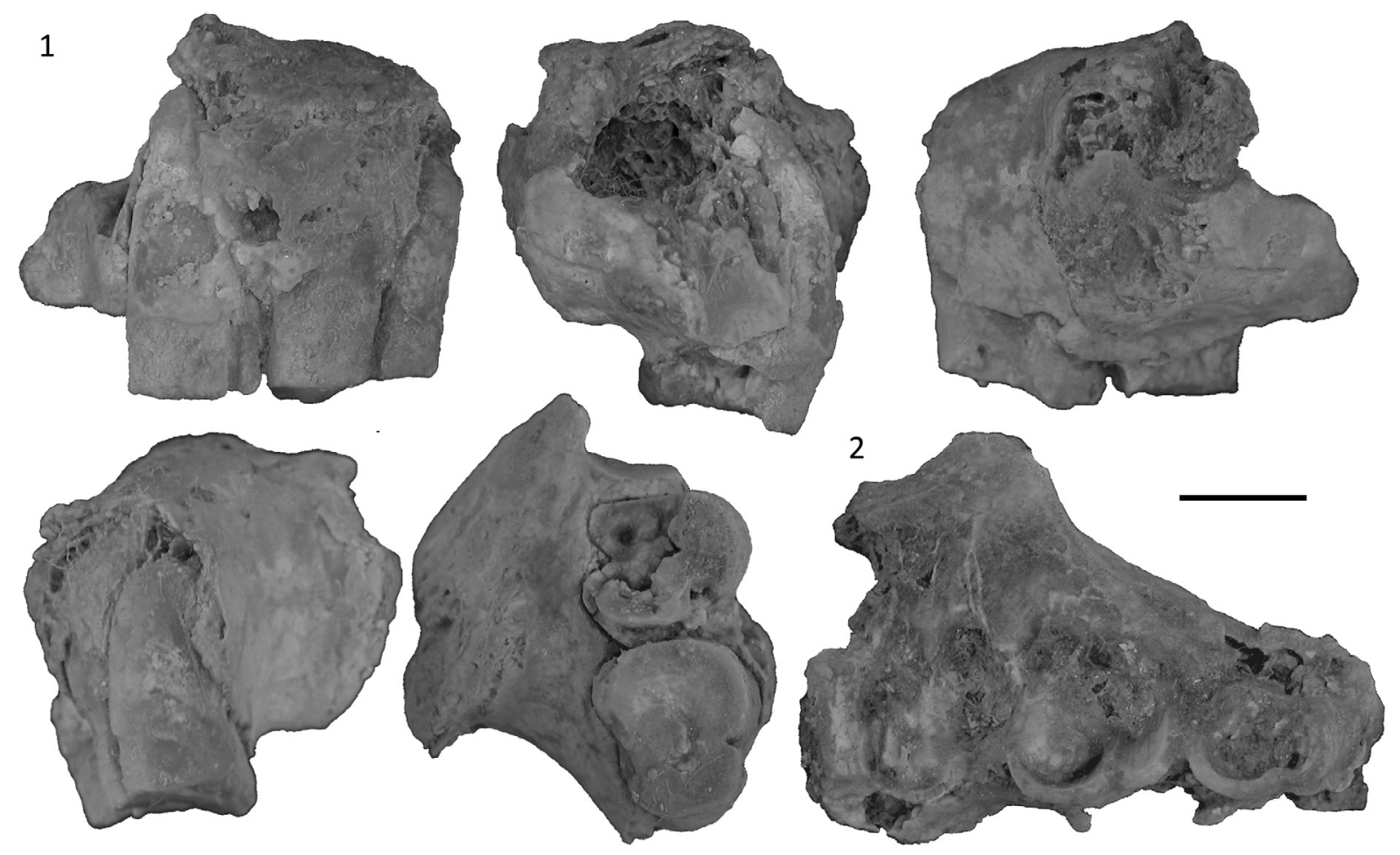

FIGURE 16. Maxillary fragments of Rhizophascolonus sp. from Baker's Delight Site. 1. QM F57964, right maxillary fragment with M2-3 in lingual, anterior and buccal view (top row) and posterior and occlusal view (bottom row). 2. QM F57965, left maxillary fragment with M2-4 in occlusal view. Scale bar represents $10 \mathrm{~mm}$.

system (Arena, 2004), part of FZ A (Archer et al., 1989, 1997; Black 1997) or FZ B, interval B1-B2 (Arena et al., 2016). Based on comparisons between Woodhead et al. (2014) and Arena et al. (2016), this suggests an age between 25 and 18.5 $\mathrm{Ma}$, i.e., late Oligocene to early Miocene.

\section{Description}

Mandible. The mandibular fragment consists of a lateral (buccal) section of the mandibular body preserved posterior to $\mathrm{m} 1$ (Figure 17). Most of the anterior border of the ascending ramus (minus the coronoid process), most of the masseteric fossa as well as some of the medial surface of the ramus are also preserved. The buccal halves of $\mathrm{m} 2$ and $\mathrm{m} 3$ are preserved within their alveoli, and there is an associated $\mathrm{m} 4$ fragment. The medial (lingual) surface of the body of the jaw is not preserved, and an anteroposterior section through the molars exposes the internal structure in lingual view.

The anterior origin of the ascending ramus (the coronoid crest) is located lateral to the anterior moiety of $\mathrm{m} 4$. The anterior border of the ascending ramus is steeply inclined. The angle between the ascending ramus and the masseteric eminence is c. $65^{\circ}$. The masseteric fossa is shallow. Very little of the ventromedial surface of the ramus is preserved, but it looks like the pterygoid fossa was relatively shallow as well. The anterior origin of the masseteric crest and fossa is located just posterior (and ventral) to the posterior edge of $\mathrm{m} 4$. The ventral border of the ramus is broken posterior to this point; however, it seems to flare laterally slightly and was probably similar in overall shape to the type specimen of $W$. wakefieldi (NMV P48980).

The mandibular and masseteric foramina are located close to the ventral border of the mandible and are relatively distant to the tooth row. The mandibular foramen is $31.5 \mathrm{~mm}$ posterior to $\mathrm{m} 4$. The mandibular foramen is oval $(5 \mathrm{~mm}$ in height and $2.5 \mathrm{~mm}$ in maximum width) and tapers slightly in width ventrally. The mandibular canal is preserved for about $15-20 \mathrm{~mm}$ anterior to the mandibular foramen and widens anteriorly to about $5 \mathrm{~mm}$. The canal slopes anteroventrally at a very shallow angle. The masseteric foramen punctuates the ramus immediately posterior to the mandibular foramen. The masseteric foramen is located $\mathrm{c}$. $28.4 \mathrm{~mm}$ posterior to the anterior border of the masseteric fossa. 


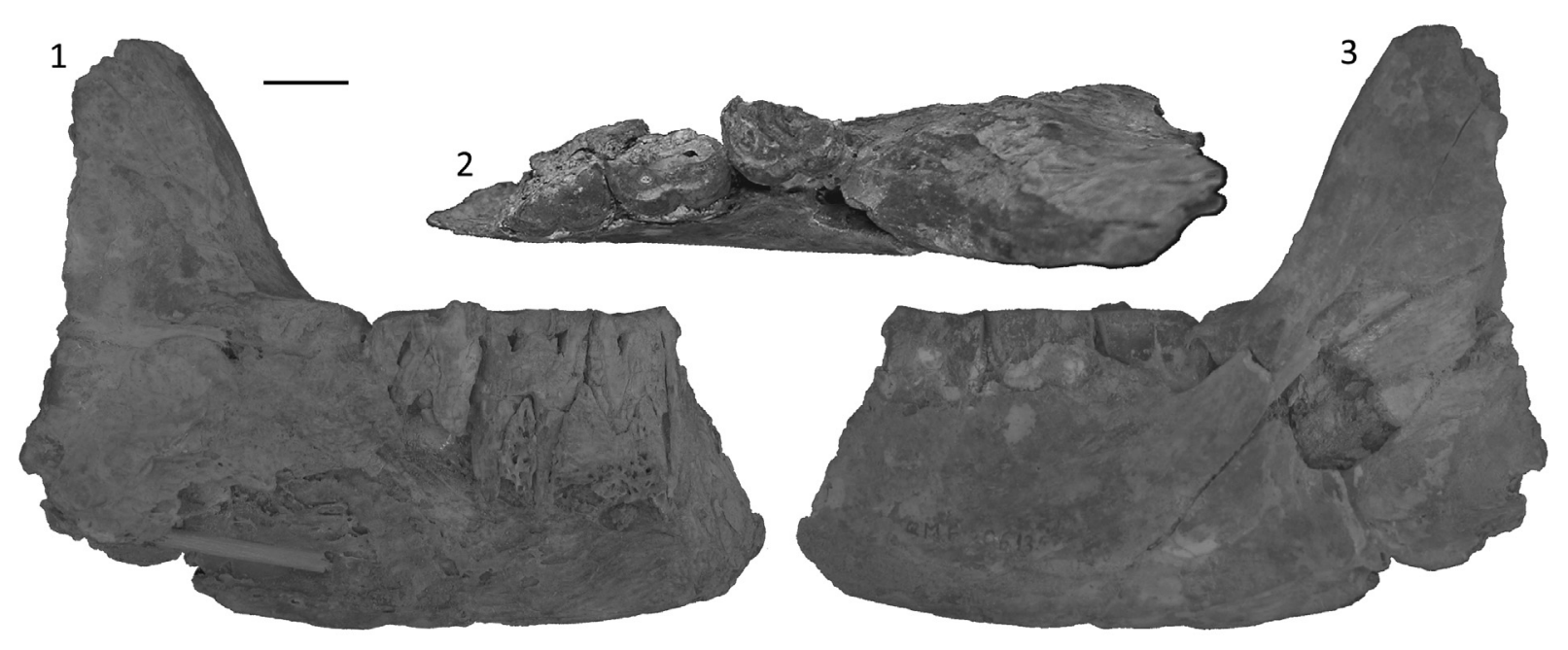

FIGURE 17. QM F20613, left mandibular fragment with m2-4 of Rhizophascolonus sp. from Bone Reef Site. 1. Buccal (medial) view. 2. Occlusal view. 3. Lingual (lateral) view. Scale bar represents $10 \mathrm{~mm}$.

Lower molars. The $\mathrm{m} 4$ preserves traces of the original occlusal morphology in the form of islands of enamel on the occlusal surface. There is also staining of the central dentine on the occlusal surface of $\mathrm{m} 3$ which matches the pattern of enamel remnants seen on $\mathrm{m} 4$. They are broadly similar to molars of species of Rhizophascolonus.

The $\mathrm{m} 4$ is similar in anteroposterior length to $\mathrm{m} 3$. The anterior moiety is very slightly longer than that of the posterior moiety. The enamel perimeter also seems slightly thicker on $\mathrm{m} 4$, but this may be due to wear (the occlusal enamel has not completely worn away on $\mathrm{m} 4$ ) and the angle between the buccal and occlusal surfaces. The occlusobasal height of $\mathrm{m} 4$ is much shorter than that of $\mathrm{m} 2-$ 3. In particular, the roots on $\mathrm{m} 4$ are greatly reduced in length.

Enamel height is greatest on the buccal surface midway across anterior and posterior moieties and is smallest at the constriction and on anterobuccal and posterobuccal 'corners'. Enamel does not extend onto the roots. Enamel height decreases from $7.6 \mathrm{~mm}$ on the buccal surface to $\mathrm{c}$. $6 \mathrm{~mm}$ at the midpoint on the posterior surface (the lingual half of which is missing). The EDJ is steeper at the anterobuccal 'corner' of the tooth relative to the posterobuccal 'corner', and there is a decrease in enamel height from $7.8 \mathrm{~mm}$ to $3.4 \mathrm{~mm}$ at the former. The EDJ is shallowly sloping (c. $10^{\circ}$ relative to the occlusal plane) across the anterior surface. The anterolingual 'corner' is not well preserved but it looks like there is a slight increase in enamel height at this position. Cementum is up to $1.3 \mathrm{~mm}$ thick.

Enamel is present on the occlusal surface along a sinuous transverse valley midway between anterior and posterior surfaces. The valley is widest midway between buccal and lingual edges at the intersection with the transverse valley between the moieties. The buccal half of the transverse valley is oriented anterolingual/posterobuccal and extends to a point slightly posterior to the buccal constriction. A groove in the enamel extends posterolingually from this point. The lingual half of the transverse valley is oriented anterobuccal-posterolingual. The lingual edge is not preserved. The enamel floor in anterior and posterior basins is preserved on the lingual side of the occlusal surface. The base of the metaconid is preserved. On the anterior edge of the tooth there is a dish-shaped concavity in the enamel. It is unclear whether this represents an inter-tooth facet or a cingulid.

\section{Remarks}

QM F20613 differs from $R$. crowcrofti in overall size, particularly in the occlusobasal height of the molars. Adding anteroposterior lengths of $\mathrm{m} 3$ and m4 for QM F20613 to those of all molars belonging to both $R$. crowcrofti and $R$. ngangaba does not increase CVs by very much (Table 1). Based on this, this specimen could be allocated to either Rhizophascolonus species, or an entirely new one. More specimens and a better understanding of size and shape variation for species of Rhizophascolonus are needed. 


\section{RESULTS}

\section{Phylogenetic Analysis}

Nine minimally parsimonious trees were generated when all taxa were included in the analysis. The strict consensus tree is shown in Figure 18.1. All trees had 130 steps, a Consistency Index $(\mathrm{Cl})$ of 0.6535 (excluding uninformative characters), a Retention Index (RI) of 0.6716 , and a Rescaled Consistency Index $(\mathrm{RCl})$ of 0.4443 . Most of these trees were generated due to the shifting position of $R$. magna. As a result, in order to analyse the character changes in more detail, this taxon was subsequently excluded and the analysis re-run. Three maximally parsimonious trees were generated in the reduced matrix. All trees had 126 steps, a Cl of 0.6639 (excluding uninformative characters), an RI of 0.6797 , and $\mathrm{RCl}$ of 0.4585 . These three trees are shown in Figure 18.2-4 and the strict consensus and $50 \%$ majority rule consensus trees are shown in Figure 18.5-6. Unambiguous apomorphies common to all three trees are provided in Appendix 6.

Bootstrap support was good (95\%) for a monophyletic Vombatidae. Bootstrap support was also relatively good (86\%) for a monophyletic group consisting of the hypselodont wombats, excluding Warendja, and the topology of the trees for these taxa was stable after removal of $R$. magna from the analysis. Warendja consistently came out as the most plesiomorphic wombat with hypselodont cheek teeth and $N$. boodjamullensis was consistently the most plesiomorphic vombatid. Beyond this, relationships between all of the OligoMiocene wombats are unresolved. This is the result of a large amount of missing data due to small sample sizes, taxa being known mainly from isolated teeth and the rarity of cusp detail being preserved on wombat teeth.

\section{Body Size}

Body mass estimates for $R$. crowcrofti and $R$. ngangaba are provided in Table 2. Based on molar measurements, $R$. crowcrofti is estimated to have weighed around $50 \mathrm{~kg}$, about twice the size of modern wombats and $R$. ngangaba is estimated to have weighed around $25 \mathrm{~kg}$, similar in size to modern wombats. Because these measurements are based on the comparison of isolated hypselodont and non-hypselodont teeth, caution is advised in over-interpreting these estimates. However, it is clear that species of Rhizophascolonus represent medium to large members of the Vombatidae.

\section{Ontogenetic Age}

All specimens of $R$. crowcrofti represent either adults or subadults. QM F57959, QM F57960, and QM F12452 are the least worn of all of the specimens and may represent individuals that had not long left the pouch at their time of death. However, because the teeth exhibit finite growth in $R$. crowcrofti (compared with $V$. ursinus and $L$. latifrons upon which the age estimates are mostly based) and probably did not wear as quickly as modern wombat teeth, it is more likely that they are young adults. In contrast, teeth of $R$. ngangaba show very little wear on the occlusal surface. Based on comparisons with modern wombats and koalas, all $R$. ngangaba specimens described here represent individuals between about 6 and 8 months of age, i.e., pouch young, which were starting to leave the pouch and explore their surroundings at their time of death (Table 3). It is not clear why all R. ngangaba specimens represent pouch young. Unfortunately, the small sample size precludes comparison of competing models (e.g., high juvenile mortality rate versus a preference for raising young in specific environments).

\section{DISCUSSION}

Comparisons between $R$. crowcrofti and $R$. ngangaba are challenging because the teeth attributable to each preserve different wear stages and different features. In addition, the cusp morphology of $V$. ursinus and $L$. latifrons, which are quite different to each other and to species of Rhizophascolonus, are intraspecifically variable (particularly $V$. ursinus). Further, our understanding of the homologies of these cusps among vombatiform marsupials is poor. Considering the small sample size, that the specimens are represented by isolated teeth, and the large geological time span represented by this material, we consider that it would be premature at this stage to compare individual cusps in any greater detail and with any more certainty about homology or intraspecific variation than we have provided here. The presence of fragmentary specimens attributable to Rhizophascolonus, but showing a wide range of variation in size, may hint at the presence of additional species of Rhizophascolonus in the Miocene.

The molars of $R$. crowcrofti and $N$. boodjamullensis show marked differences in enamel thickness and enamel height between buccal and lingual surfaces. This is partly a result of an emphasis on trailing edge grinding in these taxa (Brewer et al., 2008, 2015). Thickened enamel 
1

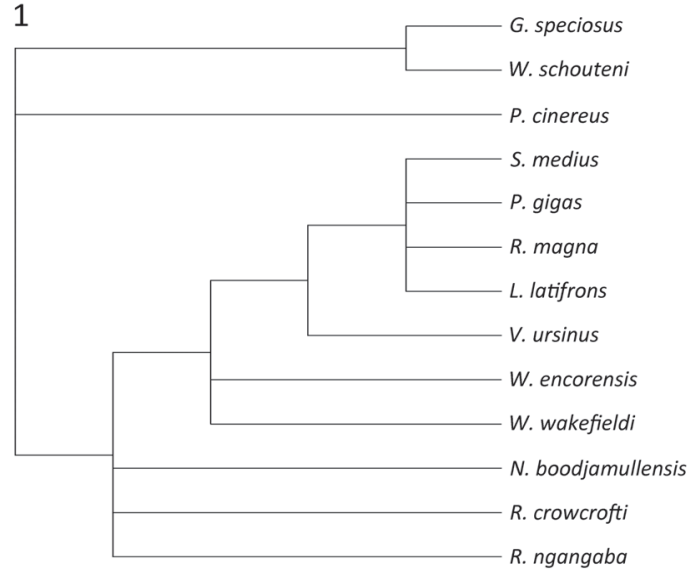

2

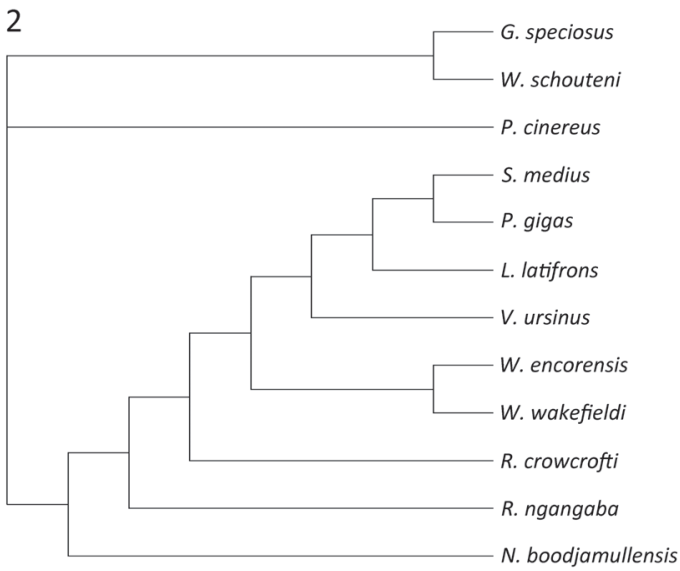

3

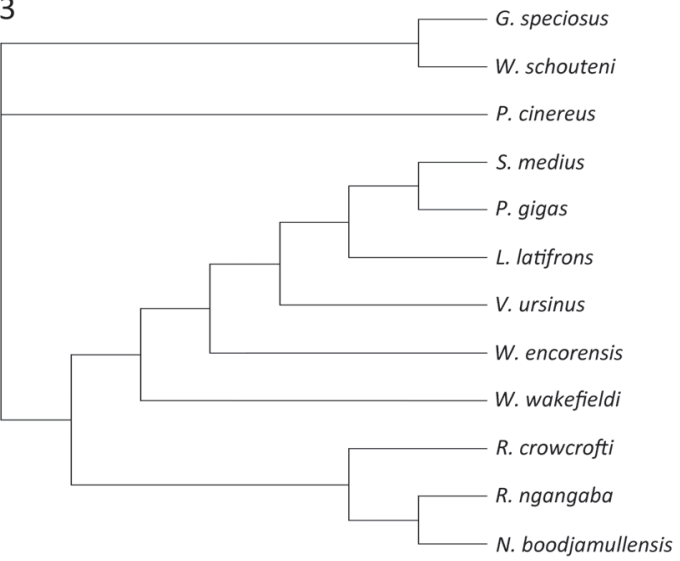

4

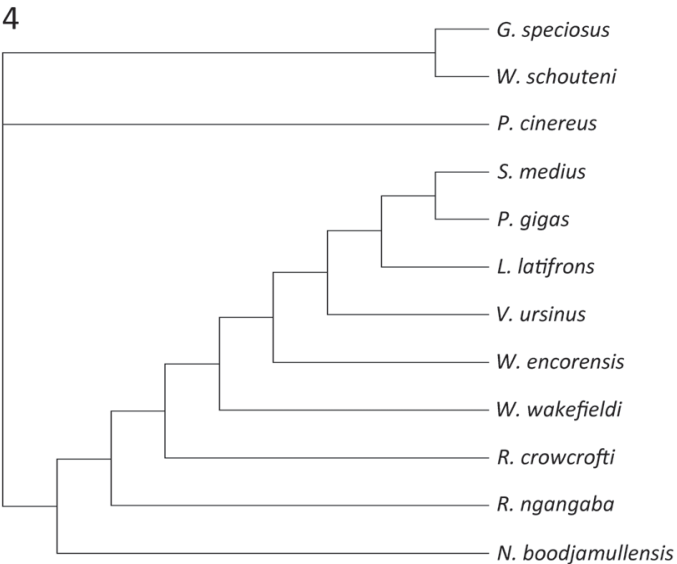

5

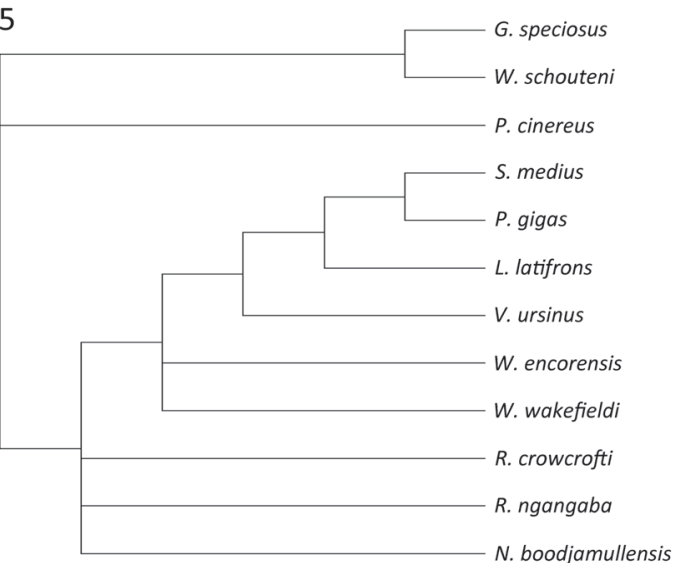

6

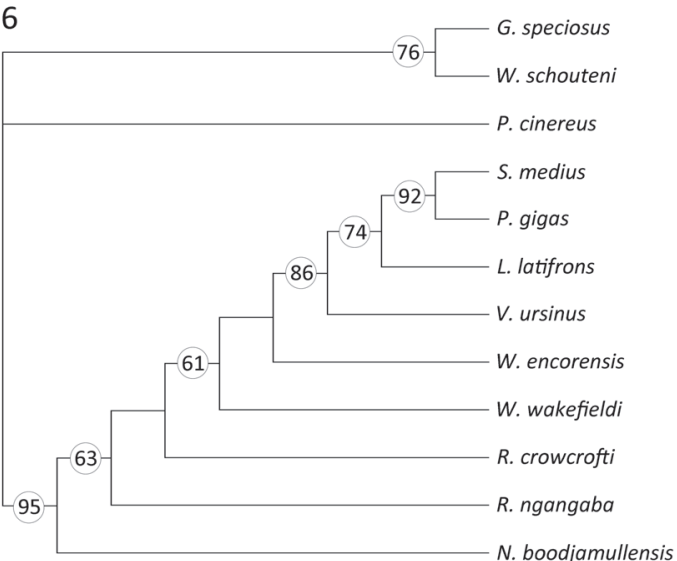

FIGURE 18. Results of the phylogenetic analysis. 1. Strict consensus tree of 9 most parsimonious trees (MPTs) before pruning. 2. Tree 1 of 3 MPTs after removing Ramsayia magna from the analysis. 3 . Tree 2 of 3 MPTs after removing $R$. magna from the analysis. 4 . Tree 3 of 3 MPTs after removing $R$. magna from the analysis. 5 . Strict consensus of 3 MPTs after removing $R$. magna from the analysis. $6.50 \%$ majority rule consensus tree after removing $R$. magna from the analysis. Numbers in circles indicate bootstrap support. 
TABLE 2. Body weight estimates for a range of taxa based on third molar area using the 'Diprotodontians only' data set in Myers (2001). The 3UMA and 3LMA equations were used for upper and lower molars, respectively. $n=$ number of measurements used in calculation.

\begin{tabular}{|c|c|c|c|c|c|c|}
\hline \multirow[b]{2}{*}{ Taxon } & \multirow{2}{*}{$\begin{array}{c}\text { Tooth } \\
\text { position }\end{array}$} & \multirow[b]{2}{*}{$\mathbf{n}$} & \multicolumn{3}{|c|}{ Body weight estimate } & \multirow[b]{2}{*}{ Notes } \\
\hline & & & Min (kg) & $\operatorname{Max}(\mathbf{k g})$ & Average (kg) & \\
\hline \multirow[t]{2}{*}{ L. latifrons } & $\mathrm{m} 2-3$ & 14 & 10 & 27 & 19 & \multirow{2}{*}{$\begin{array}{l}\text { Very low estimate based on this sample. } \\
\text { Expected body weight for } L \text {. latifronsis } 17.5- \\
36 \mathrm{~kg} \text { (Taggart and Temple-Smith, 2008). }\end{array}$} \\
\hline & M2-3 & 11 & 11 & 27 & 16 & \\
\hline N. boodjamullensis & M2-3 & 4 & 6 & 10 & 8 & \\
\hline \multirow[t]{2}{*}{$P$. cinereus } & $\mathrm{m} 2-3$ & 172 & 4 & 11 & 7 & \multirow{2}{*}{$\begin{array}{l}\text { Expected body weight is } 4.1-14.9 \mathrm{~kg} \text { (Martin } \\
\text { et al., 2008), although Myers (2001) gives 5- } \\
6 \mathrm{~kg} .\end{array}$} \\
\hline & M2-3 & 139 & 7 & 17 & 11 & \\
\hline \multirow[t]{2}{*}{ P. gigas } & $\mathrm{m} 2-3$ & 6 & 216 & 300 & 255 & \\
\hline & M2-3 & 2 & 191 & 254 & 223 & \\
\hline R. lemleyi & $\mathrm{m} 2-3$ & 2 & 147 & 165 & 156 & \\
\hline \multirow[t]{2}{*}{ R. crowcrofti } & $\mathrm{m} 2-3$ & 5 & 48 & 63 & 54 & \multirow{2}{*}{$\begin{array}{l}\text { Around } 50 \mathrm{~kg} \text {. About double the size of } \\
\text { modern wombats. }\end{array}$} \\
\hline & M2-3 & 4 & 36 & 68 & 51 & \\
\hline \multirow[t]{2}{*}{ R. ngangaba } & $\mathrm{m} 2-3$ & 1 & 25 & 25 & 25 & \multirow{2}{*}{$\begin{array}{l}\text { Half the weight of } R \text {. crowcrofti, similar in size } \\
\text { to modern wombats. }\end{array}$} \\
\hline & M2-3 & 1 & 25 & 25 & 25 & \\
\hline \multirow[t]{2}{*}{ V. ursinus } & $\mathrm{m} 2-3$ & 17 & 14 & 34 & 22 & \multirow{2}{*}{$\begin{array}{l}\text { Expected body weight for } V \text {. ursinus is } 22-39 \\
\mathrm{~kg} \text { (Mcllroy, 2008), excluding Tasmanian and } \\
\text { Flinders Island forms (which were included in } \\
\text { this sample). }\end{array}$} \\
\hline & M2-3 & 12 & 13 & 24 & 18 & \\
\hline \multirow[t]{2}{*}{ W. encorensis } & $\mathrm{m} 2-3$ & 6 & 12 & 28 & 19 & \multirow{2}{*}{$\begin{array}{l}\text { Considering the underestimates for modern } \\
\text { wombats (which are similar in size and } \\
\text { morphology), this could also be an } \\
\text { underestimate. }\end{array}$} \\
\hline & M2-3 & 6 & 13 & 19 & 16 & \\
\hline \multirow[t]{2}{*}{ W. wakefieldi } & $\mathrm{m} 2-3$ & 5 & 7 & 11 & 9 & \\
\hline & M2-3 & 5 & 5 & 8 & 7 & \\
\hline S. medius & m3 & 3 & 37 & 41 & 39 & Using 3LML equation, as don't have widths. \\
\hline
\end{tabular}

often suggests a brittle diet due to the high stresses involved and/or high rates of wear (Lucas and Luke, 1984). In the case of $R$. crowcrofti and $N$. boodjamullensis, there is only a slight increase in crown height on one side of the tooth and the pulp chamber is still relatively close to the occlusal surface. This limits the amount of dental material available for wear. The presence of enamel extending down the roots of the trailing surfaces of upper and lower molars and the position of the lingual root midway between anterior and posterior surfaces on $\mathrm{M} 1$, both strongly suggest that high stresses were being transmitted through the trailing surfaces of the molars. An investigation of the enamel ultrastructure is currently underway in order to test this hypothesis. The presence of differentially thickened enamel and large variations in enamel height in R. crowcrofti, $N$. boodjamullensis, and QM F20613 (Rhizophascolonus sp. from Bone Reef Site at Riversleigh) suggests that these had evolved by the late Oligocene.
Brewer et al. (2008) suggested that $R$. crowcrofti could have been rhizophagous. Mechanical processing of Underground Storage Organs (USOs) would seem like a potential match for the tooth morphology and wear pattern evident in this species (and to a lesser extent $N$. boodjamullensis; Dominy et al., 2008). USOs would have been available in both a rainforest environment and in more open/drier/seasonal environments, as they are today. It is possible that USOs formed part of the diet (e.g., as fallback foods) for primitive wombats long before grasslands had developed in Australia (Martin, 2006). Morphological adaptations to process USOs more efficiently would have been advantageous as the climate deteriorated in the late Oligocene. This selection pressure would have increased again around the middle Miocene climatic transition (see Figure 19), as the continent underwent an overall decrease in rainfall that led to the expansion of more open woodland habitats. In such an environment and in times of low plant pro- 
TABLE 3. Estimated ontogenetic stages for Rhizophascolonus specimens. Wear stage for each tooth corresponds to 1 = developing, 2 = erupting, 3 = in occlusion but with little or no wear and 4=noticeable wear. Ontogenetic stage is modified from Black et al., 2010. Age and life stage are based on Green and Rainbird, 1987 and Triggs, 2009 for V. ursinus, Taggart et al., 2007 for L. latifrons and Blanshard, 1990 for $P$. cinereus. * = based on P. cinereus.

\begin{tabular}{|c|c|c|c|c|c|c|c|}
\hline $\begin{array}{l}\text { Specimen } \\
\text { number }\end{array}$ & Site & Taxon & $\begin{array}{l}\text { Tooth } \\
\text { position }\end{array}$ & $\begin{array}{l}\text { Wear } \\
\text { stage }\end{array}$ & $\begin{array}{l}\text { Ontogenetic } \\
\text { stage }\end{array}$ & $\begin{array}{c}\text { Approximate } \\
\text { age }\end{array}$ & Early life stage \\
\hline QM F57959 & COA & R. crowcrofti & $\mathrm{MX}$ & 4 & At least stage IV & $>8$ months & \\
\hline QM F57960 & COA & R. crowcrofti & $\mathrm{mx}$ & 4 & At least stage IV & $>8$ months & \\
\hline QM F57963 & COA & R. crowcrofti & $M X$ & 4 & At least stage IV & $>8$ months & \\
\hline QM F12452 & COA & R. crowcrofti & $\mathrm{mx}$ & 3 & At least stage IV & $\begin{array}{l}\text { If } \mathrm{m} 3=10-12 \\
\text { months; If } \mathrm{m} 4= \\
\text { older than } 12 \\
\text { months }^{*}\end{array}$ & \\
\hline QM F20706 & CS & R. ngangaba & $\mathrm{MX}$ & (1 to) 2 & $\begin{array}{l}\text { Late II to III } \\
\text { (depending on } \\
\text { whether M2 or M3) }\end{array}$ & $6-8$ months & $\begin{array}{l}\text { In and out of pouch, still } \\
\text { suckles, at least } \\
\text { occassionally }\end{array}$ \\
\hline QM F57967 & CS & R. ngangaba & $\mathrm{m} 1$ & 3 & II & 5-7 months & $\begin{array}{l}\text { Suckling pouch young, } \\
\text { starts to venture out of } \\
\text { pouch occassionally }\end{array}$ \\
\hline QM F23772 & CS & R. ngangaba & M1 & 3 & II & 5-7 months & $\begin{array}{l}\text { Suckling pouch young, } \\
\text { starts to venture out of } \\
\text { pouch occassionally }\end{array}$ \\
\hline QM F57968 & GGS & R. ngangaba & $\mathrm{mx}$ & 2 (to 3 ) & $\begin{array}{l}\text { Late II to III } \\
\text { (depending on } \\
\text { whether m2 or m3) }\end{array}$ & $6-8$ months & $\begin{array}{l}\text { In and out of pouch, still } \\
\text { suckles, at least } \\
\text { occassionally }\end{array}$ \\
\hline QM F23765 & Upper & R. ngangaba & M1 & 2 to 3 & Early II & $5-6$ months & $\begin{array}{l}\text { Suckling pouch young, } \\
\text { first emergence from } \\
\text { pouch }\end{array}$ \\
\hline QM F23769 & CS & R. ngangaba & $\mathrm{mx}$ & 2 to 3 & $\begin{array}{l}\text { Late II to III } \\
\text { (depending on } \\
\text { whether m2 or m3) }\end{array}$ & $6-8$ months & $\begin{array}{l}\text { In and out of pouch, still } \\
\text { suckles, at least } \\
\text { occassionally }\end{array}$ \\
\hline QM F23764 & Upper & R. ngangaba & $\mathrm{m} 1$ & 3 & II & 5-7 months & $\begin{array}{l}\text { Suckling pouch young, } \\
\text { first emergence from } \\
\text { pouch }\end{array}$ \\
\hline QM F23768 & Upper & R. ngangaba & $\mathrm{mx}$ & 3 & $\begin{array}{l}\text { Late II to III } \\
\text { (depending on } \\
\text { whether m2 or m3) }\end{array}$ & $6-8$ months & $\begin{array}{l}\text { In and out of pouch, still } \\
\text { suckles, at least } \\
\text { occassionally }\end{array}$ \\
\hline QM F23903 & CS & R. ngangaba & P3 & 3 (to 4 ) & III & $7-8$ months & $\begin{array}{l}\text { At foot, occassionally } \\
\text { suckles }\end{array}$ \\
\hline QM F23763 & Upper & $\begin{array}{l}\text { Rhizophascol } \\
\text { onus sp. }\end{array}$ & $\mathrm{mx}$ & 2 & $\begin{array}{l}\text { If } \mathrm{m} 3=\text { III; If } \mathrm{m} 4=\text { at } \\
\text { least stage IV }\end{array}$ & $>7$ months & \\
\hline QM F57966 & $\mathrm{COA}$ & $\begin{array}{l}\text { Rhizophascol } \\
\text { onus sp. }\end{array}$ & p3 or dp3 & 3 (to 4 ) & $\begin{array}{l}\text { If } \mathrm{dp} 3=\text { I to early II; } \\
\text { If p3 = late II or early } \\
\text { III }\end{array}$ & $\begin{array}{l}\text { If } \mathrm{dp} 3=<6 \text { months; } \\
\text { If } \mathrm{p} 3=6-8 \text { months }\end{array}$ & Suckling pouch young \\
\hline
\end{tabular}

ductivity, an ability to process USOs and other hard/brittle foods such as bark, would be highly advantageous. Modern V. ursinus includes USOs and bark among other items in their diet (Rishworth et al., 1995; Evans et al., 2006). The youngest known specimen of $R$. crowcrofti is from the late Miocene. At that time, this species would have overlapped with $W$. encorensis, which had hypselodont cheek teeth enabling the latter species to sustain even more extensive tooth wear. It is possi- ble that the relative limitation in $R$. crowcrofti to cope with increasingly abrasive food items drove this species to extinction in the late Miocene, leaving the future of vombatid evolution to the hypselodont forms.

In contrast to the molars, the upper incisor of $R$. crowcrofti was hypselodont (the incisor is unknown for $R$. ngangaba and $N$. boodjamullensis) showing that hypselodonty evolved at different tooth positions at different times. This is not sur- 


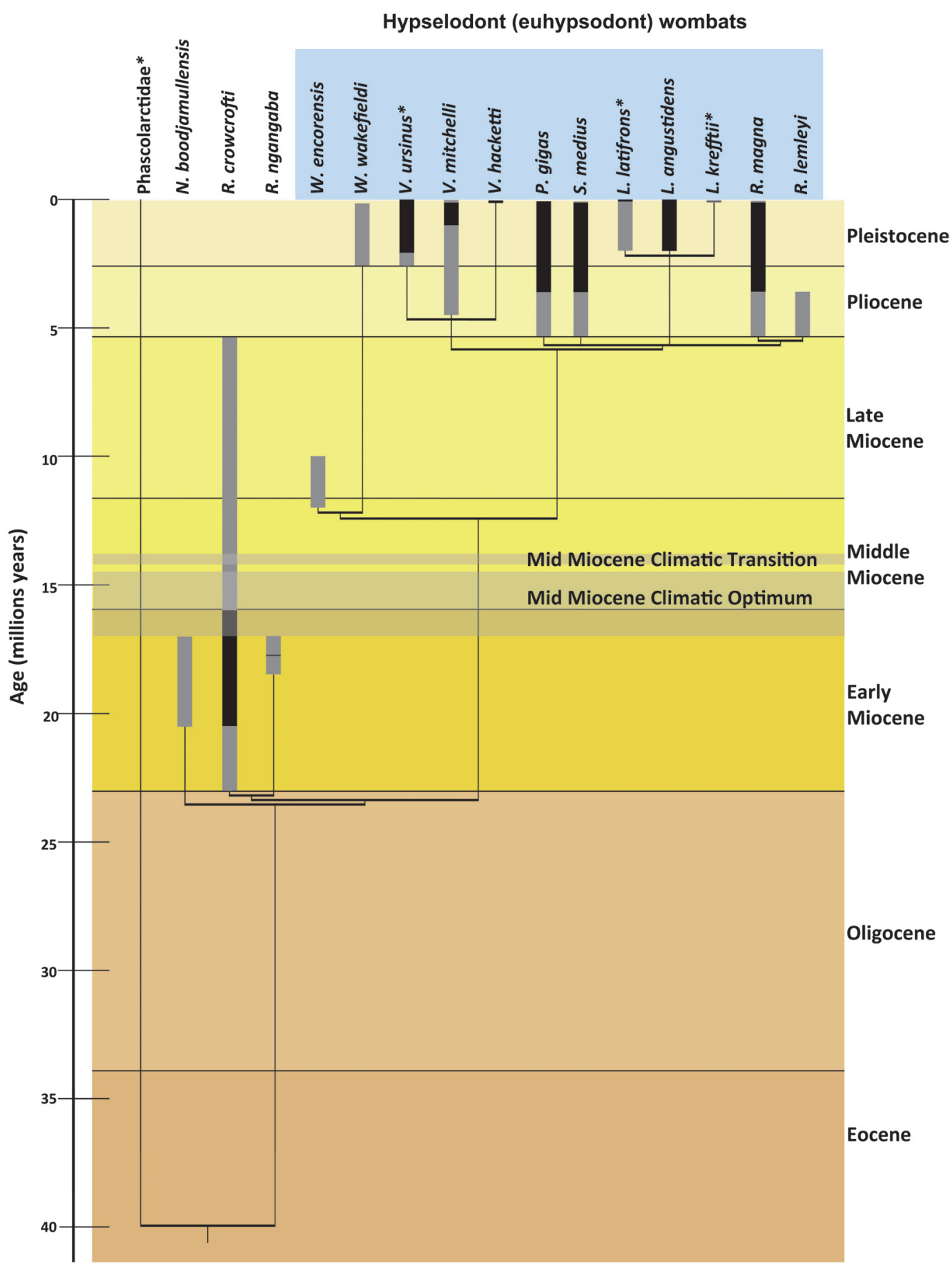

FIGURE 19. Results of the phylogenetic analysis with additional species added (relative branching order of these additional taxa are shown here as not resolved) against the geological time scale (Gradstein et al., 2012). Age span of deposits containing all known wombat taxa are provided, with black bars indicating certainty (such as radiometrically dated sites) and grey indicating uncertainty (ages are based on Archer and Wade, 1976; Archer et al., 1989, 1997, 2016; Arena et al., 2016; Beck, 2008; Beheregaray et al., 2000; Black, 1997; Black et al., 2012b; Cupper and Duncan, 2006; Dawson, 1985; Hope and Wilkinson, 1982; Myers et al., 2001, 2017; Piper et al., 2006; Pledge, 1992; Price et al., 2009, 2011; Prideaux et al., 2010; Vickers-Rich et al., 1991; Roberts et al., 2001; Stirton et al., 1967; Taylor et al., 1994; Tedford et al., 2006; Travouillon et al., 2006, 2011; Whitelaw 1989, 1991; Woodhead et al., 2014). Age of split between taxa is based on oldest possible deposits containing those taxa and as such will change as more information becomes available. Asterix indicates taxon is extant. 
prising as teeth in different parts of the jaw perform different functions. Hypselodonty is also much more common in the anterior dentition in mammals than the posterior dentition (e.g., Renvoisé and Michon, 2014). Unfortunately, only a single incisor is known for Rhizophascolonus, and it remains to be seen whether the occlusal surface preserved on this specimen is representative of its shape during life or for the taxon. The next challenge will then be to understand tooth function at each tooth position before presenting a synthesis outlining the function of the dentition as a whole.

The early Miocene saw greenhouse conditions and the presence of widespread rainforest in Australia, particularly at Riversleigh (Black et al., 2012b). The presence of three species of wombat in early Miocene deposits at Riversleigh (the only time this occurs in this region of Australia) could be evidence of a diversification event in the early Miocene, a range expansion due to favourable conditions and/or evidence that this kind of environment was optimal for early vombatids.

Nimbavombatus boodjamullensis is a small, apparently generalised wombat, which, based solely on general morphology, had the capacity to eat a wide range of foods (Brewer et al., 2015). Rhizophascolonus ngangaba is more enigmatic; known only from isolated teeth of pouch young, it is difficult to judge whether the shape of the crests and cusps of the occlusal surface were important in mastication (other than in pouch young) or whether these were quickly worn away, as in other wombats. If they were important in mastication, the crests and cusps on the occlusal tooth surface of this taxon are relatively slender (although there is thick enamel on the trailing surfaces) and the narrow anterior moieties of $\mathrm{M} 1 / \mathrm{m} 1$ forming continuous crests with the premolars suggest a browsing diet. The crests forming the buccal and lingual margins of the molars are orientated in an overall longitudinal direction. Unless these crests were being utilised in orthal shearing, it is hard to imagine what selective advantage they have, unless they change shape with wear given that the secant crests that might result would act to increase pressure, reduce friction, and trap food (Rensberger, 1973, 1975; Lucas, 1982; Lucas and Luke, 1984; Evans and Sanson, 2003). Although detailed studies of microwear and simulations of wear processes could be performed to explore these possibilities, more complete tooth rows for individuals at different ontogenetic ages would be needed to develop an overall understanding of occlusal mechanics in these early vombatids.
Despite their diversity, why are wombats rare in Riversleigh deposits? Is it because we are not sampling their natural habitat, at least until the middle to late Miocene? The late Oligocene environment at Riversleigh is interpreted to be more open than the early Miocene (and more similar in structure to the late Miocene), and yet we don't have a single confirmed example of a wombat from this time. This is despite the fact that the already-specialised species of Rhizophascolonus are represented in Riversleigh's early Miocene deposits. It is conceivable that early wombats were particularly rare in the late Oligocene, and that they did not become significant components of biotas until the late Miocene to Pliocene. Wombats seem to be most speciose at Riversleigh in early Miocene deposits, which are interpreted to have sampled rainforest habitats, and yet even here they are still rare components of the fauna. Interestingly, an unidentified fragment of a wombat molar was reported from the early Pliocene Hamilton LF (Turnbull et al., 2003), interpreted to represent a rainforest environment. This may indicate that primitive wombats were components of closed forest environments (unlike modern wombats), but due to their evolutionary focus on trailing edge grinding and reinforced enamel, were later able to exploit resources from a range of drier environments. On the other hand, they may have been limited to more open spaces within these forest environments, for example, along watercourses. At the present day $V$. ursinus often preferentially select burrow and mound sites along watercourses and in areas away from dense leafy vegetation (e.g., Roger et al., 2007). In this case, however, this is due to the grazing requirements of this species as well as its need to find suitable friable soils in which to excavate complex burrows. It is not known when wombats first started to dig burrows, but grazing as a feeding strategy is unlikely to have developed prior to the Pliocene when grasslands first became a feature of Australian landscapes (Martin, 2006).

The late Miocene Warendja encorensis from Riversleigh is the oldest wombat known to have had hypselodont cheek teeth (Brewer et al., 2007). Warendja wakefieldi, the only other species in this genus, is found in Pleistocene deposits (Hope and Wilkinson, 1982; Flannery and Pledge, 1987; Brewer, 2007). Although no postcranial remains of the Miocene species have been found, a humerus of the Pleistocene one has been described (Brewer, 2007) and indicates scratch-digging adaptations. Whether it dug burrows or mounds and/or 
used these adaptations for food acquisition is not known. It is noteworthy that all three occurrences of the Pleistocene species are from caves as are the late Miocene specimens of $W$. encorensis from Riversleigh. It is possible that species of Warendja utilised caves to help thermoregulate and conserve energy, benefits modern wombats acquire instead from living in burrows.

Five genera of medium to large wombats make their first appearance in Pliocene deposits. Common to all of these taxa, and differing from the Miocene forms, is the synapomorphic transversely wide upper incisor. This reaches an extreme in the upper incisors of $P$. gigas. This, combined with the hypselodont cheek teeth and relatively large body size, suggests that these Pliocene forms, unlike the early to middle Miocene vombatids, were adapted for bulk feeding on low-quality forage. It is possible that these features represent symplesiomorphies inherited from an as yet unknown common ancestor in the late Miocene that was adapting to the steady decline in the quality of vegetation as most of Australia began its steep descent into arid/ semiarid conditions. Differences in overall size and incisor shape suggest that some of these Pliocene taxa were occupying slightly different ecological niches, although the specifics of these differences still need teasing out. The early Pliocene saw a brief milder greenhouse phase (at least in southeastern Australia), with a diversity of habitats represented (Martin, 1994, 1998, 2006; Sniderman et al., 2016), and this may have been an additional complicating factor in the post-Miocene diversification of vombatids.

\section{CONCLUSIONS}

Three species of wombat are now known from the Australian early Miocene, of which N. boodjamullensis is the most plesiomorphic. Rhizophascolonus crowcrofti is a large wombat found in deposits ranging in age from early to late Miocene, making it the longest-lived species of wombat known. This species had already evolved hypselodont upper incisors by the early Miocene. However, its molars remained rooted, showing that hypselodonty evolved at different tooth positions at different times. Tooth cusps are described here for this taxon for the first time. Rhizophascolonus ngangaba sp. nov. is a medium-sized wombat known from two sites at Riversleigh, both dated to around $18 \mathrm{Ma}$. This taxon is only known from isolated teeth of pouch young.

Adaptations to high levels of tooth wear such as hypselodont incisors as well as differential enamel thickness and height on the molars probably evolved in the late Oligocene, possibly in response to an opening up of the environment and/ or increased seasonality. Rainforests which dominated the Riversleigh WHA during the early Miocene supported at least three species of wombat, albeit as rare components of the terrestrial faunas. The effects of the middle Miocene Climatic Oscillation may have led to an increase in the abundance and range of $R$. crowcrofti, but it is not until the Tortonian (late Miocene) that the first species with hypselodont cheek teeth appear. A late Miocene to Pliocene diversification interval resulted in the evolution of large species with adaptations for grazing and/or bulk feeding. The potential to track changes in climate and vegetation from the late Paleogene to Neogene, reflected in the morphological adaptations of the vombatid dentition, will improve when the earlier part of the record is better known.

\section{ACKNOWLEDGEMENTS}

Support for research at Riversleigh has come from the Australian Research Council (LP0989969, LP100200486, DP1094569, DP130100197, DE130100467 and DP170101420 grants to M. Archer, S.J. Hand and K.H. Black at the University of New South Wales); XSTRATA Community Partnership Program (North Queensland); UNSW Sydney; P. Creaser and the CREATE Fund at UNSW; the Queensland Parks and Wildlife Service; Environment Australia; the Queensland Museum; the Riversleigh Society, Inc.; Scientific and Information Technology Consulting; Outback at Isa; Mount Isa City Council; and private supporters including K. and M. Pettit, E. Clark, M. Beavis, and M. Dickson. Assistance in the field has come from many hundreds of volunteers as well as staff and postgraduate students of the University of New South Wales. Support for this project has come from a Northcote Graduate Scholarship from the Menzies Centre for Australian Studies (to P. Brewer) and a Sylvester Bradley Award (to P. Brewer) from the Palaeontological Association. Access to specimens and associated information was provided by R. PortelaMiguez (for NHMUK modern mammals), Y.Y. Zhen (for AM fossil mammals), W. Longmore (for NMV modern mammals), E. Fitzgerald and D. Pickering (for NMV fossil mammals), C. Phillips (for RCSOM modern mammals), D. Stemmer (for SAMA modern mammals), N. Pledge and M. Binnie (for SAM fossil mammals) and S. Hocknull and K. Spring (for QM fossil mammals). A. Gillespie and K. Black prepared the specimens, K. Black donated images of modern koalas for comparisons and R. Abel facili- 
tated CT access at the NHMUK. J. Hooker and L. Humphrey provided useful discussions. Thank you to the reviewers and editors for helping to improve this manuscript.

\section{REFERENCES}

Aplin, K.P. and Archer, M. 1987. Recent advances in marsupial systematics with a new syncretic classification, p. xv-Ixxii. In Archer, M. (ed.), Possums and Opossums: Studies in Evolution. Australia: Surrey Beatty \&; Sons Pty Limited in Association with the Royal Zoological Society of New South Wales, Australia.

Archer, M. 1984. The Australian marsupial radiation, p. 633-808. In Archer, M. and Clayton, G. (eds.), Vertebrate Zoogeography \& Evolution in Australasia (Animals in Space \& Time). Hesperian Press, Carlisle, Western Australia.

Archer, M., Godthelp, H., Hand, S.J., and Megirian, D. 1989. Fossil mammals of Riversleigh, northwestern Queensland: preliminary overview of biostratigraphy, correlation and environmental change. Australian Zoologist, 25(2):29-65. https://doi.org/10.7882/ az.1989.001

Archer, M., Hand, S.J., Black, K.H., Beck, R.M.D., Arena, D.A., Wilson, L.A.B., Kealy, S., and Hung, T.T. 2016. A new family of bizarre durophagous carnivorous marsupials from Miocene deposits in the Riversleigh World Heritage Area, northwestern Queensland. Scientific Reports, 6. https://doi:10.1038/srep26911

Archer, M., Hand, S.J., Godthelp, H., and Creaser, P. 1997. Correlation of the Cainozoic sediments of the Riversleigh World Heritage fossil property, Queensland, Australia, p. 131152. In Aguiler, J.P., Legendre, S., and Michaux, J. (eds.), Actes du Congres BiochroM '97.

Archer, M. and Wade, M. 1976. Results of the Ray E. Lemley expeditions; Part 1, the Allingham Formation and a new Pliocene vertebrate fauna from northern Queensland. Memoirs of the Queensland Museum, 17:379-398.

Arena, D.A. 2004. The geological history and development of the terrain at the Riversleigh World Heritage Area during the middle Tertiary. Unpublished PhD Thesis, University of New South Wales, Sydney, Australia.

Arena, D.A., Black, K.H., Archer, M., Hand, S.J., Godthelp, H., and Creaser, P. 2014. Reconstructing a Miocene pitfall trap: Recognition and interpretation of fossiliferous Cenozoic palaeokarst. Sedimentary Geology, 304:28-43.

Arena, D.A., Travouillon, K.J., Beck, R.M.D., Black, K.H., Gillespie, A.K., Myers, T.J., Archer, M., and Hand, S.J. 2016. Mammalian lineages and the biostratigraphy and biochronology of Cenozoic faunas from the Riversleigh World Heritage Area, Australia. Lethaia, 49(1):43-60. https://doi.org/10.1111/let.12131

Beck, R.M.D. 2008. A dated phylogeny of marsupials using a molecular supermatrix and multiple fossil constraints. Journal of Mammalogy, 89(1):175-189. https://doi.org/10.1644/06-mamma-437.1

Beheregaray, L., Sunnucks, P., Alpers, D., Banks, S., and Taylor, A. 2000. A set of microsatellite loci for the hairy-nosed wombats (Lasiorhinus krefftii and L. latifrons). Conservation Genetics, 1(1):89-92.

Black, K. 1997. Diversity and biostratigraphy of the Diprotodontoidea of Riversleigh, northwestern Queensland. Memoirs of the Queensland Museum, 41:187-192.

Black, K. 2007. Maradidae: a new family of vombatomorphian marsupial from the late Oligocene of Riversleigh, northwestern Queensland. Alcheringa: An Australasian Journal of Palaeontology, 31(1):17-32. https://doi.org/10.1080/03115510601123601

Black, K.H., Archer, M., and Hand, S.J. 2012a. New Tertiary koala (Marsupialia, Phascolarctidae) from Riversleigh, Australia, with a revision of phascolarctid phylogenetics, paleoecology, and paleobiodiversity. Journal of Vertebrate Paleontology, 32(1):125-138. https://doi.org/10.1080/02724634.2012.626825

Black, K.H., Archer, M., Hand, S.J., and Godthelp, H. 2010. First comprehensive analysis of cranial ontogeny in a fossil marsupial-from a 15-million-year-old cave deposit in northern Australia. Journal of Vertebrate Paleontology, 30(4):993-1011. https://doi.org/10.1080/ 02724634.2010.483567 
Black, K.H., Archer, M., Hand, S.J., and Godthelp, H. 2012b. The rise of Australian marsupials: A synopsis of biostratigraphic, phylogenetic, palaeoecologic and palaeobiogeographic understanding, p. 983-1078. In Talent, J.A. (ed.), Earth and Life: Global Biodiversity, Extinction Intervals and Biogeographic Perturbations Through Time. Springer. https://doi.org/ 10.1007/978-90-481-3428-1_35

Black, K.H., Archer, M., Hand, S.J., and Godthelp, H. 2013. Revision in the diprotodontid marsupial genus Neohelos: Systematics and biostratigraphy. Acta Palaeontologica Polonica, 58(4):679-706. https://doi.org/10.4202/app.2012.0001

Black, K.H., Louys, J., and Price, G.J. 2014. Understanding morphological variation in the extant koala as a framework for identification of species boundaries in extinct koalas (Phascolarctidae; Marsupialia). Journal of Systematic Palaeontology, 12:237-264.

Blanshard, W.H. 1990. Growth and development of the koala from birth to weaning, p. 193-202. In Lee, A.K., Handasyde, K.A., and Sanson, G.D. (eds.), Biology of the Koala. Surrey Beatty \& Sons, Sydney, Australia.

Brewer, P. 2007. New record of Warendja wakefieldi (Vombatidae; Marsupialia) from Wombeyan Caves, New South Wales. Alcheringa: An Australasian Journal of Palaeontology, 31(2):153171. https://doi.org/10.1080/03115510701305132

Brewer, P., Archer, M., and Hand, S. 2008. Additional specimens of the oldest wombat Rhizophascolonus crowcrofti (Vombatidae; Marsupialia) from the Wipajiri Formation, South Australia: an intermediate morphology? Journal of Vertebrate Paleontology, 28(4):1144-1148. https://doi.org/10.1671/0272-4634-28.4.1144

Brewer, P., Archer, M., Hand, S., and Godthelp, H. 2007. A new species of the wombat Warendja from the late Miocene deposits at Riversleigh, north-west Queensland, Australia. Palaeontology, 50:811-828. https://doi.org/10.1111/j.1475-4983.2007.00678.x

Brewer, P., Archer, M., Hand, S.J., and Abel, R. 2015. New genus of primitive wombat (Vombatidae, Marsupialia) from Miocene deposits in the Riversleigh World Heritage area (Queensland, Australia). Palaeontologia Electronica, 18.1.9A:1-40. https://doi.org/10.26879/ 472

Burnett, G.T. 1830. Illustrations of the Quadrupeda, or quadrupeds; being an arrangement of the true four-footed beasts indicated in outline. Quarterly Journal of Science, Literature and Art, 28:336-353.

Calendini, F. and Martin, J.F. 2005. PaupUP v1.0.3.1 A free graphical frontend for Paup* Dos software.

Cifelli, R.L. and Muizon, C.de 1998. Tooth eruption and replacement pattern in early marsupials. Comptes Rendus de I'Academie des Sciences Series IIA Earth and Planetary Science, 326(3):215-220. https://doi.org/10.1016/s1251-8050(00)89038-2

Creaser, P. 1997. Oligocene-Miocene sediments of Riversleigh; the potential significance of topography. Memoirs of the Queensland Museum, 41:303-314.

Cupper, M.L. and Duncan, J. 2006. Last glacial megafaunal death assemblage and early human occupation at Lake Menindee, southeastern Australia. Quaternary Research, 66(2):332-341. https://doi.org/10.1016/j.yqres.2006.06.004

Dawson, L. 1981. The status of the taxa of extinct giant wombats (Vombatidae: Marsupialia), and a consideration of vombatid phylogeny. Australian Mammalogy, 4(2):65-79.

Dawson, L. 1983a. The taxonomic status of small fossil wombats (Vombatidae: Marsupialia) from Quaternary deposits, and of related modern wombats. Proceedings of the Linnean Society of New South Wales, 107(2):99-121.

Dawson, L. 1983b. On the uncertain generic status and phylogenetic relationships of the large extinct vombatid species Phascolomys medius Owen, 1972 (Marsupialia, Vombatidae). Australian Mammalogy, 6(1):5-13.

Dawson, L. 1985. Marsupial fossils from Wellington Caves, New South Wales; the historic and scientific significance of the collections in the Australian Museum, Sydney. Records of the Australian Museum, 37(2):55-69. https://doi.org/10.3853/j.0067-1975.37.1985.335

Dominy, N., Vogel, E., Yeakel, J., Constantino, P., and Lucas, P. 2008. Mechanical properties of plant underground storage organs and implications for dietary models of early hominins. Evolutionary Biology, 35(3):159-175. https://doi.org/10.1007/s11692-008-9026-7

Evans, A.R. and Sanson, G.D. 2003. The tooth of perfection: functional and spatial constraints on mammalian tooth shape. Biological Journal of the Linnean Society, 78(2):173-191. https:// doi.org/10.1046/j.1095-8312.2003.00146.x 
Flannery, T.F. and Pledge, N.S. 1987. Specimens of Warendja wakefieldi (Vombatidae: Marsupialia) from the Pleistocene of South Australia, p. 365-368. In Archer, M. (ed.), Possums and Opossums: Studies in Evolution. Surrey Beatty \& Sons Pty Limited, Chipping Norton, England.

Flower, W.H. 1867. On the development and succession of the teeth in the Marsupialia. Philosophical Transactions of the Royal Society of London, 157:631-641. https://doi.org/ 10.1098/rstl.1867.0020

Forasiepi, A.M. and Sánchez?Villagra, M.R. 2014. Heterochrony, dental ontogenetic diversity, and the circumvention of constraints in marsupial mammals and extinct relatives. Paleobiology, 40(2):222-237. https://doi.org/10.1666/13034

Gradstein, F.M., Ogg, J.G., Schmitz, M.D., and Ogg, G.M. 2012. The Geologic Time Scale, 2012. Elsevier, Amsterdam, Boston. https://doi.org/10.1016/c2011-1-08249-8

Green, R.H. and Rainbird, J.L. 1987. The common wombat Vombatus ursinus (Shaw 1800) in Northern Tasmania-Part 1. Breeding, growth and development. Records of the Queen Victoria Museum, 91:1-19.

Hope, J.H. and Wilkinson, H.E. 1982. Warendja wakefieldi, a new genus of wombat (Marsupiala: Vombatidae) from Pleistocene sediments in McEacherns Cave, western Victoria. Memoirs of the National Museum of Victoria, 43(2):109-120. https://doi.org/10.24199/j.mmv.1982.43.08

Horovitz, I. and Sánchez?Villagra, M.R. 2003. A morphological analysis of marsupial mammal higher?level phylogenetic relationships. Cladistics, 19(3):181-212. https://doi.org/10.1111/ j.1096-0031.2003.tb00363.x

Janis, C.M. 1988. An estimation of tooth volume and hypsodonty indices in ungulate mammals, and the correlation of these factors with dietary preference, p. 367-387. In Russell, D.E., Santoro, J.P., and Sigogneau-Russell, D. (eds), Teeth Revisited: Proceedings of the VIIth International Symposium on Dental Morphology, Mémoires du Muséum national d'histoire Naturelle Paris (serie C), 53.

Kielen-Jaworowska, Z., Cifelli, R.L., and Luo, Z.-X. 2005. Mammals from the Age of Dinosaurs: Origins, Evolution, and Structure. Columbia University Press.

Louys, J. 2015. Wombats (Vombatidae: Marsupialia) from the Pliocene Chinchilla Sand, southeast Queensland, Australia. Alcheringa: An Australasian Journal of Palaeontology, 39:1-13. https://doi.org/10.1080/03115518.2015.1014737

Lucas, P.W. 1982. Basic principles of tooth design, p. 154-162. In Kurtén, B. (ed.), Teeth: Form, Function and Evolution. Columbia University Press, New York.

Lucas, P.W. and Luke, D.A. 1984. Chewing it over: basic principles of food breakdown, p. 283302. In Chivers, D.J., Wood, B.A., and Bilsborough, A. (eds.), Food Acquisition and Processing in Primates. Plenum Press, New York. https://doi.org/10.1007/978-1-4757-52441 12

Luckett, W.P. 1993. An ontogenetic assessment of dental homologies in therian mammals, p. 182-204. In Szalay, F.S., Novacek, M.J., and McKenna, M.C. (eds.), Mammal Phylogeny: Mesozoic Differentiation, Multituberculates, Monotremes, Early Therians and Marsupials. Springer-Verlag, New York. https://doi.org/10.1007/978-1-4615-7381-4_13

Luo, Z.-X., Kielan-Jaworowska, Z., and Cifelli, R.L. 2002. In quest for a phylogeny of Mesozoic mammals. Acta Palaeontologica Polonica, 47:1-78.

Martin, H.A. 1994. Australian Tertiary phytogeography: evidence from pollen, p. 104-142. In Hill, R.S. (ed.), History of the Australian Vegetation: Cretaceous to Recent. Cambridge University Press, Cambridge.

Martin, H.A. 1998. The Tertiary climatic evolution and the development of aridity in Australia. Proceedings of the Linnean Society of New South Wales, 119:115-136.

Martin, H.A. 2006. Cenozoic climatic change and the development of the arid vegetation in Australia. Journal of Arid Environments, 66(3):533-563. https://doi.org/10.1016/ j.jaridenv.2006.01.009

Martin, R.W., Handasyde, K.A., and Krockenberger, A. 2008. Family Phascolarctidae: Koala, p. 112-114. In Van Dyck, S., and Strahan, R. (eds.), The Mammals of Australia. Reed New Holland, Sydney, Australia.

Mcllroy, J.C. 2008. Common wombat: Vombatus ursinus, p. 206-208. In Van Dyck, S. and Strahan, R. (eds.), The Mammals of Australia. Reed New Holland, Sydney, Australia.

Merrilees, D. 1967. Cranial and mandibular characters of modern mainland wombats (Marsupialia, Vombatidae) from a palaeontological viewpoint, and their bearing on the fossils 
called Phascolomys parvus by Owen (1872). Records of the South Australian Museum, 15:398-418.

Murray, P.F. 1998. Palaeontology and palaeobiology of wombats, p. 1-33. In Wells, R.T. and Pridmore, P.A. (eds.), Wombats. Gaughwin \& J. Ferris, Surrey Beatty \& Sons, in association with The Royal Zoological Society of South Australia Inc., Chipping Norton.

Myers, T., Crosby, K., Archer, M., and Tyler, M. 2001. The Encore Local Fauna, a late Miocene assemblage from Riversleigh, northwestern Queensland, p. 147-154. In Hand, S.J. and Laurie, J.R. (eds.), Sydney, N.S.W., Australia: Memoirs of the Association of Australasian Palaeontologists, Sydney, Australia.

Myers, T.J. 2001. Prediction of marsupial body mass. Australian Journal of Zoology, 49(2):99118.

Myers, T.J. and Archer, M. 1997. Kuterintja ngama (Marsupialia, Ilariidae): a revised systematic analysis based on material from the late Oligocene of Riversleigh, northwestern Queensland. Memoirs of the Queensland Museum, 41(2):379-392.

Myers, T.J., Black, K.H., Archer, M., and Hand, S.J. 2017. The identification of Oligo-Miocene mammalian palaeocommunities from the Riversleigh World Heritage Area, Australia and an appraisal of palaeoecological techniques. PeerJ, 5:e3511. https://doi.org/10.7717/peerj.3511.

Owen, R. 1866. Comparative Anatomy and Physiology of Vertebrates. Longmans Green, London.

Piper, K.J., Fitzgerald, E.M.G., and Rich, T.H. 2006. Mesozoic to Early Quaternary mammal faunas of Victoria, South-East Australia. Palaeontology, 49:1237-1262. https://doi.org/ 10.1111/j.1475-4983.2006.00595.x

Pledge, N.S. 1992. The Curramulka local fauna: a new Late Tertiary fossil assemblage from Yorke Peninsula, South Australia. Records of the Museums and Art Galleries of the Northern Territory, 9:115-142.

Price, G.J., Webb, G.E., Zhao, J.-X., Feng, Y.-X., Murray, A.S., Cooke, B.N., Hocknull, S.A., and Sobbe, I.H. 2011. Dating megafaunal extinction on the Pleistocene Darling Downs, eastern Australia: the promise and pitfalls of dating as a test of extinction hypotheses. Quaternary Science Reviews, 30(7):899-914. https://doi.org/10.1016/j.quascirev.2011.01.011

Price, G.J., Zhao, J.-X., Feng, Y.-X., and Hocknull, S.A. 2009. New U/Th ages for Pleistocene megafauna deposits of southeastern Queensland, Australia. Journal of Asian Earth Sciences, 34(2):190-197. https://doi.org/10.1016/j.jseaes.2008.04.008

Prideaux, G.J., Gully, G.A., Couzens, A.M.C., Ayliffe, L.K., Jankowski, N.R., Jacobs, Z., Roberts, R.G., Hellstrom, J.C., Gagan, M.K., and Hatcher, L.M. 2010. Timing and dynamics of late Pleistocene mammal extinctions in southwestern Australia. Proceedings of the National Academy of Sciences of the United States of America, 107(51):22157. https://doi.org/ 10.1073/pnas.1011073107

Reig, O.A., Kirsch, J.A.W., and Marshall, L.G. 1987. Systematic relationships of the living and the neocenozoic American "opossum-like" marsupials (Suborder Didelphimorphia), with comments on the classification of these and of the Cretaceous and Paleogene New World and European metatherians, p. 1-89. In Archer, M. (ed.), Possums and Opossums: Studies in Evolution. Surrey Beatty and Sons Pty. Ltd, Chipping Norton, New South Wales.

Rensberger, J.M. 1973. An occlusion model for mastication and dental wear in herbivorous mammals. Journal of Paleontology, 47(3):515-528.

Rensberger, J.M. 1975. Function in the cheek tooth evolution of some hypsodont geomyoid rodents. Journal of Paleontology, 49(1):10-22.

Renvoisé, E. and Michon, F. 2014. An evo-devo perspective on ever-growing teeth in mammals and dental stem cell maintenance. Frontiers in Physiology, 5(324). https://doi.org/10.3389/ fphys.2014.00324

Rishworth, C., Mcllroy, J.C., and Tanton, M.T. 1995. Diet of the Common Wombat, Vombatus ursinus, in plantations of Pinus radiata. Wildlife Research, 22(3):333-339. https://doi.org/ 10.1071/wr9950333

Roberts, R.G., Flannery, T.F., Ayliffe, L.K., Yoshida, H., Olley, J.M., Prideaux, G.J., Laslett, G.M., Baynes, A., Smith, M.A., Jones, R., and Smith, B.L. 2001. New ages for the last Australian megafauna; continent-wide extinction about 46,000 years ago. Science, 292(5523):18881892. https://doi.org/10.1126/science.1060264

Roger, E., Laffan, S.W., and Ramp, D. 2007. Habitat selection by the common wombat (Vombatus ursinus) in disturbed environments: Implications for the conservation of a 
'common' species. Biological Conservation, 137(3):437-449. https://doi.org/10.1016/ j.biocon.2007.03.001

Röse, C. 1893. Über die Zahnentwickelung von Phascolomys Wombat. Deutsche Akademie der Wissenschaften zu Berlin. Physikalisch-Mathematische Klasse:749-755.

Rougier, G.W., Wible, J. R., and Novacek, M. J. 1998. Implications of Deltatheridium specimens for early marsupial history. Nature, 396(6710):463. https://doi.org/10.1038/24856

Sánchez?Villagra, M.R. and Wible, J.R. 2002. Patterns of evolutionary transformation in the petrosal bone and some basicranial features in marsupial mammals, with special reference to didelphids. Journal of Zoological Systematics and Evolutionary Research, 40(1):26-45. https://doi.org/10.1046/j.1439-0469.2002.00173.x

Scott, C.C. and Richardson, K.C. 1988. Appendicular osteological differences between Lasiorhinus latifrons (Owen, 1845) and Vombatus ursinus (Shaw 1800) (Marsupialia: Vombatidae). Records of the South Australian Museum, 22(2):95-102.

Scott, G.G., Richardson, K.C., and Groves, C.P. 1988. Osteological differences of the skulls of Lasiorhinus latifrons Owen, 1845 and Vombatus ursinus Shaw, 1800 (Marsupialia, Vombatidae). Australian Journal of Zoology, 36(5):599-609. https://doi.org/10.1071/ zo9880599

Sniderman, J.M.K., Woodhead, J.D., Hellstrom, J., Jordan, G.J., Drysdale, R.N., Tyler, J.J., and Porch, N. 2016. Pliocene reversal of late Neogene aridification. Proceedings of the National Academy of Sciences, 113(8):1999-2004. https://doi.org/10.1073/pnas.1520188113. Epub 2016 Feb 8.

Springer, M.S., Kirsch, J.A.W., and Case, J.A. 1997. The chronicle of marsupial evolution, p. 129-161. In Givnish, T.J. and Sytsma, K.J. (eds.), Molecular Evolution and Adaptive Radiation. Cambridge University Press, Cambridge, UK.

Stirton, R.A., Tedford, R.H., and Woodburne, M.O. 1967. A new Tertiary formation and fauna from the Tirari Desert, South Australia. Records of the South Australian Museum, 15:427461.

Swofford, D.L. 2002. Phylogenetic Analysis Using Parimony. Sinauer Associates, Sunderland, Massachusetts.

Taggart, D.A., Finlayson, G.R., Shimmin, G., Gover, C., Dibben, R., White, C.R., Steele, V., and Temple-Smith, P.D. 2007. Growth and development of the southern hairy-nosed wombat, (Vombatidae). Australian Journal of Zoology, 55(5):309-316.

Taggart, D.A. and Temple-Smith, P.D. 2008. Southern hairy-nosed wombat: Lasiorhinus latifrons, p. 204-206. In Van Dyck, S. and Strahan, R. (eds.), The Mammals of Australia. Reed New Holland, Sydney, Australia.

Taylor, A.C., Sherwin, W.B., and Wayne, R.K. 1994. Genetic variation of microsatellite loci in a bottlenecked species: the northern hairy?nosed wombat Lasiorhinus krefftii. Molecular Ecology, 3(4):277-290. https://doi.org/10.1111/j.1365-294x.1994.tb00068.x

Tedford, R.H. 2002. The basicranium of the giant wombat Phascolonus gigas Owen (Vombatidae: Marsupialia) and its significance in phylogeny, p. 39-47. In Emery, R.J. (ed.), Cenozoic Mammals of Land and Sea: Tributes to the Career of Clayton E. Ray. Smithsonian Institution Press.

Tedford, R.H., Wells, R.T., and Prideaux, G.J. 2006. Pliocene and earlier Pleistocene marsupial evolution in southeastern Australia. Alcheringa: An Australasian Journal of Palaeontology, 30:313-322. https://doi.org/10.1080/03115510609506870

Travouillon, K.J., Archer, M., Hand, S.J., and Godthelp, H. 2006. Multivariate analyses of Cenozoic mammalian faunas from Riversleigh, northwestern Queensland. Alcheringa: An Australasian Journal of Palaeontology, 30:323-349. https://doi.org/10.1080/ 03115510609506871

Travouillon, K., Archer, M., Hand, S., and Muirhead, J. 2015. Sexually dimorphic bandicoots (Marsupialia: Peramelemorphia) from the Oligo-Miocene of Australia, first cranial ontogeny for fossil bandicoots and new species descriptions. Journal of Mammalian Evolution, 22(2):141-167. https://doi.org/10.1007/s10914-014-9271-8

Travouillon, K.J., Escarguel, G., Legendre, S., Archer, M., and Hand, S.J. 2011. The use of MSR (Minimum Sample Richness) for sample assemblage comparisons. Paleobiology, 37(4):696709. https://doi.org/10.1666/09050.1

Travouillon, K.J., Gurovich, Y., Beck, R.M.D., and Muirhead, J. 2010. An exceptionally wellpreserved short-snouted bandicoot (Marsupialia; Peramelemorphia) from Riversleigh's 
Oligo-Miocene deposits, northwestern Queensland, Australia. Journal of Vertebrate Paleontology, 30(5):1528-1546. https://doi.org/10.1080/02724634.2010.501463

Triggs, B. 2009. Wombats. CSIRO Publishing, Collingwood.

Turnbull, W.D., Lundelius, E.L., and Archer, M. 2003. Dasyurids, perameloids, phalangeroids, and vombatoids from the early Pliocene Hamilton fauna, Victoria, Australia. Bulletin of the American Museum of Natural History, 279:513-540.

van Nievelt, A.F.H. and Smith, K.K. 2005. To replace or not to replace: the significance of reduced functional tooth replacement in marsupial and placental mammals. Paleobiology, 31(2):324-346. https://doi.org/10.1666/0094-8373(2005)031[0324:trontr]2.0.co;2

Vickers-Rich, P., Monaghan, J.M., Baird, R.F., and Rich, T.H. 1991. Vertebrate Palaeontology of Australasia. Pioneer Design Studio in co-operation with Monash University Publications Committee, Melbourne, Victoria. https://doi.org/10.5962/bhl.title.60647

Whitelaw, M.J. 1989. Magnetic polarity stratigraphy and mammalian fauna of the Late Pliocene (Early Matuyama) section at Batesford (Victoria), Australia. The Journal of Geology, 97(5):624-631. https://doi.org/10.1086/629339

Whitelaw, M.J. 1991. Magnetic polarity stratigraphy of Pliocene and Pleistocene fossil vertebrate localities in southeastern Australia. Geological Society of America Bulletin, 103(11):14931503. https://doi.org/10.1130/0016-7606(1991)103<1493:mpsopa>2.3.co;2

Woodburne, M.O. 1984. Families of marsupials: relationships, evolution and biogeography, p. 48-71. In Broadhead, T.W. (ed.), Mammals: Notes for a Short Course.

Woodburne, M.O., Macfadden, B.J., Case, J.A., Springer, M.S., Pledge, N.S., Power, J.D., Woodburne, J.M., and Springer, K.B. 1994. Land mammal biostratigraphy and magnetostratigraphy of the Etadunna Formation (late Oligocene) of South Australia. Journal of Vertebrate Paleontology, 13(4):483-515. https://doi.org/10.1080/02724634.1994.10011527

Woodhead, J., Hand, S.J., Archer, M., Graham, I., Sniderman, K., Arena, D.A., Black, K.H., Godthelp, H., Creaser, P., and Price, E. 2016. Developing a radiometrically-dated chronologic sequence for Neogene biotic change in Australia, from the Riversleigh World Heritage Area of Queensland. Gondwana Research, 29(1):153-167. https://doi.org/10.1016/ j.gr.2014.10.004

Wroe, S., Brammall, J., and Cooke, B.N. 1998. The skull of Ekaltadeta ima (Marsupialia, Hypsiprymnodontidae?): An analysis of some marsupial cranial features and a reinvestigation of propleopine phylogeny, with notes on the inference of carnivory in mammals. Journal of Paleontology, 72(4):738-751.

Wroe, S., Ebach, M., Ahyong, S., Muizon, C.d., and Muirhead, J. 2000. Cladistic analysis of dasyuromorphian (Marsupialia) phylogeny using cranial and dental characters. Journal of Mammalogy, 81(4):1008-1024. https://doi.org/10.1644/1545-

1542(2000)081<1008:caodmp>2.0.co;2 


\section{APPENDIX 1.}

Size and development of $p 3$ in early ontogeny in Vombatus ursinus, relative to m1-2. 1. NMV C3133, mandible with i1, p3, m1-3. 2. NMV C10928, right hemimandible with i1, p3 and m1-2.
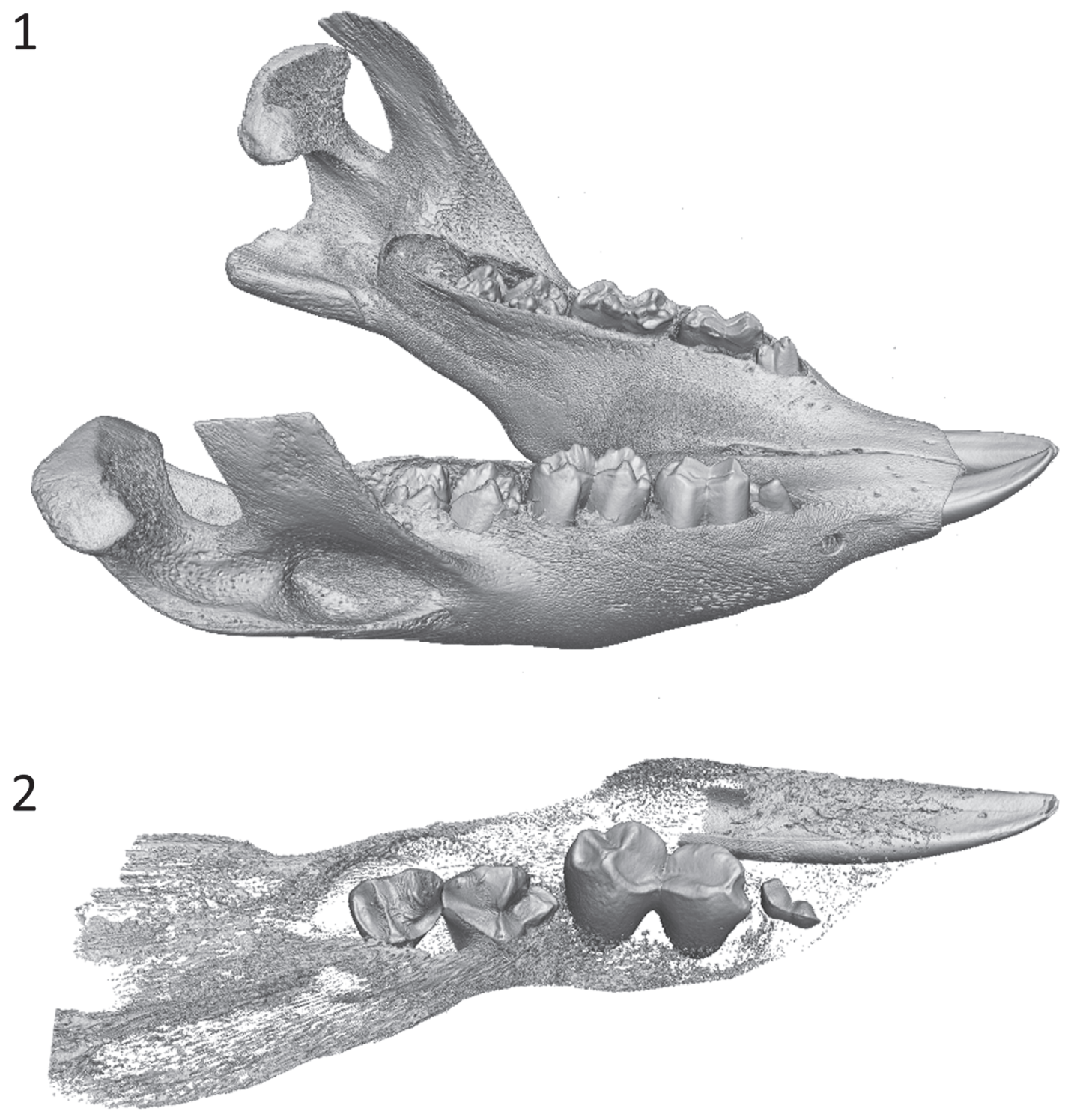


\section{APPENDIX 2.}

Comparison of $V$. ursinus molar width measurements when measured at the occlusal surface in the jaw (which is affected by curvature of tooth and angle of wear) and when measured on isolated teeth and at $90^{\circ}$ to tooth height (i.e., true width).

\begin{tabular}{|c|c|c|c|c|c|c|c|}
\hline Institution & Specimen number & $\begin{array}{c}\text { Tooth } \\
\text { position }\end{array}$ & Moiety & 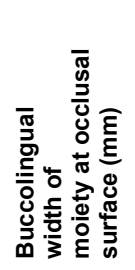 & 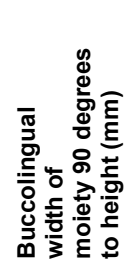 & 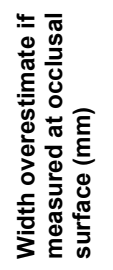 & 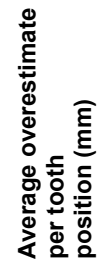 \\
\hline NHMUK & ZD 1900.3.16.1 & $\mathrm{m} 1$ & Anterior & 6.13 & 6.28 & -0.15 & 0.22 \\
\hline NHMUK & ZD 1856.12.10.690 & & & 4.9 & 4.78 & 0.12 & \\
\hline NHMUK & ZD 1877.2.6.8 & & & 6.67 & 5.97 & 0.7 & \\
\hline NHMUK & ZD 1846.8.7.13 & $\mathrm{m} 2$ & & 7.31 & 5.8 & 1.51 & 1.82 \\
\hline NHMUK & ZD 1877.2.6.8 & & & 8.95 & 6.83 & 2.12 & \\
\hline NHMUK & ZD 1900.3.16.1 & m3 & & 8.74 & 7.24 & 1.5 & 1.09 \\
\hline NHMUK & ZD 1846.8.7.13 & & & 7.02 & 5.64 & 1.38 & \\
\hline NHMUK & ZD 1856.12.10.690 & & & 6.06 & 5.66 & 0.4 & \\
\hline NHMUK & ZD 1900.3.16.1 & $\mathrm{m} 4$ & & 8.27 & 6.85 & 1.42 & 1.5 \\
\hline NHMUK & ZD 1846.8.7.13 & & & 7.35 & 5.64 & 1.71 & \\
\hline NHMUK & ZD 1877.2.6.8 & & & 7.68 & 6.25 & 1.43 & \\
\hline NHMUK & GERM 1496 a & & & 7.91 & 6.48 & 1.43 & \\
\hline NHMUK & ZD 1900.3.16.1 & M2 & & 7.61 & 7.62 & -0.01 & 0.21 \\
\hline NHMUK & ZD 1887.3.1.2 & & & 7.26 & 7.23 & 0.03 & \\
\hline NHMUK & GERM 1496 a & & & 7.76 & 7.16 & 0.6 & \\
\hline NHMUK & ZD 1900.3.16.1 & M3 & & 7.42 & 7.39 & 0.03 & 0.79 \\
\hline NHMUK & ZD 1846.8.7.13 & & & 7.22 & 6.03 & 1.19 & \\
\hline NHMUK & GERM 1496 a & & & 8.08 & 6.94 & 1.14 & \\
\hline NHMUK & ZD 1900.3.16.1 & M4 & & 7.04 & 6.8 & 0.24 & 0.89 \\
\hline NHMUK & ZD 1926.3.11.127 & & & 8.09 & 6.32 & 1.77 & \\
\hline NHMUK & ZD 1846.8.7.13 & & & 6.07 & 5.42 & 0.65 & \\
\hline NHMUK & ZD 1900.3.16.1 & $\mathrm{m} 1$ & Posterior & 7 & 6.81 & 0.19 & 0.58 \\
\hline NHMUK & ZD 1856.12.10.690 & & & 5.42 & 5.17 & 0.25 & \\
\hline NHMUK & ZD 1877.2.6.8 & & & 7.8 & 6.49 & 1.31 & \\
\hline NHMUK & ZD 1846.8.7.13 & $\mathrm{m} 2$ & & 6.58 & 5.59 & 0.99 & - \\
\hline NHMUK & ZD 1900.3.16.1 & m3 & & 8.14 & 6.77 & 1.37 & 0.92 \\
\hline NHMUK & ZD 1846.8.7.13 & & & 6.79 & 5.62 & 1.17 & \\
\hline NHMUK & ZD 1856.12.10.690 & & & 5.63 & 5.41 & 0.22 & \\
\hline NHMUK & ZD 1900.3.16.1 & $\mathrm{m} 4$ & & 7.72 & 6.5 & 1.22 & 1.17 \\
\hline NHMUK & ZD 1846.8.7.13 & & & 6.64 & 5.7 & 0.94 & \\
\hline NHMUK & ZD 1877.2.6.8 & & & 6.97 & 5.58 & 1.39 & \\
\hline NHMUK & GERM 1496 a & & & 7.96 & 6.82 & 1.14 & \\
\hline NHMUK & ZD 1900.3.16.1 & M2 & & 8.56 & 7.03 & 1.53 & 1.72 \\
\hline NHMUK & ZD 1887.3.1.2 & & & 8.51 & 6.97 & 1.54 & \\
\hline NHMUK & GERM 1496 a & & & 9.02 & 6.93 & 2.09 & \\
\hline NHMUK & ZD 1900.3.16.1 & M3 & & 7.59 & 6.67 & 0.92 & 0.91 \\
\hline
\end{tabular}


BREWER ET AL.: NEW RHIZOPHASCOlONUS SPECIES

\begin{tabular}{|c|c|c|c|c|c|c|}
\hline NHMUK & ZD 1846.8.7.13 & & 6.69 & 5.76 & 0.93 & \\
\hline NHMUK & GERM 1496 a & & 7.53 & 6.64 & 0.89 & \\
\hline NHMUK & ZD 1900.3.16.1 & M4 & 5.44 & 4.96 & 0.48 & 0.94 \\
\hline NHMUK & ZD 1926.3.11.127 & & 6.65 & 4.7 & 1.95 & \\
\hline NHMUK & ZD 1846.8.7.13 & & 4.59 & 4.21 & 0.38 & \\
\hline
\end{tabular}

\section{APPENDIX 3.}

Molar measurements. Refer to Materials and Methods section for information on measurement of widths. (Appendix 3 supplied as electronic file at palaeo-electronica.org/content/2018/2173gazella-qingyang)

\section{APPENDIX 4.}

Description of characters and character states used in the phylogenetic analysis. All characters are unordered, except the ones marked by an asterix.

1. Number of upper incisors (modified from Springer et al., 1997; modified from Rougier et al., 1998; modified from Wroe et al., 2000; modified from Horovitz and Sánchez-Villagra, 2003; modified from Black et al., 2012a): (0) More than three; (1) Two or three; (2) One.

2. Presence of hypselodont 11: (0) Absent; (1) Present.

3. Maximum height versus maximum width of 11: (0) Maximum dorsoventral height greater than maximum mediolateral width: (1) Maximum height and width about same (within 10\% either side); (2) 11 wider than deep.

4. Upper canine (modified Springer et al., 1997; Horovitz and Sánchez-Villagra, 2003; Black et al., 2012a): (0) Present; (1) Absent or vestigial.

5. Molar morphology (modified from Springer et al., 1997; Horovitz and Sánchez-Villagra, 2003; Black, 2007; Black et al., 2012a): (0) Tribosphenic; (1) Selenodont; (2) Semi-lophodont/bunodont.

6. Hypselodont cheek teeth (modified from Murray, 1998): (0) No; (1) Yes.

7. Enamel noticeably thicker on trailing edge (lingual surface on upper molars and buccal surface on lower molars) relative to leading edge of molars (buccal surface on upper molars and lingual surface on lower molars): (0) No; (1) Yes.

8. Enamel tracts that extend down the lingual surface of upper molars and buccal surface of lower molars: (0) No; (1) To a moderate extent; (2) Extensively.

9. Lingual cusps slightly higher than buccal cusps on upper molars: (0) No; (1) Yes.

10. Stylar cusp posterobuccal to the paracone (in the position of St-C) is large and well-developed (better than the stylar cusp buccal or anterobuccal to the paracone and equivalent to St B in koalas): (0) No; (1) Yes.
11.* Separation of stylar cusps $C$ and $D$ (modified from Myers and Archer, 1997; modified from Black et al., 2012a): (0) Close together; (1) Separated.

12. Postprotocrista meets premetaconulecrista: (0) Present, they are closely associated; (1) Absent, there is a large gap between postprotocrista and premetaconulecrista .

13. Cusp immediately posterior to metaconule on lingual margin (at posterolingual corner of tooth): (0) Absent; (1) Present.

14. Molars equally constricted on buccal and lingual sides M2-4/m2-4: (0) Yes; (1) No, deeper on lingual side of uppers and buccal side of lowers.

15. Relatively high and complete crest forming anterior margin of occlusal surface on M2-4 and m2-4: (0) No; (1) Yes.

16. * Anteroposterior length of $M 2 / 3$ and $m 2 / 3$ : (0) Small (<8.5 mm); (1) Medium (8.5-12.5 mm); (2) Large $(>12.5 \mathrm{~mm})$.

17. M1 with decrease in enamel height on lingual surface at constriction or just posterior to this: (0) No; (1) Yes.

18. Paracone located on buccal margin of M1: (0) No; (1) Yes.

19. Occlusal surface on anterior moiety of M1 very narrow: (0) No; (1) Yes.

20. * Presence of a cusp on posterobuccal side of M1 (and occassionally M2) in position of St-E: (0) No; (1) Yes but poorly developed; (2) Yes.

21. * Anterior moiety of M1 wider than posterior moiety (on average): (0) Yes; (1) Similar in size; (2) Posterior moiety is wider.

22. M2 width of anterior moiety versus tooth length (modified from Springer et al., 1997; Horovitz and Sánchez-Villagra, 2003 and Black et al., 2012a): (0) 
M2 longer than wide; (1) M2 width and length approximately equal or M2 wider than long.

23. * M2 width of anterior moiety versus posterior moiety: (0) Anterior wider than posterior; (1) Anterior similar to posterior; (2) Posterior wider than anterior.

24. Number of lower incisors (modified from Springer et al., 1997; modified from Rougier et al., 1998; modified from Wroe et al., 2000; modified from Luo et al., 2002; modified from Horovitz and Sánchez-Villagra, 2003; modified from Black et al., 2012a): (0) Two or more; (1) One.

25. Apex of lingual cusp (entoconid) slightly anterior to apex of buccal cusp (hypoconid) on posterior moiety of lower m2-3: (0) No; (1) Yes.

26. * Pre-entocristid and postmetacristid don't really meet except at their base. This is most obvious on the posterior moiety: (0) Absent; (1) Slightly developed; (2) Well-developed.

27. Medial crest from hypoconid connects to a lingual medial crest which extends to the entoconid: (0) Absent; (1) Present.

28. Hypoconulid: (0) Absent; (1) Present.

29. Dentine tract at buccal constriction on $m 1$ : (0) Absent; (1) Present.

30. Distinct and separate paraconid on M2-3: (0) No; (1) Yes.

31. Incisive foramen in deep fossa formed by intradiastemal ridges/crests that " $\mathrm{V}$ " posteriorly to a point at or posterior to incisivomaxillary suture (modified from Merrilees, 1967 and Tedford, 2002): (0) No; (1) Yes.

32. Incisive foramen posterior (modified from Dawson, 1983b; Murray, 1998; Tedford, 2002): (0) No; (1) Yes, the incisive foramina lie posteriorly, just anterior to $\mathrm{P} 3$, in a deep pocket at the rear of the diastema. The posterior position of the foramina correspondingly displaces the incisivomaxillary suture to a position just anterior to the cheek tooth row.

33. Lateral edge of palate emarginated from 11 to $P 3$ in ventral view (modified from Tedford, 2002): (0) No; (1) Yes.

34. Palate wide anteriorly (modified from Dawson, 1981, 1983; Murray, 1998; Tedford, 2002): (0) Diastemal palate is parallel-sided or narrows anteriorly; (1) Palate consistently widens anteriorly.

35. Palate width opposite first molar (ventral view) (Merrilees, 1967; Scott et al., 1988): (0) Narrow, less than mesiodistal width of first molar; (1) Wide, equal to or greater than mesiodistal width of first molar.

36. Median premaxillary process (Tedford, 2002): (0) No; (1) Well-developed or present as a low spine at the midline dorsal surface of the premaxillary bones.

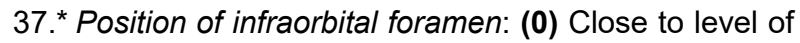
alveolar process; (1) Approximately midway between dorsal surface of skull and alveolar process; (2) Closer to dorsal surface of skull than alveolar process of tooth row.
38. Posterior palatal vacuities (maxillopalatine vacuity) (modified from Archer, 1984; modified Reig et al., 1987; modified Rougier et al., 1998; modified Wroe et al., 2000; modified Horovitz and Sánchez-Villagra, 2003; modified Black et al., 2012a): (0) Extends anteriorly to anterior or opposite M1 or M2; (1) Confined within palatine, opposite M3-4.

39.* Nasal aperture retracted beyond incisor arcade (modified from Black et al., 2012a): (0) Absent or just posterior to incisor arcade; (1) Retracted to above diastema (or level of incisivomaxillary suture); (2) Retracted to above cheek tooth row.

40. Nasomaxillary suture length relative to nasopremaxillary suture length (dorsal view) (Scott et al., 1988): (0) Nearly same or greater; (1) Far less than nasopremaxillary suture length.

41. Combined breadth of nasal bones (dorsal view) (Merrilees, 1967; Scott et al., 1988): (0) Much less than length; (1) Equal to or greater than length.

42. Angle between rostral part of zygomatic bone and the maxillary bone (ventral view) (Scott et al., 1988): (0) About $45^{\circ}$; (1) About $90^{\circ}$.

43. Dorsoventral position of ventral extent of anterior zygomatic root (relative to the cheek tooth row): (0) Close to level of alveolar process; (1) Distant to alveolar process.

44. * Anteroposterior position of ventral extent of anterior zygomatic root (relative to the cheek tooth row): (0) Posterior to M2; (1) Above M2; (2) Anterior to M2.

45. Postglenoid process (Springer et al., 1997; Horovitz and Sánchez-Villagra, 2003; modified Black et al., 2012a): (0) Present; (1) Absent.

46. Tympanic cavity roof elements (Travoullion et al., 2010 modified; Black et al., 2012a modified): (0) Alisphenoid contributes to roof; (1) Alisphenoid does not contribute to roof.

47. Tympanic floor elements (Black et al., 2012a): (0) Alisphenoid; (1) Some squamosal contribution.

48. * Postglenoid cavity / epitympanic fossa (modified Murray, 1998; modified Tedford, 2002; modified Black et al., 2012a): (0) Absent; (1) Present, but shallow; (2) Present and moderately extensive/ deep.

49. Squamosal epitympanic wings inflated (modified from Tedford, 2002): (0) No; (1) Yes.

50. Hypotympanic sinus large (Tedford, 2002): (0) No; (1) Extends anterolaterally into the zygomatic root of the squamosal.

51. Rostral tympanic process of periotic (Rougier et al., 1998; Sánchez -Villagra and Wible, 2002; Horovitz and Sánchez-Villagra, 2003 modified; Black et al., 2012a): (0) Strong; (1) Weak / absent.

52. Narrow mastoid strip on occiput (Murray, 1986; Black et al., 2012a): (0) Absent; (1) Present.

53. Ventrolaterally flared mastoid process on occiput (Murray, 1986; Black et al., 2012a): (0) Absent; (1) Present. 
54. ${ }^{*}$ Rostral origin of ascending ramus (mandible) (modified from Scott et al., 1988): (0) Mid m3 or anterior to this; (1) Posterior m3 to posterior m4; (2) Posterior to fourth molar.

55. * Depth of masseteric fossa (mandible) (Merrilees, 1967; Scott et al., 1988): (0) Shallow to medium; (1) Deep; (2) Very deep.

56. Angle of the anterior border of the ascending ramus (mandible) (modified from Hope and Wilkinson, 1982; modified from Black, 2007; modified from Black et al., 2012a): (0) < 70 ; (1) >=70'.

57. * Posterior extent of mandibular symphysis (mandible) (Black, 2007; Black et al., 2012a): (0) Anterior to $\mathrm{m} 1$; (1) Below $\mathrm{m} 1$; (2) Posterior to $\mathrm{m} 1$.

58. Fused mandibular symphysis: (0) Absent; (1) Present.
59. Flared masseteric eminences (mandible) (Murray, 1998; Black et al., 2012a): (0) Absent/weak; (1) Moderately to strongly flared.

60. Maximum depth of ramus: (0) Below junction between $\mathrm{m} 3$ and $\mathrm{m} 4$ or posterior to this; (1) Below $\mathrm{m} 2$ or m3; (2) Below $\mathrm{m} 1$ or anterior to this.

61. Maximum width across flared masseteric eminences divided by cheek tooth row length: (0) Below 2 on average; (1) Above 2 on average.

62. *Humerus: deltoid tuberosity (modified from Scott and Richardson, 1988): (0) Acutely angled ridge-less than 30 degrees; (1) Shallow angled ridge- between about 30 and 40 degrees; (2) Very shallowly angled ridge-greater than 40 degrees. 


\section{APPENDIX 5.}

Character matrix for the phylogenetic analysis. Character numbers are in bold at top of tables.

Character descriptions are provided in Appendix 4. ? = missing data.

\begin{tabular}{|c|c|c|c|c|c|c|c|c|c|c|c|c|c|c|c|c|c|c|c|c|c|c|c|c|c|c|c|c|c|c|c|}
\hline & 1 & 2 & 3 & 4 & 5 & 6 & 7 & 8 & 9 & 10 & 11 & 12 & 13 & 14 & 15 & 16 & 17 & 18 & 19 & 20 & 21 & 22 & 23 & 24 & 25 & 26 & 27 & 28 & 29 & 30 & 31 \\
\hline $\begin{array}{l}\text { Galadi } \\
\text { speciosus }\end{array}$ & 0 & 0 & 1 & 0 & 0 & 0 & 0 & 0 & 0 & 1 & 0 & 0 & 0 & 0 & 0 & 0 & 0 & 0 & 0 & 1 & 0 & 1 & 1 & 0 & 0 & 1 & 0 & 1 & 0 & 1 & 0 \\
\hline $\begin{array}{l}\text { Phascolarctos } \\
\text { cinereus }\end{array}$ & 1 & 0 & 0 & 0 & 1 & $c$ & 0 & 0 & 0 & 0 & 0 & 0 & 0 & 0 & 0 & 0 & 0 & 0 & 0 & 0 & 0 & 1 & 0 & 1 & 0 & 0 & 0 & 0 & 0 & 0 & 0 \\
\hline $\begin{array}{l}\text { Wakaleo } \\
\text { schouteni }\end{array}$ & 1 & 0 & 0 & 0 & 2 & 0 & 0 & 0 & 0 & 0 & ? & 0 & 0 & 0 & 0 & 0 & 0 & 1 & 0 & 0 & 0 & 1 & 0 & 0 & ? & 1 & 0 & 0 & 0 & 0 & 0 \\
\hline $\begin{array}{l}\text { Sedophascolom } \\
\text { ys medius }\end{array}$ & 2 & 1 & 2 & 1 & ? & 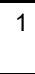 & 1 & 2 & ? & ? & ? & ? & $?$ & 1 & ? & 2 & ? & ? & ? & ? & 1 & 0 & 1 & 1 & ? & ? & $?$ & $?$ & $?$ & ? & 1 \\
\hline $\begin{array}{l}\text { Phascolonus } \\
\text { gigas }\end{array}$ & 2 & 1 & 2 & 1 & ? & 1 & 1 & 2 & ? & ? & ? & ? & $?$ & 1 & ? & 2 & 0 & ? & ? & ? & 1 & 0 & 0 & 1 & ? & ? & ? & $?$ & $?$ & ? & 1 \\
\hline & 2 & 1 & 2 & 1 & ? & 1 & 1 & 2 & ? & ? & $?$ & ? & $?$ & 1 & ? & 2 & ? & ? & ? & ? & ? & 0 & 0 & 1 & ? & ? & $?$ & ? & $?$ & ? & ? \\
\hline $\begin{array}{l}\text { Warendja } \\
\text { encorensis }\end{array}$ & ? & 1 & 1 & ? & 2 & 1 & 1 & 2 & 1 & ? & 1 & 1 & 1 & 0 & 1 & 1 & ? & ? & $?$ & ? & ? & 0 & 1 & ? & $?$ & $?$ & 1 & 1 & 1 & $?$ & ? \\
\hline & 2 & 1 & 0 & 1 & ? & 1 & 1 & 2 & ? & $?$ & $?$ & $?$ & $?$ & 0 & ? & 0 & 0 & $?$ & $?$ & $?$ & 2 & 0 & 1 & 1 & ? & $?$ & $?$ & $?$ & 1 & ? & 0 \\
\hline $\begin{array}{l}\text { Nimbavombatus } \\
\text { boodjamullensis }\end{array}$ & $?$ & 1 & 0 & 0 & 2 & 0 & 1 & 1 & ? & ? & ? & ? & 0 & 0 & 0 & 0 & 1 & 1 & ? & ? & 0 & 0 & 0 & ? & ? & ? & $?$ & $?$ & 0 & ? & 0 \\
\hline $\begin{array}{l}\text { Lasiorhinus } \\
\text { latifrons }\end{array}$ & 2 & 1 & 2 & 1 & 2 & 1 & 1 & 2 & 0 & 0 & 1 & 1 & 0 & 1 & 0 & 1 & $?$ & $?$ & 1 & 2 & 2 & 0 & 2 & 1 & 1 & 1 & 1 & 0 & 0 & 1 & 0 \\
\hline $\begin{array}{l}\text { Vombatus } \\
\text { ursinus }\end{array}$ & 2 & 1 & 2 & 1 & 2 & 1 & 1 & 2 & 0 & 0 & 1 & 1 & 1 & 1 & 0 & 1 & 0 & 0 & 1 & 2 & 2 & 0 & 2 & 1 & 1 & 1 & ? & ? & 0 & 1 & 0 \\
\hline $\begin{array}{l}\text { Rhizophascolon } \\
\text { us crowcrofti }\end{array}$ & $?$ & 1 & 0 & ? & 2 & 0 & 1 & 2 & 1 & $?$ & $?$ & 0 & 1 & 0 & 1 & 2 & 1 & $?$ & $?$ & $?$ & 0 & 0 & 0 & $?$ & $?$ & 2 & 1 & 1 & 0 & $?$ & $?$ \\
\hline $\begin{array}{l}\text { Rhizophascolon } \\
\text { us ngangaba }\end{array}$ & ? & ? & ? & $?$ & 2 & 0 & 1 & 2 & 1 & 1 & 1 & 0 & 0 & 0 & 1 & 1 & 1 & 1 & 1 & ? & 2 & 0 & 0 & ? & ? & 2 & 1 & 1 & 0 & 0 & ? \\
\hline
\end{tabular}

$\begin{array}{lllllllllllllllllllllllllllllll}32 & 33 & 34 & 35 & 36 & 37 & 38 & 39 & 40 & 41 & 42 & 43 & 44 & 45 & 46 & 47 & 48 & 49 & 50 & 51 & 52 & 53 & 54 & 55 & 56 & 57 & 58 & 59 & 60 & 61 & 62\end{array}$

Galadi

speciosus

Phascolarctos cinereus

Wakaleo

schouteni

Sedophascolom ys medius

Phascolonus

gigas

Ramsayia magna

Warendja

encorensis

Warendja

wakefieldi

Nimbavombatus boodjamullensis

Lasiorhinus

latifrons

Vombatus

ursinus

Rhizophascolon us crowcrofti

Rhizophascolon us ngangaba

\begin{tabular}{|l|l|l|l|l|l|l|l|l|l|l|l|l|l|l|l|l|l|l|l|l|l|l|l|l|l|l|l|l|l|l|}
\hline 0 & 0 & 0 & 1 & 0 & 0 & 0 & 0 & 0 & 0 & 0 & 0 & 0 & 0 & 0 & 0 & 0 & 0 & $?$ & 0 & 0 & 0 & 2 & 0 & 1 & 0 & 0 & 0 & 1 & $?$ & $?$ \\
\hline 0 & 0 & 0 & 1 & 0 & 1 & 1 & 1 & 1 & 1 & 1 & 0 & 2 & 0 & 0 & 0 & 2 & 0 & 0 & 1 & 1 & 0 & 1 & 0 & 1 & 1 & 1 & 1 & 0 & 0 & 0 \\
\hline 0 & 0 & 0 & 1 & $?$ & 0 & 0 & 0 & 1 & 0 & 0 & 0 & 2 & 0 & 1 & 0 & 2 & 0 & 0 & 0 & 0 & 0 & 1 & 1 & 0 & 0 & 0 & 1 & 2 & 1 & 0 \\
\hline 1 & 1 & 1 & 1 & $?$ & $?$ & 1 & $?$ & $?$ & $?$ & 0 & 1 & 1 & $?$ & $?$ & $?$ & $?$ & $?$ & $?$ & $?$ & $?$ & $?$ & $?$ & $?$ & 0 & 2 & 1 & 1 & $?$ & $?$ & $?$ \\
\hline 1 & 1 & 1 & 0 & 1 & $?$ & 1 & 2 & $?$ & $?$ & 1 & 1 & $?$ & 1 & $?$ & $?$ & 2 & 0 & 1 & $?$ & $?$ & $?$ & 0 & 2 & 0 & 2 & 1 & 1 & 1 & 0 & 2 \\
\hline$?$ & 0 & 0 & $?$ & 1 & $?$ & 1 & $?$ & $?$ & $?$ & $?$ & $?$ & $?$ & $?$ & $?$ & $?$ & $?$ & 1 & 1 & $?$ & $?$ & $?$ & $?$ & $?$ & $?$ & $?$ & 1 & $?$ & $?$ & $?$ & $?$ \\
\hline$?$ & $?$ & $?$ & $?$ & $?$ & $?$ & $?$ & $?$ & $?$ & $?$ & $?$ & $?$ & $?$ & $?$ & $?$ & $?$ & $?$ & $?$ & $?$ & $?$ & $?$ & $?$ & 1 & 1 & 0 & $?$ & $?$ & 1 & $?$ & $?$ & $?$ \\
\hline 0 & 0 & 0 & 1 & $?$ & 1 & 0 & $?$ & $?$ & $?$ & 0 & 0 & 0 & 1 & 1 & 1 & 1 & 1 & $?$ & $?$ & $?$ & $?$ & 1 & 0 & 0 & 1 & 0 & 1 & 1 & $?$ & 1 \\
\hline$?$ & 0 & $?$ & 1 & $?$ & 1 & 0 & $?$ & $?$ & $?$ & 0 & 0 & 1 & $?$ & $?$ & $?$ & $?$ & $?$ & $?$ & $?$ & $?$ & $?$ & $?$ & $?$ & $?$ & $?$ & $?$ & $?$ & $?$ & $?$ & $?$ \\
\hline 0 & 1 & 0 & 1 & 1 & 2 & 1 & 0 & 0 & 1 & 1 & 1 & 1 & 1 & 1 & 1 & 2 & 0 & 0 & 1 & 1 & 1 & 0 & 1 & 1 & 2 & 1 & 1 & 1 & 1 & 2 \\
\hline 0 & 0 & 0 & 0 & 0 & 2 & 1 & 1 & 1 & 0 & 0 & 1 & 1 & 1 & 1 & 1 & $?$ & 1 & 0 & 1 & 1 & 1 & 1 & 2 & 1 & 2 & 1 & 1 & 0 & 1 & 1 \\
\hline$?$ & $?$ & $?$ & $?$ & $?$ & $?$ & $?$ & $?$ & $?$ & $?$ & $?$ & $?$ & $?$ & $?$ & $?$ & $?$ & $?$ & $?$ & $?$ & $?$ & $?$ & $?$ & $?$ & $?$ & $?$ & $?$ & $?$ & $?$ & $?$ & $?$ & $?$ \\
\hline$?$ & $?$ & $?$ & $?$ & $?$ & $?$ & $?$ & $?$ & $?$ & $?$ & $?$ & $?$ & $?$ & $?$ & $?$ & $?$ & $?$ & $?$ & $?$ & $?$ & $?$ & $?$ & $?$ & $?$ & $?$ & $?$ & $?$ & $?$ & $?$ & $?$ & $?$ \\
\hline
\end{tabular}




\section{APPENDIX 6.}

List of unambiguous apomorphies common to all three most parsimonious trees after removal of Ramsayia magna from the analysis.

\begin{tabular}{|c|c|c|c|c|}
\hline Node (from) & Node (to) & $\begin{array}{l}\text { Character } \\
\text { number }\end{array}$ & Change & Character Description (new state) \\
\hline \multirow[t]{15}{*}{ Outgroup } & Ingroup & 2 & $0 \rightarrow 1$ & Presence of hypselodont I1 \\
\hline & & 7 & $0 \rightarrow 1$ & $\begin{array}{l}\text { Enamel noticeably thicker on trailing edge (lingual } \\
\text { surface on upper molars and buccal surface on lower } \\
\text { molars) relative to leading edge of molars (buccal } \\
\text { surface on upper molars and lingual surface on lower } \\
\text { molars) }\end{array}$ \\
\hline & & 8 & $0 \rightarrow 1$ & $\begin{array}{l}\text { Enamel tracts that extend down the lingual surface of } \\
\text { upper molars and buccal surface of lower molars }\end{array}$ \\
\hline & & 22 & $1 \rightarrow 0$ & M2 longer than anterior width \\
\hline & Hypselodont wombats & 6 & $0 \rightarrow 1$ & Hypselodont cheek teeth \\
\hline & & 23 & $0 \rightarrow 1$ & M2 anterior and posterior widths are similar \\
\hline & $\begin{array}{l}\text { Hypselodont wombats } \\
\text { excl. Warendja }\end{array}$ & 3 & $1 \rightarrow 2$ & 11 wider than deep \\
\hline & & 14 & $0 \rightarrow 1$ & $\begin{array}{l}\text { Molars are not equally constricted on buccal and lingual } \\
\text { sides } \mathrm{M} 2-4 / \mathrm{m} 2-4\end{array}$ \\
\hline & V. ursinus & 35 & $1 \rightarrow 0$ & $\begin{array}{l}\text { Palate width opposite first molar (ventral view) is narrow, } \\
\text { less than mesiodistal width of first molar }\end{array}$ \\
\hline & & 60 & $1 \rightarrow 0$ & $\begin{array}{l}\text { Maximum depth of ramus is below junction between } \mathrm{m} 3 \\
\text { and } \mathrm{m} 4 \text { or posterior to this }\end{array}$ \\
\hline & $\begin{array}{l}\text { Hypselodont wombats } \\
\text { excl. Warendja and } \\
\text { Vombatus }\end{array}$ & 33 & $0 \rightarrow 1$ & $\begin{array}{l}\text { Lateral edge of palate emarginated from I1 to P3 in } \\
\text { ventral view }\end{array}$ \\
\hline & & 36 & $0 \rightarrow 1$ & $\begin{array}{l}\text { Median premaxillary process is well-developed or } \\
\text { present as a low spine at the midline dorsal surface of } \\
\text { the incisive bones }\end{array}$ \\
\hline & & 54 & $1 \rightarrow 0$ & $\begin{array}{l}\text { Rostral origin of ascending ramus (mandible) is mid } \mathrm{m} 3 \\
\text { or anterior to this }\end{array}$ \\
\hline & & 62 & $1 \rightarrow 2$ & $\begin{array}{l}\text { Deltoid tuberosity of humerus forms a very shallowly } \\
\text { angled ridge-greater than } 40 \text { degrees }\end{array}$ \\
\hline & L. latifrons & 39 & $1 \rightarrow 0$ & $\begin{array}{l}\text { Nasal aperture is not retracted beyond incisor arcade or } \\
\text { just posterior to incisor arcade }\end{array}$ \\
\hline \multirow[t]{5}{*}{$\begin{array}{l}\text { S. medius, } P \text {. gigas } \\
\text { and } L \text {. latifrons }\end{array}$} & S. medius and $P$. gigas & 16 & $1 \rightarrow 2$ & $\begin{array}{l}\text { Anteroposterior length of } \mathrm{M} 2 / 3 \text { and } \mathrm{m} 2 / 3 \text { is greater than } \\
12.5 \mathrm{~mm}\end{array}$ \\
\hline & & 21 & $2 \rightarrow 1$ & Anterior and posterior moieties of $\mathrm{M} 1$ are similar in size \\
\hline & & 31 & $0 \rightarrow 1$ & $\begin{array}{l}\text { Incisive foramen in deep fossa formed by intradiastemal } \\
\text { ridges/crests that "V" posteriorly to a point at or posterior } \\
\text { to premaxillomaxillary suture }\end{array}$ \\
\hline & & 32 & $0 \rightarrow 1$ & $\begin{array}{l}\text { Incisive foramina lie posteriorly, just anterior to P3, in a } \\
\text { deep pocket at the rear of the diastema. The posterior } \\
\text { position of the foramina correspondingly displaces the } \\
\text { premaxillomaxillary suture to a position just anterior to } \\
\text { the cheek tooth row }\end{array}$ \\
\hline & & 34 & $0 \rightarrow 1$ & Palate consistently widens anteriorly \\
\hline \multirow{2}{*}{$\begin{array}{l}\text { S. medius and } P \text {. } \\
\text { gigas }\end{array}$} & P. gigas & 23 & $1 \rightarrow 0$ & Anterior moiety of $\mathrm{M} 2$ is wider than posterior moiety \\
\hline & & 35 & $1 \rightarrow 0$ & $\begin{array}{l}\text { Palate width opposite first molar (ventral view) is narrow, } \\
\text { less than mesiodistal width of first molar }\end{array}$ \\
\hline
\end{tabular}

